University of Wollongong

Research Online

Australian Institute for Innovative Materials -

Papers

Australian Institute for Innovative Materials

$1-1-2010$

Wet chemical routes to the assembly of organic monolayers on silicon surfaces via the formation of Si-C bonds: Surface preparation, passivation and functionalization

\author{
Simone Ciampi \\ University of New South Wales, sciampi@uow.edu.au \\ Jason Brian Harper \\ University of New South Wales \\ J Justin Gooding \\ University of New South Wales, justin.gooding@unsw.edu.au
}

Follow this and additional works at: https://ro.uow.edu.au/aiimpapers

Part of the Engineering Commons, and the Physical Sciences and Mathematics Commons

Research Online is the open access institutional repository for the University of Wollongong. For further information contact the UOW Library: research-pubs@uow.edu.au 


\title{
Wet chemical routes to the assembly of organic monolayers on silicon surfaces via the formation of Si-C bonds: Surface preparation, passivation and functionalization
}

\begin{abstract}
Organic functionalization of non-oxidized silicon surfaces, while allowing for robust chemical passivation of the inorganic substrate, is intended and expected to broaden the chemical, physical and electronic properties of the currently most relevant technological material. Numerous protocols are now available for the preparation of $\mathrm{Si}-\mathrm{C}, \mathrm{Si}-\mathrm{O}$ and $\mathrm{Si}-\mathrm{N}$ bound layers. In particular, the covalent attachment of 1-alkenes and 1-alkynes onto hydride-terminated $\mathrm{Si}(100)$ and $\mathrm{Si}(111)$ has seen a wealth of research activity starting from the pioneering work of Linford and Chidsey (Alkyl monolayers covalently bonded to silicon surfaces, J. Am. Chem. Soc., 1993, 115(26), 12631-12632). This critical review aims to bring together the available wet-chemical routes toward the formation of silicon-organic monolayers under ambient conditions.

Particular emphasis is placed on discussing the reasons behind the need for novel chemical approaches that are straightforward, modular and of wide scope so as to allow the application of silicon electrodes in aqueous electrolytes. A general introduction to biomolecular recognition events at functionalized silicon surfaces is also presented (281 references). The Royal Society of Chemistry 2010.
\end{abstract}

\section{Keywords}

assembly, organic, monolayers, silicon, surfaces, via, formation, si, c, routes, bonds, wet, surface, preparation, passivation, functionalization, chemical

Disciplines

Engineering | Physical Sciences and Mathematics

\section{Publication Details}

Ciampi, S., Harper, J. B. \& Gooding, J. Justin. (2010). Wet chemical routes to the assembly of organic monolayers on silicon surfaces via the formation of Si-C bonds: Surface preparation, passivation and functionalization. Chemical Society Reviews, 39 (6), 2158-2183. 


\title{
Wet chemical routes to the assembly of organic monolayers on silicon surfaces via the formation of Si-C bonds: surface preparation, passivation and functionalization
}

\author{
Simone Ciampi, Jason B. Harper and J. Justin Gooding* \\ Received 4th February 2010 \\ First published as an Advance Article on the web 14th April 2010 \\ DOI: $10.1039 / b 923890 p$
}

\begin{abstract}
Organic functionalization of non-oxidized silicon surfaces, while allowing for robust chemical passivation of the inorganic substrate, is intended and expected to broaden the chemical, physical and electronic properties of the currently most relevant technological material. Numerous protocols are now available for the preparation of $\mathrm{Si}-\mathrm{C}, \mathrm{Si}-\mathrm{O}$ and $\mathrm{Si}-\mathrm{N}$ bound layers. In particular, the covalent attachment of 1-alkenes and 1-alkynes onto hydride-terminated $\mathrm{Si}(100)$ and $\mathrm{Si}(111)$ has seen a wealth of research activity starting from the pioneering work of Linford and Chidsey (Alkyl monolayers covalently bonded to silicon surfaces, J. Am. Chem. Soc., 1993, 115(26), 12631-12632). This critical review aims to bring together the available wet-chemical routes toward the formation of silicon-organic monolayers under ambient conditions. Particular emphasis is placed on discussing the reasons behind the need for novel chemical approaches that are straightforward, modular and of wide scope so as to allow the application of silicon electrodes in aqueous electrolytes. A general introduction to biomolecular recognition events at functionalized silicon surfaces is also presented (281 references).
\end{abstract}

\section{Introduction}

As micro-devices are reduced down to the nanoscale, surface properties gain more and more importance. As a consequence, molecular layers attached onto either crystalline, nanowire or nanoporous material surfaces, arguably, become more than a mere passivating coating. The notion that chemically

School of Chemistry, The University of New South Wales, Sydney, NSW, 2052, Australia.E-mail: justin.gooding@unsw.edu.au; Fax: +61-2-9385 5384; Tel: +61-2-93856141 well-defined organic films could impart precise functionalities to a bulk inorganic material, and hence open the door to new technologies, has prompted a vast research effort in the area of self-assembled monolayers (SAMs). ${ }^{1-4}$ In 1980, Sagiv published a seminal paper reporting the reaction of chloro- and alkoxysilanes $\left(\mathrm{RSiCl}_{3}\right.$ and $\mathrm{RSi}(\mathrm{OH})_{3}$ with $\left.\mathrm{R}=\mathrm{C}_{18} \mathrm{H}_{37}\right)$ with hydroxylterminated surfaces of oxidized substrates (glass, poly(vinyl alcohol), oxidized polyethylene and aluminium) to afford a covalent molecular layer. ${ }^{2}$ This work represents the first report of SAMs ('ordered molecular assemblies formed by the adsorption of an active surfactants on a solid surface' $\left.{ }^{1}\right)$. The 'oleophobic'

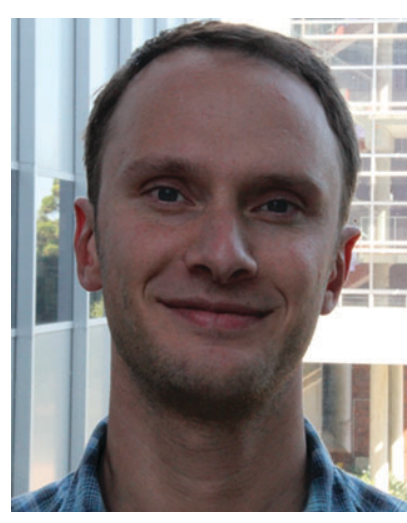

Simone Ciampi
Simone Ciampi graduated with a B.Sc. (Hons) in Industrial Biotechnology from Universita' di Modena e Reggio Emilia in 2004 after working with Dr Luca Forti on synthetic analogous of resveratrol. In 2006 he joined the group of Professor Justin Gooding at University of New South Wales, where he has been ever since. In 2010 he obtained his doctorate studying the modification of silicon electrodes for electrochemical applications. $H$ is research interests are in organic reactions applied to surface science and the electrochemical application of modified silicon and porous silicon electrodes.

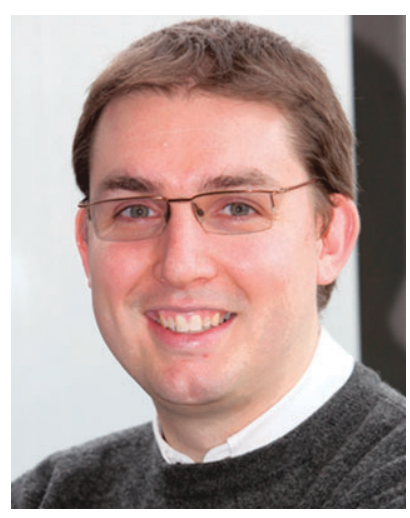

Jason B. Harper
Jason Harper is a graduate of the University of Adelaide and the Australian National University. After a position at the University of Cambridge (as an NHMRC C. J. Martin Postdoctoral Fellow), he was appointed to the academic staff in the School of Chemistry, University of New South Wales in 2002. His research interests fall broadly in the area of mechanistic and physical organic chemistry, including examining organic reactions on surfaces and on understanding the outcome of organic processes in ionic liquids. 
structure that Sagiv reported suffered from limitations dictated by both the glass-like nature of the substrate and by the silane chemistry used. Namely, there was an inhomogeneous in-plane distribution of surface active sites and poorly defined polymerised material among the reaction products. ${ }^{5}$ Further, the silicon-oxygen bonds that are formed tend to be prone to hydrolysis, especially under basic conditions, and thermal degradation of the structure has been reported. ${ }^{6}$ Despite their intrinsic limitations, silane layers $(\mathrm{Si}-\mathrm{O}-\mathrm{SiR})$ gave researchers a novel tool to modify surfaces with unprecedented control. ${ }^{7,8}$

It was not until almost a decade later that reports of alkanethiols forming well-ordered and dense SAMs on gold $^{4,9-12}$ opened the possibility of easily accessible model systems to study fundamental physical-chemistry phenomena (e.g. heterogeneous electron transfer, double-layer effects). ${ }^{13-17}$ Despite the gold-thiolate bond being thermally unstable in heated solvents, ${ }^{1}$ and prone to oxidation in air, ${ }^{18}$ monolayers of alkanethiols on gold are sufficiently stable for a range of applications. Further, because of the simplicity in preparing and handling thiol SAMs on gold, thiol and disulfide tagged biomolecules have frequently been used in biosensing studies. ${ }^{19-21}$ A notable exception are multi-step fabrication procedures, where the experimental complications encountered have been associated with the SAM oxidation. ${ }^{22}$ Further, severe limitations exist that need to be considered if the SAMs are intended for electrochemical applications, since stability is limited to a relatively narrow potential window. $^{23-25}$ As comprehensively reviewed elsewhere, ${ }^{26-30}$ and as discussed to an introductory level in a following section of this review (Section 2), formation of molecular layers on crystalline silicon surfaces without an intervening oxide layer is an extremely appealing approach toward robust layers on a surface. ${ }^{31-34}$ Silicon-carbon linked monolayers on silicon substrates are expected to complement and/or extend the applications of the currently most relevant technological material ${ }^{35}$ toward the development of atomic scale devices, ${ }^{36-38}$ diverse molecular devices, ${ }^{39-48}$ and well-defined sensing interfaces. ${ }^{49-53}$

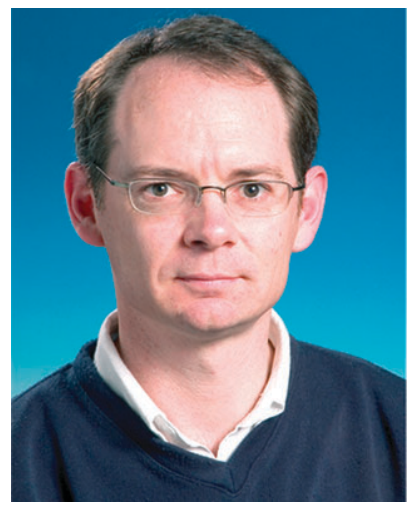

J. Justin Gooding
Professor Justin Gooding is an ARC Australian Professorial Fellow. He graduated with a B.Sc. (Hons) from Melbourne University in 1988 and a DPhil from Oxford University. Subsequently he was post-doctoral appointment at the Institute of Biotechnology in Cambridge University. He accepted a lectureship at UNSW in 1999 and was promoted to full professor in 2006. He was a recipient of a 2004 NSW Young Tall Poppy award, the 2007 RACI Lloyd Smythe Medal for Analytical Chemistry, and the 2009 Eureka Prize for Scientific Research. His research interests are in surface modification using self-assembled monolayers for sensing, molecular electronics and biomaterials applications.
The following sections are intended as an up-to-date presentation of the topic of molecular layers on non-oxidized silicon surfaces. Particular emphasis is put on outlining the strategies toward the goal of chemically well-defined structures. An outline of this review is as follows. Concepts relevant to the understanding of the silicon surface passivation using simple monatomic reagents (e.g. hydrogen) are introduced in Section 2. Subsequently, an overview of the available repertoire of chemical strategies toward organic-silicon devices is presented, with a discussion on the current understanding of the mechanism for the monolayer formation onto $\mathrm{Si}(111)$ and $\mathrm{Si}(100)$, the most common crystal orientations. The major motivations for the development of synthetic schemes to passivate, and controllably functionalize, crystalline silicon surfaces are then the subject of Section 3. Explored approaches toward functional monolayers, where sequential reactions are used to address chemical, physical, and electrical properties of the organic-silicon architecture, are expanded in detail. The last section of this article (Section 4), before an outlook on future challenges and opportunities is presented, introduces the current state of silicon-organic devices for biological sensing.

Four notable and broad areas of research in the organic/ silicon field are either not treated here or considered only briefly, since they are either discussed or reviewed in detail elsewhere. Those are: (a) the expanding literature on porous silicon chemistry and porous silicon biosensing applications; ${ }^{54-62}$ (b) metal-insulator-semiconductor (MIS) studies on organic modified silicon surfaces; ; $^{39,43,48,63-67}$ (c) chemomechanical functionalisation approaches (i.e. 'wetting and scribe' methods), ${ }^{68,69}$ and (d) ultra-high vacuum reactions (UHV, $10^{-10}$ mbar or lower) of unsaturated molecules on reconstructed semiconductor surfaces. $^{42,70,71}$

\section{Silicon-carbon-bound monolayers}

\subsection{Surface preparation}

Organic monolayer formation via solution methods unequivocally starts with the chemical etching of the silicon oxide layer and the saturation of exposed surface bonds. Ensuring that the coordination requirements of surface atoms are satisfied reduces the reactivity of the etched surface and allows for temporary handling of the sample under ambient conditions which are not stringent in terms of the presence of moisture and oxygen. Hydrogen is the most commonly used passivating agent for surface preparation, ${ }^{72}$ but strategies relying on halogens such as iodine ${ }^{73}$ and chlorine ${ }^{74}$ have been also reported. Hydrideterminated silicon surfaces are typically prepared by chemical etching in fluoride-containing solutions, with dilute $(<10 \%)$ hydrofluoric acid used to passivate the $\mathrm{Si}(100)$ orientation and ca. $40 \%$ ammonium fluoride solutions used for the (111) face (Fig. 1) ${ }^{75-78}$ Hydrogenated silicon surfaces are attractive to work with because of their ease of preparation, ${ }^{78}$ their relative stability in air ${ }^{79,80}$ and during brief water ring procedures, ${ }^{31,76}$ and their lack of appreciable reactivity toward a range of common solvents (including acetonitrile, ${ }^{81}$ diethyl ether, ${ }^{46}$ chlorobenzene, ${ }^{82}$ hexane, ${ }^{83}$ toluene $^{84}$ and mesitylene $\left.{ }^{85,86}\right)$. These features allow for the experimentally straightforward 

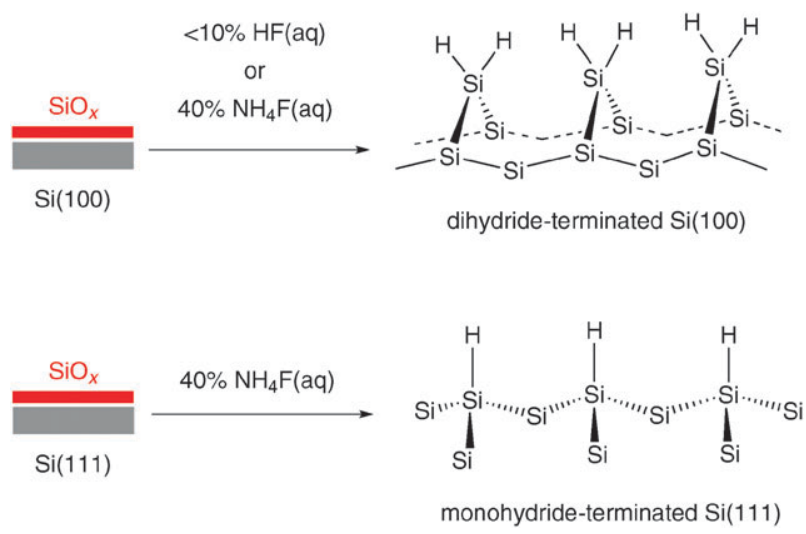

Fig. 1 Preparation of hydride-terminated $\mathrm{Si}(100)$ and $\mathrm{Si}(111)$ surfaces by chemical etching in fluoride-containing solutions (ref. 75-78, 90 and 105). Alternative etchants (e.g. $\mathrm{KOH}, \mathrm{NaOH}$ ) have also been reported and a comprehensive discussion on the available wet-chemical routes to $\mathrm{Si}(h k l)-\mathrm{H}$ surfaces is found in ref. 95.

preparation of covalent organic layers by wet chemical methods. ${ }^{87}$

Notable exceptions to the typically straightforward conditions are [2+2] and [4+2] cycloaddition reactions under 'dry' UHV conditions. Under UHV, the surface oxide layer is thermally removed (i.e. sublimed at temperatures above $1100^{\circ} \mathrm{C}$ ) and the surface can undergo numerous types of reconstruction under appropriate annealing conditions. ${ }^{42}$ Cycloaddition reactions have been reported on the $2 \times 1$ reconstructed $\mathrm{Si}(100)$ surfaces for alkenes and alkynes ${ }^{27,28,70}$ and UHV reactions of $\mathrm{Si}(111)-\mathrm{H}$ with olefins are also documented. ${ }^{88}$

Unreconstructed monohydride, ${ }^{78}$ atomically flat, ${ }^{76,89} \mathrm{Si}(111)$ can be prepared by wet chemical etching in ammonium fluoride, and the mechanism has been studied in detail. ${ }^{90}$ Further, both the doping-level and the miscut angle are reported to influence the quality of the etched substrate. ${ }^{91}$ It is worth noting that what is generally referred to as a chemical etch is better explained as a competition between a purely chemical and an electrochemical process (Fig. 2), even at open circuit potentials (OCP) in a modest accumulation regime (n-type, OCP $<$ flat-band potential). ${ }^{90}$ Alternative etchants, such as aqueous hydrofluoric acid ${ }^{76,92}$ and sodium hydroxide $\mathrm{e}^{93,94}$ can also be used and mechanisms for the silicon dissolution have been proposed for both systems. ${ }^{75,94}$ However, both hydrofluoric acid and sodium hydroxide mediated etchings are generally found to yield microscopically rough surfaces showing a mixture of mono-, di- and tri-hydrides. ${ }^{92}$

For $\mathrm{Si}(100)$, the material that is currently used in the majority of semiconductor devices largely because of a fortunate matching of the interatomic spacing of silicon atoms with the lattice constant of silicon dioxide, ${ }^{95}$ the preparation of monoand di-hydrogen terminated and atomically flat surfaces can only be achieved with UHV techniques. This is most commonly achieved by exposing either a reconstructed $\mathrm{Si}(100)$ $(2 \times 1)^{96}$ (pairing of dangling bonds on adjacent atoms ${ }^{97}$ ) or (un)reconstructed $\mathrm{Si}(100)-(1 \times 1),{ }^{98-100}$ to molecular hydrogen at high temperatures. If prepared outside of the UHV chamber, as in device-quality surfaces, ${ }^{99}$ the hydrofluoric acid-etched hydrogen-terminated $\mathrm{Si}(100)$ surface is best described as having a complex ${ }^{101}$ mono-, di- and tri-hydride configuration ${ }^{75,77,102}$ with minor oxygenated defect sites. Because of the anisotropic nature of the ammonium fluoride etching, and in agreement with early spectroscopic data, ${ }^{103}$ this etching procedure has been generally limited to the (111) orientation since it is generally believed to lead to roughening of the (100) surface. ${ }^{104}$ (a)

chemical
reaction<smiles>C[SiH2]C(C)(C)[SiH]([SiH3])C(C)(C)[SiH2]C</smiles>

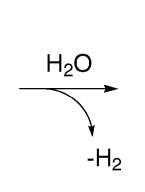<smiles>C[SiH2]C(C)(C)[Si](O)([SiH3])C(C)(C)[SiH2]C</smiles><smiles></smiles><smiles>C[SiH2]C(C)(C)[Si](F)(F)C(C)(C)[SiH2]C</smiles>
$\mathrm{H}_{2} \mathrm{O}$<smiles>C[SiH2][SiH](C)C(C)(C)[SiH](O)F</smiles><smiles>CC(C=O)CO</smiles><smiles>C[SiH2][SiH](C)C</smiles>

(b)

anodic

reaction<smiles>C[SiH2]C(C)(C)[SiH]([SiH3])C(C)(C)[SiH2]C</smiles>

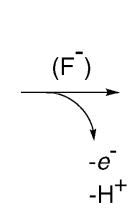

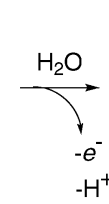<smiles>C[SiH2]C(C)(C)[SiH](F)C(C)(C)[SiH2]C</smiles><smiles>C[SiH2][SiH](C)[SiH](C)CC(C)O</smiles>

(c)

electrochemical reaction at open circuit potential<smiles>C[SiH2]C(C)(C)[Si]([OH+])([SiH2]C)C(C)(C)C</smiles><smiles>C[SiH2]C(C)(O)C(C)(C)[Si](O)([SiH2]C)C(C)(C)[GeH2]C</smiles><smiles>C[SiH2]C(C)(C)[SiH](F)[Si](C)(C)[SiH2]C</smiles><smiles>C[SiH2][SiH](C)[SiH](C)C(C)O[SiH3]</smiles>

Fig. 2 Reaction models for the etching mechanism of silicon surfaces in ammonium fluoride aqueous solutions. The dissolution of silicon is believed to comprise both a chemical and an electrochemical component (ref. 89 and 90). 
However, Hines and co-workers have very recently disproved previous assignments of the FTIR spectrum of ammonium fluoride-etched $\mathrm{Si}(100)$ surfaces and argued in favour of a mainly dihydride-terminated and a near-atomically smooth surface. ${ }^{105}$ This finding is in sharp contrast with the general consensus, and is very likely to stimulate new work in the area. Note that due to steric reasons, further reaction of a $\mathrm{R}-\mathrm{Si}\left(\mathrm{Si}_{x}\right) \mathrm{H}_{n}$ termination (with $n=1$ or $2, x=4-(n+1)$, $\mathrm{R}=$ alkyl/alkenyl chain) is greatly hampered. Therefore the complete chemical reaction of all $\mathrm{Si}-\mathrm{H}$ surface sites is not expected for the chemically etched $\mathrm{Si}(100)$ surface. ${ }^{102}$ Further, the presence of oxygen-containing defect sites at the $\mathrm{Si}(100)-\mathrm{H}$ surface introduces a relevant practical complication in that traces of oxygen and water contaminants ${ }^{79}$ (even as low as $10^{-9}$ mole in the reaction chamber during a thermal promoted reaction) might react with olefins and acetylenes. The resulting products of such reactions will eventually condense with defect surface sites, to yield $\mathrm{Si}-\mathrm{O}-\mathrm{C}$-bridged species. ${ }^{98}$

The superior chemical homogeneity of the fluoride ${ }^{78}$ etched $\mathrm{Si}(111)$ surface, relative to the $\mathrm{Si}(100)$ counterpart, is reflected in the high number of reports on non-oxidized (111) passivated surfaces, ${ }^{31,47,66,74,83,87,106-124}$ compared with $\operatorname{Si}(100){ }^{33,102,125-129}$

\subsection{Reactions of the hydride-terminated silicon surface}

2.2.1 Thermal hydrosilylation of unsaturated molecules. Prompted by a vast body of knowledge in analogous solution phase reactions for silicon compounds, Linford and Chidsey published in 1993 the first report of $\mathrm{Si}-\mathrm{C}$ bound alkyl chain on non-oxidized $\mathrm{Si}(111)-\mathrm{H}$ surfaces. ${ }^{87}$ These monolayers were prepared via the pyrolysis of diacyl peroxides $\left(\left[\mathrm{CH}_{3} \mathrm{RC}(\mathrm{O}) \mathrm{O}\right]_{2}\right.$, $100{ }^{\circ} \mathrm{C}, 1 \mathrm{~h}$ ). In a later report, ${ }^{31}$ Chidsey and co-workers described how 1-alkenes (and 1-alkynes) could be grafted in a thermal reaction $\left(100{ }^{\circ} \mathrm{C}, 1 \mathrm{~h}\right)$ to $\mathrm{Si}(111)-\mathrm{H}$ surfaces in the presence of a varying concentration of a diacyl peroxide initiator. ${ }^{130}$ According to the results of deuterium labelling experiments, and observing a preferential reaction of the 1-alkene species $\left(\mathrm{CH}_{3}\left(\mathrm{CH}_{2}\right)_{15} \mathrm{CH}=\mathrm{CH}_{2}\right)$ compared with that of the diacylperoxide, even for the high peroxide/olefin ratios, the authors suggested a radical mechanism. The proposed mechanism involves initiation at a silyl radical site (after the homolytic cleavage of a $\mathrm{Si}-\mathrm{H}$ by a peroxide-derived radical) with the addition to the $\alpha$-carbon of a terminal olefin to give a carbon-centered radical on the grafted molecule. ${ }^{31}$ The secondary alkyl radical will, in turn, abstract a hydrogen atom at an adjacent $\mathrm{Si}-\mathrm{H}^{131}$ site to give a new silicon radical (dangling bond) and therefore provide a new alkene addition site. This radical chain mechanism, as depicted in Fig. 3, was also supported by the knowledge of analogous reactions occurring in gas-phase organosilane chemistry. ${ }^{132}$ Importantly, the secondary radical on the $\beta$-carbon, as shown in Fig. 3, would allow for a sterically favoured six-membered transition state after hydrogen abstraction from a $\mathrm{Si}-\mathrm{H}$ site. The relative ease of the hydrogen abstraction step in the chain propagation was suggested to account for the apparent lack of side reactions, for example, the apparent absence of adventitious formation of polymeric multilayers. ${ }^{133}$

Interestingly, high-quality films were also obtained for a 1-alkyne (1-hexadecyne), ${ }^{134}$ as well as for a chlorine-terminated 1-alkene (11-chloro-1-undecene). This supports the versatility of the approach and the compatibility of chloro compounds with the hydrosilylation conditions. ${ }^{31,135}$ Quite controversial are the available results for the hydrosilylation of $\omega$-bromo-1alkenes (e.g. 11-bromo-1-undecene). Initial results from Linford et al. suggested the formation of poor-quality surfaces and the authors reasoned this as an incompatibility of bromine with the radical reaction. ${ }^{31}$ However, more recent reports by Bedzyk and co-workers and by Cahen and co-workers advocate for densely-packed, but chemically poorly-defined, $\mathrm{Si}$ (111) monolayers of undecylenic acid 2-bromo-ethyl ester and 11-bromo-1-undecene, respectively. ${ }^{136,137}$

We note that Bedzyk and co-workers introduced the use of X-ray standing waves (XSW) to measure simultaneously chemical and physical properties of monolayers on a singlecrystal surface. From the available XSW data on undecylenic acid 2-bromo-ethyl ester SAMs, and in good agreement with X-ray photoelectron spectroscopy (XPS), X-ray reflectometry (XRR) and X-ray fluorescence (XRF) measurements, the authors ${ }^{136}$ concluded that abstraction of bromine at the silicon surface occurs during the SAM formation. This event generates silicon surface atoms bound to bromine and a terminal methylene radical that opens the possibility of alternate grafting routes not involving the terminal olefin in the molecule. The proposed binding configurations, and an estimated abundance of each grafted species as calculated from XSW, XPS and XRF data, are presented in Fig. 4.

While it is difficult to argue against the proposed alkene addition/hydrogen abstraction chain mechanism, crucial evidence in favour of the plausible surface chain reaction were afforded in 2000 and 2002 by Lopinski et al. ${ }^{71}$ and by Cicero et al., ${ }^{88}$ respectively, using UHV scanning tunnelling microscopy (STM) analysis. Since the hexagonal array of sites of the Si(111) surface $^{88}$ and the parallel alignment of dimers of the reconstructed $\mathrm{Si}(100)$ surface $^{71}$ are expected to dictate the formation of differently shaped arrays of tethered organic molecules, the authors found evidence to support a propagating radical chain initiating at isolated sites defined by the STM tip. ${ }^{71,88}$ On $\mathrm{Si}(100)$ surfaces, molecular lines of styrene, up to 130 molecules long, grew until stopped by surface defects (e.g. missing dimers). ${ }^{71}$ In contrast, on the hexagonal $\mathrm{Si}(111)$ lattice

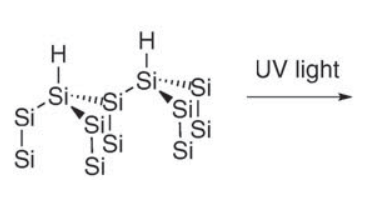

Fig. 3 Schematic depiction of the chain propagation mechanism for 1-alkenes reacting with Si(111) silyl radical as proposed by Linford and Chidsey (ref. 31). 
<smiles>C=CCCCCCCCCC(=O)OCCBr</smiles>

$\mathrm{hv}(254 \mathrm{~nm}, 2 \mathrm{~h})$

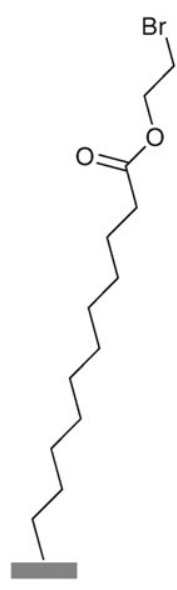

A

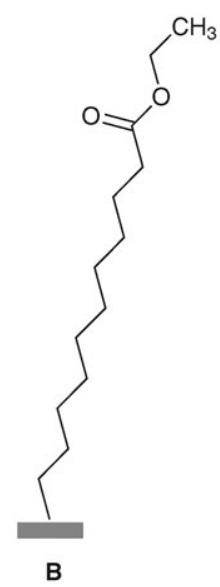

B

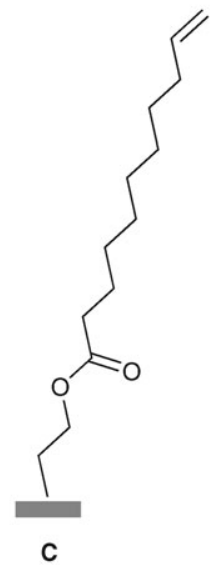

Fig. 4 Concurrent alternative binding modes in the UV-mediated attachement of undecylenic acid 2-bromo-ethyl esters onto $\mathrm{Si}(111)-\mathrm{H}$ surfaces (ref. 136). The predominant structure is believed to be the hydrosilylated, but partially degraded, monolayer $\mathrm{B}$ ( $\mathrm{A} \leq 0.10$ monolayers (ML); $\mathrm{B} \geq 0.27 \mathrm{ML} ; \mathrm{C} \leq 0.13 \mathrm{ML}$ ).

a random walk $^{133}$ of the radical chain leads to poorly defined island of grafted styrene. ${ }^{88}$ While UHV studies suggest a radical chain mechanism they do not prove that the same mechanism is operating in wet chemical systems. However, the observation that monolayer growth is self-limiting and comes to a halt after a finite number of adsorption events, e.g. abstraction, ${ }^{88,133}$ is a strong evidence of monolayer rather than multilayer formation. ${ }^{138}$ Further, in contrast to layers grafted via siloxo ( $\mathrm{Si}-\mathrm{O}-\mathrm{Si}$ ) bridges, ${ }^{81,139,140}$ the silicon-to-carbon bond $^{141}$ structure is relatively ordered and not prone to hydrolysis. ${ }^{31}$ That is, the silicon-carbon bond is highly stable under a range of conditions. ${ }^{31-33,87}$

We note that a major departure from the prevailing theories on the hydrosilylation mechanism has recently emerged. when adjacent hydrogen atoms are no longer available for
Willey and co-workers have observed a significant retention of unsaturation for the thermal and chemomechanical (i.e. scribing) hydrosilylation of 1-octene at both smooth and rough $\mathrm{Si}(100)$ surfaces. ${ }^{142}$ Most surprisingly, strong $\mathrm{C}=\mathrm{C}$ spectral features, either due to $\mathrm{Si}-\mathrm{C}=\mathrm{C}$ or $\mathrm{R}-\mathrm{C}=\mathrm{C}-\mathrm{R}$ functionalities in the monolayer, were observed in near-edge X-ray absorption fine structure (NEXAFS) spectra using synchrotron radiation. The authors estimated that the fraction of surface-bound molecules retaining a double bond is in the 0.13-0.21 range for the smooth substrates and between $0.28-0.40$ for rough ones. Similar NEXAFS $C=C$ features had also been observed by Cahen and co-workers, but dismissed as being due to irradiation-induced damage under the experimental conditions used. ${ }^{143}$ In the recent report of Willey and co-workers, precautions were taken to minimize exposure of the film while retaining a satisfactory signalto-noise ratio. Most importantly the incident X-ray flux was kept at a level two orders of magnitude less than that required to induce damage in similar monolayers prepared on $\operatorname{Si}(111) .{ }^{143}$ Mechanistic implications to account for the significant $\mathrm{sp}^{2}$ character of monolayers prepared from 1-alkenes are striking. Further studies will help in elucidating these preliminary observations but it is likely that in order for the monolayer to retain a substantial level of unsaturation a pathway that simultaneously continues radical propagation and accounts for double bond formation must be operative during the hydrosilylation reaction. As the authors noted, unsaturation may be either retained by donation of a hydrogen atom to the surface (pathway A, Fig. 5) or by disproportionation of neighbouring $\beta$-radical intermediates (pathway B, Fig. 5).

2.2.2 Alkylation of halide-terminated surfaces. A twostep chlorination/alkylation sequence on hydride-terminated silicon surfaces, as initially reported by Bansal et al. ${ }^{74}$ has also been demonstrated on numerous occasions. This method generally results in ordered, ${ }^{144}$ electrically and chemically well-passivated alkyl $\operatorname{Si}(111)^{82,109,114,124,144-150}$ and $\operatorname{Si}(100)^{102}$ surfaces (Fig. 6). A brief discussion is required to elucidate the unique features, and intrinsic limitations, of the chlorination/ alkylation approach.

First, the displacement of a surface halogen atom by either an alkyl Grignard $(\mathrm{RMgBr})$ or an alkyl lithium reagent (RLi) is the only reported method for single methyl groups to be reacted with unoxidized silicon surfaces. Most importantly, pathway $\mathbf{A}$

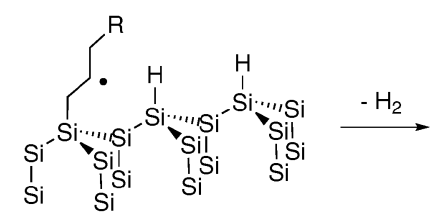

pathway $\mathbf{B}$ (disproportionation)
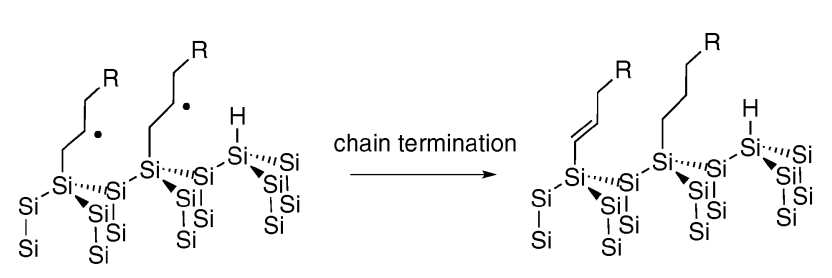

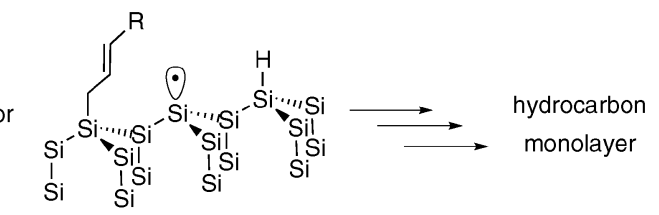

Fig. 5 Re-evaluation of the radical chain mechanism for the hydrosilylation of 1-alkenes (ref. 142). 


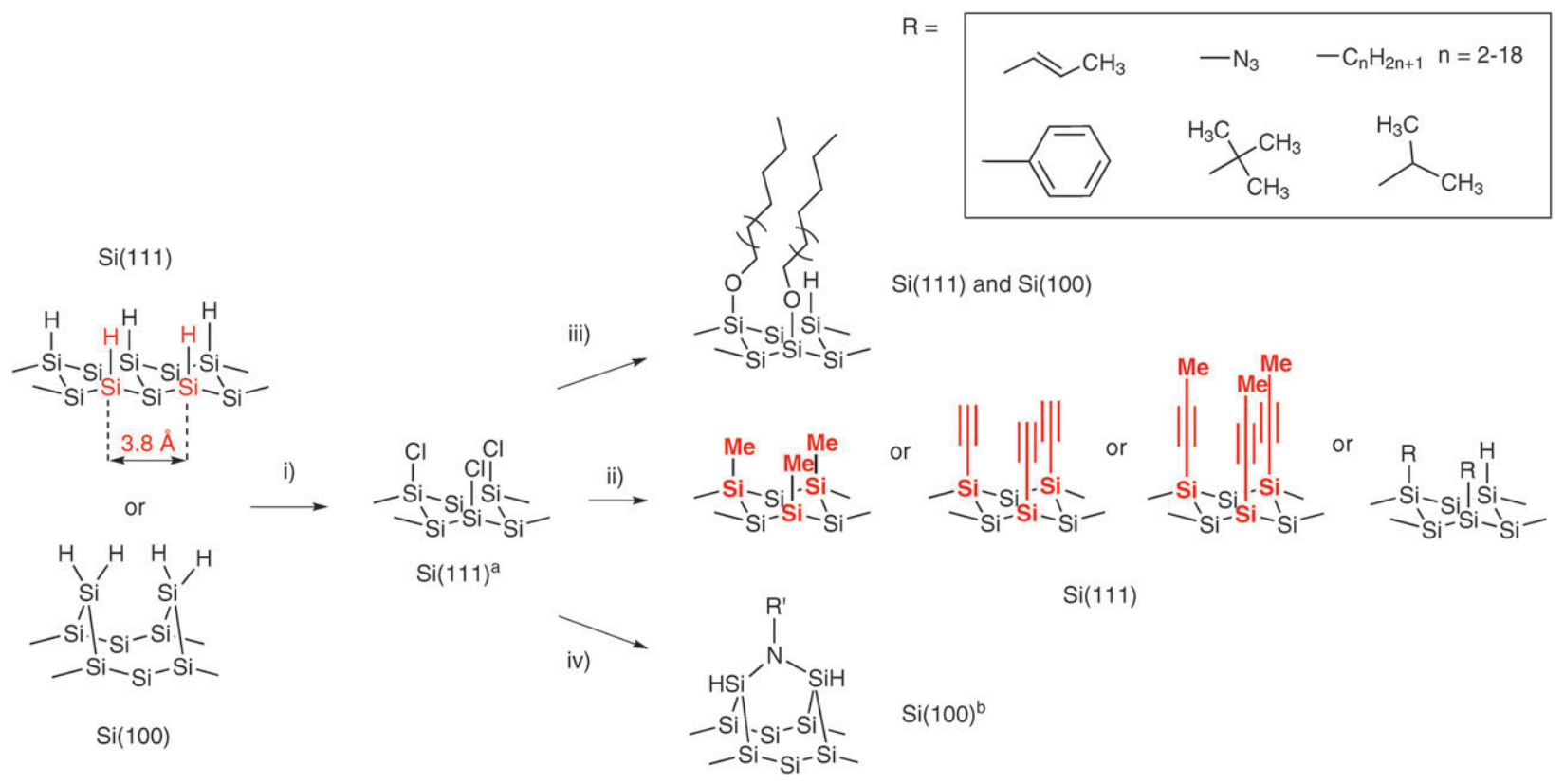

Fig. 6 Representative modification schemes for halogenated $\mathrm{Si}(111)$ and $\mathrm{Si}(100)$ surfaces. Chlorinated surfaces are a versatile substrate (i), and can be further reacted with a range of organic molecules (ii-iv). Selected examples include: (i) $\mathrm{PCl}_{5}$ or $\mathrm{Cl}_{2}\left(\right.$ g) ; (ii) $\mathrm{RLi}\left(\mathrm{R}={ }_{-} \mathrm{CH}_{3},-\mathrm{C}_{4} \mathrm{H}_{9},-\mathrm{C}_{6} \mathrm{H}_{13}\right.$, $\left.-\mathrm{C}_{10} \mathrm{H}_{21},-\mathrm{Cl}_{8} \mathrm{H}_{37}\right)$, or $\mathrm{RMgX}\left(\mathrm{R}=-\mathrm{C}_{n} \mathrm{H}_{2 n+1}(n=1-18),-t-\mathrm{Bu},-i-\mathrm{Pr},-\mathrm{C}_{6} \mathrm{H}_{5},-\mathrm{CH}=\mathrm{CHCH}_{3} ; \mathrm{X}=\mathrm{Br}\right.$ or $\left.\mathrm{Cl}\right)$, or $\mathrm{NaN}, \mathrm{NaC} \equiv \mathrm{CH}_{3}$, $\mathrm{NaC} \equiv \mathrm{CCH}_{3}$; (iii) $\mathrm{ROH}\left(\mathrm{R}=-\mathrm{C}_{n} \mathrm{H}_{2 n+1}\right)(n=12,18)$; and (iv) $\mathrm{R}^{\prime} \mathrm{NH}_{2}\left(\mathrm{R}^{\prime}=-\mathrm{C}_{4} \mathrm{H}_{9},-\mathrm{C}_{8} \mathrm{H}_{17},-\mathrm{C}_{6} \mathrm{H}_{5}\right)(\mathrm{ref} .74,102,109,110,114,124$ and 153-158). The reaction of acetylydes and methyl Grignard with chlorinated surfaces allows full $\mathrm{Si}-\mathrm{C}$ atop site termination on the $\mathrm{Si}(111)$ surface (structures in bold). ${ }^{a}$ With the exception of the work by Nemanick et al. (ref. 102), alkylation of chlorinated surfaces has been generally reported for $\mathrm{Si}(111)$ substrates. ${ }^{\mathrm{b}} \mathrm{UHV}$ reaction (ref. 156).

this method is claimed to allow for the complete passivation of $\mathrm{Si}$ surface sites of the unreconstructed $\mathrm{Si}(111)-\mathrm{H}$ surface. ${ }^{74,144,145,150}$ As schematically depicted in Fig. 6 the distance between $\mathrm{Si}$ surface sites on the $\mathrm{Si}(111)$ surfaces is $3.8 \AA,{ }^{95}$ while the van der Waals radius of a methyl group is $c a$. $2 \AA{ }^{124}$ It is thus possible to react every $\mathrm{Si}-\mathrm{H}$ site (colored for clarity in Fig. 6), and fully-passivated $\mathrm{Si}(111)-\mathrm{CH}_{3}$ surfaces have been prepared. ${ }^{109,144,150}$ Somewhat larger (ca. 4.5-5.0 ̊) is the van der Waals radius of the methylene units in longer alkyl chains (i.e. $\mathrm{C}_{n} \mathrm{H}_{2 n+1}, n \geq 2$ ). ${ }^{31}$ As such, regardless of the chemical strategy used, complete passivation of the $\mathrm{Si}(111)$ surface cannot be achieved due to van der Waals interactions between methylene units of adjacent alkyl chains. ${ }^{31,150}$

Second, alkylated and methylated $\mathrm{Si}(111)$ surfaces prepared via this route have a satisfactory stability in air ${ }^{150}$ and show remarkable electrical properties, ${ }^{114,145}$ with the lowest surface recombination velocity $\left(<25 \mathrm{~cm} \mathrm{~s}^{-1}\right)$ reported to date for a passivated (non-hydride-terminated ${ }^{72}$ ) silicon surface. ${ }^{151}$ The low recombination velocity of charge carriers is supporting evidence that there is a negligible number of surface defect sites (trap density $<3 \times 10^{-9} \mathrm{~cm}^{-2}$ ). ${ }^{145}$ Importantly, the high quality of the surfaces prepared in this two-step route, together with allowing access to short methyl films, made possible a systematic evaluation of the influence of the passivating layer thickness over the rate of native oxide growth. ${ }^{150}$ Through a detailed high-resolution soft X-ray photoelectron spectroscopy (SXPS, synchrotron radiation between 10 and $300 \mathrm{eV}$ ) study, Webb et al. ${ }^{150}$ showed how the protective role of the film had little or no dependence on both chain length and density of step edges. This was done by varying (i) the alkyl chain length $\left(\mathrm{CH}_{3}-\mathrm{Si}(111)\right.$ and $\left.\mathrm{C}_{2} \mathrm{H}_{5}-\mathrm{Si}(111)\right)$ and (ii) the fractional number of silicon surface atoms localized along step edges (wafers with different nominal miscut angles were used, namely $0.5^{\circ}$ and $7^{\circ}$ ). As the authors concluded, ${ }^{150}$ their observations strongly support an oxidative protective mechanism largely due to $\mathrm{Si}-\mathrm{C}$ bonds disrupting the native oxide growth mechanism ${ }^{80}$ and not exclusively resulting from limited access of oxygenated species to the substrate. ${ }^{32,115,152}$

Despite the vast literature now available on the tandem chlorination/alkyl Grignard route, ${ }^{74,102,109,114,124,145,148,150}$ and the general agreement over the high quality of the reaction product, the most obvious limitation of this methodology appears to be the complicated and inefficient (see Section 3.1) derivatization of films having a $\mathrm{C}_{n} \mathrm{H}_{2 n+1}$ structure. Further, the need for stringent conditions (such as the exclusion of water and oxygen) for both the chlorination (generally phosphorus(v) chloride with radical initiators) and the Grignard reaction might discourage the routine use of this two-step strategy. The latter issue was partially addressed in an improved and simplified method for the preparation of halogenated silicon surfaces reported by Eves and Lopinski ${ }^{153}$ that relied on gas phase reactions of $\mathrm{Si}(111)-\mathrm{H}$ surfaces with molecular chlorine and bromine at room temperature (e.g. $2 \%$ chlorine in argon at $c a .760$ Torr, $1 \mathrm{~h}$ ). Chlorinated surfaces (but not the brominated versions) prepared under these conditions are remarkably stable toward oxidation in the presence of air and water, despite the expected polarization of $\mathrm{Si}-\mathrm{Si}$ back bonds. ${ }^{90}$ Analogous gas phase reactions have also been reported for $\mathrm{Si}(100)-\mathrm{H}$ using an experimental protocol that is only slightly more demanding. ${ }^{154}$ 
For completeness it should be noted that halogenated $\mathrm{Si}(111)$ surfaces have also been reacted with sodium acetylides (to generate $\mathrm{Si}-\mathrm{C} \equiv \mathrm{CH}$ and $\mathrm{Si}-\mathrm{C} \equiv \mathrm{C}-\mathrm{CH}_{3}$ linkages), ${ }^{110,155}$ primary amines ( $\mathrm{Si}-\mathrm{N}$ linkage), ${ }^{156}$ primary alcohols ( $\mathrm{Si}-\mathrm{O}$ linkage) ${ }^{157}$ and sodium azide $\left(\mathrm{Si}-\mathrm{N}_{3}\right.$ surfaces) (Fig. 6). ${ }^{158}$ The reaction of acetylides with chlorinated surfaces, in an analogous fashion to that discussed above for the $\mathrm{Si}(111)-\mathrm{CH}_{3}$ surfaces, allows full $\mathrm{Si}-\mathrm{C}$ site termination on the $\mathrm{Si}(111)$ surface (see Fig. 6), and will be further detailed in Section 3.4.

2.2.3 Direct attachment of alkyl Grignard onto Si-H surfaces. In a study aimed to expand the number of available wet-chemical approaches toward $\mathrm{Si}-\mathrm{C}$ bound layers Boukherroub et $a .^{83}$ described the direct thermal attachment of an alkyl Grignard reagent (decylmagnesium bromide) onto hydrogenterminated $\mathrm{Si}(111)$ surface. The layers obtained showed only minor degradation upon immersion in both concentrated aqueous potassium hydroxide and $40 \%$ aqueous ammonium fluoride solutions, as judged from attenuation of the methylene stretch vibrations in the FTIR spectrum. While this direct approach surely represents a simplified protocol in regards to the two-step procedure of Bansal et al. ${ }^{74}$ conclusive evidence on its mechanism is still lacking. This lack of evidence is despite a suggestion of a role played by alkyl halide contaminants ${ }^{159}$ from the Grignard solution proposed by Chazalviel and co-workers. ${ }^{160}$ In brief, Chazalviel reasoned that on the grounds of higher reaction yields found in n-type substrates, as compared to p-type, an electrochemical, ${ }^{161}$ rather than merely chemical, ${ }^{162}$ mechanism was involved. This is in agreement with the more positive reduction potential for the alkyl halide $(\mathrm{RBr})$, relative to the redox potential of the Grignard reagent $(\mathrm{RMgBr})$. The oxidative decomposition of the Grignard reagent and the reduction of alkyl bromide are suggested to occur simultaneously at the surface. To account for the more efficient grafting process observed on the n-type, as compared to p-type surfaces, the alkyl halide reduction to afford an initial radical species is suggested by the authors ${ }^{160}$ to be the rate-limiting step of the entire ${ }^{163}$ reaction sequence

$$
\mathrm{RMgBr} \rightarrow \mathrm{R}^{\bullet}+\mathrm{MgBr}^{+}+\mathrm{e}^{-}
$$

and

$$
\mathrm{RBr}+\mathrm{e}^{-} \rightarrow \mathrm{R}^{\bullet}+\mathrm{Br}^{-}
$$

where electrons are exchanged with the silicon conduction band. This would require either holes to be injected into silicon valence band or electrons being captured from the conduction band. The energy level for a weak oxidizing agent is expected to be comparable to the energy levels in the conduction band and therefore lowered activation energies will favor an electron capture rather than a hole injection event. In the absence of appreciable photogenerated hole-electron pair formation, an event that would result in accumulation in a region close to the surface (i.e. space charge region) of electrons on a p-type material and holes in an n-type, the $\mathrm{RBr}$ reduction will proceed faster over n-type electrodes than in p-type (empty conduction band). This may account for a superior grafting efficiency.
2.2.4 Photochemical hydrosilylation reactions and mechanistic considerations. The discussion in the last section afforded insights into the energetics of the semiconductor-electrolyte interface, a topic that has been discussed in greater detail elsewhere, ${ }^{164}$ but most importantly will serve to introduce an intriguing ongoing debate over the effect mediated by the doping level and type in light-mediated hydrosilylation reactions at the hydride-terminated silicon surface. ${ }^{165,166}$ Initially reported by Terry et al. in a study aimed to provide direct evidence of the silicon-carbon bond formation for the reaction of 1-pentene with $\mathrm{Si}(111)-\mathrm{H},{ }^{146}$ the UV-mediated hydrosilylation reaction of unsaturated hydrocarbons has since seen numerous applications. ${ }^{50-52,113,133,167-169}$ The process generally affords good hydrocarbon chain surface coverages, ${ }^{113,133}$ chemically stable surfaces, ${ }^{83}$ and allows for a straightforward light-addressable surface patterning. ${ }^{51,52,168}$ For further details on the early body of work on the photochemical hydrosilylation, the reader should consult the comprehensive reviews of Buriak. ${ }^{27,28}$ Here we will mainly focus our discussion on more recent advances, while trying to bring to the attention of the reader the need for conclusive data to resolve the details of the surface hydrosilylation reaction mechanism, both under illumination and thermal conditions.

Interestingly, as discovered by Stewart and Buriak ${ }^{170}$ for porous silicon and more recently reported by Sudhölter and co-workers for crystalline $\mathrm{Si}(100)$ and $\mathrm{Si}(111)$ substrates (Fig. 7), ${ }^{126,171}$ attachment of olefins (and acetylenes ${ }^{172}$ ) can be successfully carried out under visible light irradiation (up to $\left.658 \mathrm{~nm}^{126,166}\right)$. However, contact angle and FTIR spectral data for the hydrosilylation of 1-undecenylic acid $\left(\mathrm{CH}_{2}=\mathrm{CH}\left(\mathrm{CH}_{2}\right)_{8} \mathrm{COOH}\right)$, under visible light (447 and $658 \mathrm{~nm}$ ), suggest that the monolayers formed are not densely packed. ${ }^{166}$ This mild approach (generally $477 \mathrm{~nm}$ light is used) promises to allow the immobilization of labile biomolecules and has been used to attach fully-acetylated olefin-bearing carbohydrates onto $\mathrm{Si}(100)$ surfaces. ${ }^{126,171}$

From a mechanistic standpoint, however, visible light reactions have considerable implications with regards to the initiation of the radical chain reaction. ${ }^{88,119,133}$ As Chidsey and colleagues noted in their early work, ${ }^{133}$ homolytic cleavage of the $\mathrm{Si}-\mathrm{H}$ bond $\left(\geq 84 \mathrm{kcal} \mathrm{mol}^{-1}\right)^{173,174}$ requires $c a .350 \mathrm{~nm}$ (or lower) photons. Illumination at $450 \mathrm{~nm}$ of hydrideterminated substrates kept in air showed no appreciable effects in regard to surface photooxidation by radical reaction with dioxygen. ${ }^{175}$ Analogously, homolytic dissociation of $\mathrm{Si}-\mathrm{Si}$ bonds requires light of wavelengths shorter than $540 \mathrm{~nm} .^{126}$ For these reasons, there is general agreement over the mechanism involved in the chain propagation, ${ }^{71,88,119,133}$ which is assumed to proceed through an identical radical chain to that described above for thermal method ${ }^{31}$ and UHV techniques $^{71,88}$ (Fig. 3). However, less clear are the events leading to the formation of silyl radicals (silicon dangling bonds) under white light illumination as well as in uncatalyzed thermal reactions. ${ }^{176}$

Using light at a wavelength of $447 \mathrm{~nm}$ with a controlled light intensity Eves et al. estimated, ${ }^{119}$ using STM analysis, changes in the number of nucleation sites with increasing exposure times, and hence presented evidence for a low efficiency process governing the initial stages of the hydrosilylation of 
irradiation at 447,504 or $658 \mathrm{~nm}$

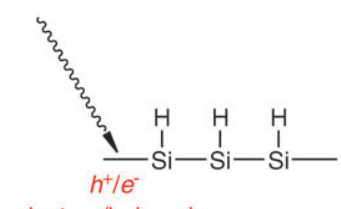

electron/hole pairs

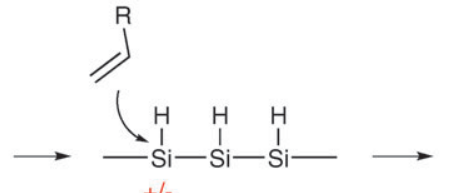

+ /-

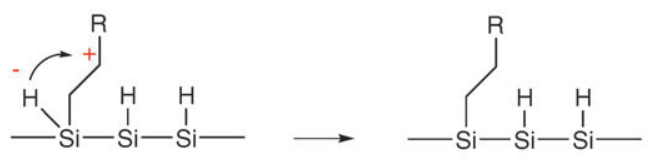

hydrocarbon monolayer

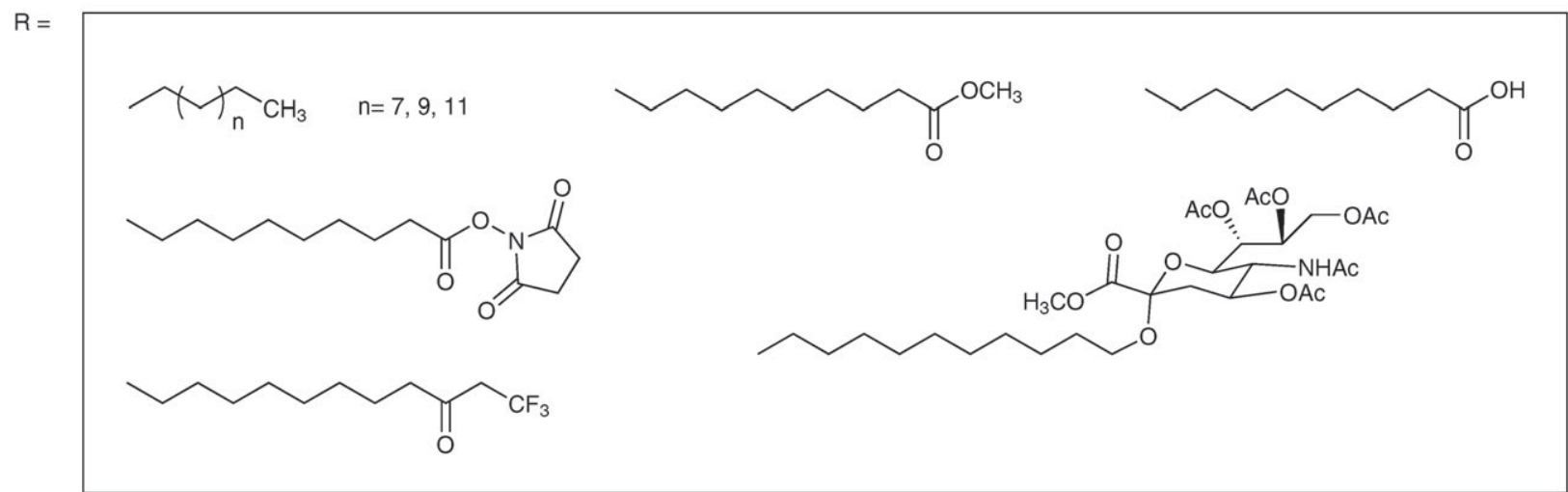

Fig. 7 White-light promoted hydrosilylation reaction (ref. 126, 166, 171 and 201). It has been proposed that surface-localized holes facilitate the nucleophilic attack of 1-alkene species $\left(\mathrm{CH}_{2}=\mathrm{CH}-\mathrm{R}, \mathrm{R}\right.$ is detailed in the figure inset).

1-decene. It was concluded that each photon had a remarkably low $\left(\mathrm{ca} .10^{-7}\right)$ probability of forming a nucleation site. Since the homolytic dissociation of surface $\mathrm{Si}-\mathrm{H}$ (and $\mathrm{Si}-\mathrm{Si}$ ) cannot be operative under white light illumination ${ }^{126}$ and given the low efficiency of the initiation process, plausible alternative mechanisms include light-induced radical formation from impurities in solution ${ }^{119}$ and a hole-related mechanism (Fig. 7) favouring the reaction on illuminated n-type substrates, as compared to p-type, as proposed by Sun et al. ${ }^{126}$

Alternatively, as in the case of 1-alkynes thermally reacted onto p-type $\mathrm{H}-\mathrm{Si}(100)-(1 \times 1)$ samples, ${ }^{177}$ a concerted hydrosilylation mechanism has been argued for by Cerofolini and colleagues ${ }^{178-181}$ (Fig. 8). On the basis of detailed angleresolved XPS analysis, ${ }^{180}$ this group showed the formation of densely packed layers and suggested in the case of 1-alkynes (specifically 1-octyne), ${ }^{98,179}$ that a large fraction of surface attached vinyl moieties survive the thermal reaction (a, Fig. 8). ${ }^{182}$ In the opinion of Cerofolini et al. the remaining $\pi$ bonds are available for subsequent insertion of either water or oxygen. These events account for a slow (negligible oxidation in the time scale of several months ${ }^{100,180}$ ) formation of an oxo-bridge between carbonaceous material and the silicon substrate (e, Fig. 8). Note that the hydrosilylation reaction could, in principle, proceed via routes (iii) and (iv) shown in Fig. 8 to yield the bridged species $\mathbf{b}$ and $\mathbf{c}$. The XPS evidence of Cerofolini and co-workers supporting an alkenyl layer on $\mathrm{Si}(100)$ are in good agreement with the $c a .1600 \mathrm{~cm}^{-1}$ FTIR vibration $(\mathrm{Si}-\mathrm{C}=\mathrm{C}$ stretch) for the 1-alkyne hydrosilylation on $\mathrm{Si}(111)-\mathrm{H}$ of Linford and Chidsey. ${ }^{31}$

It is important to comment on the findings of Sieval et al. ${ }^{125}$ on the thermal reaction of 1-alkynes onto a non-rigorous dihydride phase (i.e. hydrofluoric acid-etched and not otherwise treated $\mathrm{Si}(100)$ surface). These are highly significant with regards to the need for multiple tools in the chemical analysis

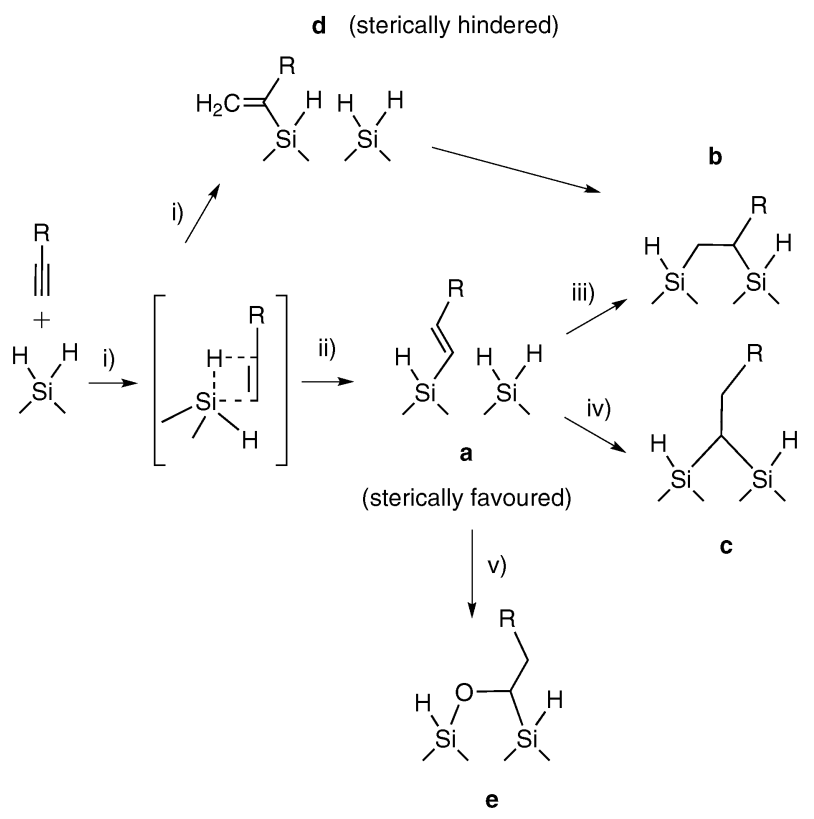

Fig. 8 Thermal hydrosilylation of 1-alkynes at the dihydride $1 \times 1$ $\mathrm{Si}(100)$ surface as proposed by Cerofolini and co-workers (ref. 178-181). A plausible concerted reaction mechanism (i), and the candidate surface products (a-d) are outlined. XPS evidence supports the sterically favoured alkenyl anti-Markovnikov (ii) surface as the major product (a) in the hydrosilylation of terminal alkynes. Steric reasons are believed to dictate the stereochemistry of the reaction, and prevent the formation (i) of the sterically hindered Markovnikov product (d). Possible oxidation products (e.g. e) are also shown.

of monolayers and to the pivotal role played by the substrate orientation and preparation. This group observed a total attenuation of the $\mathrm{Si}-\mathrm{C}=\mathrm{C}$ stretch which was considered as plausible evidence for complete cleavage of both alkyne $\pi$ 


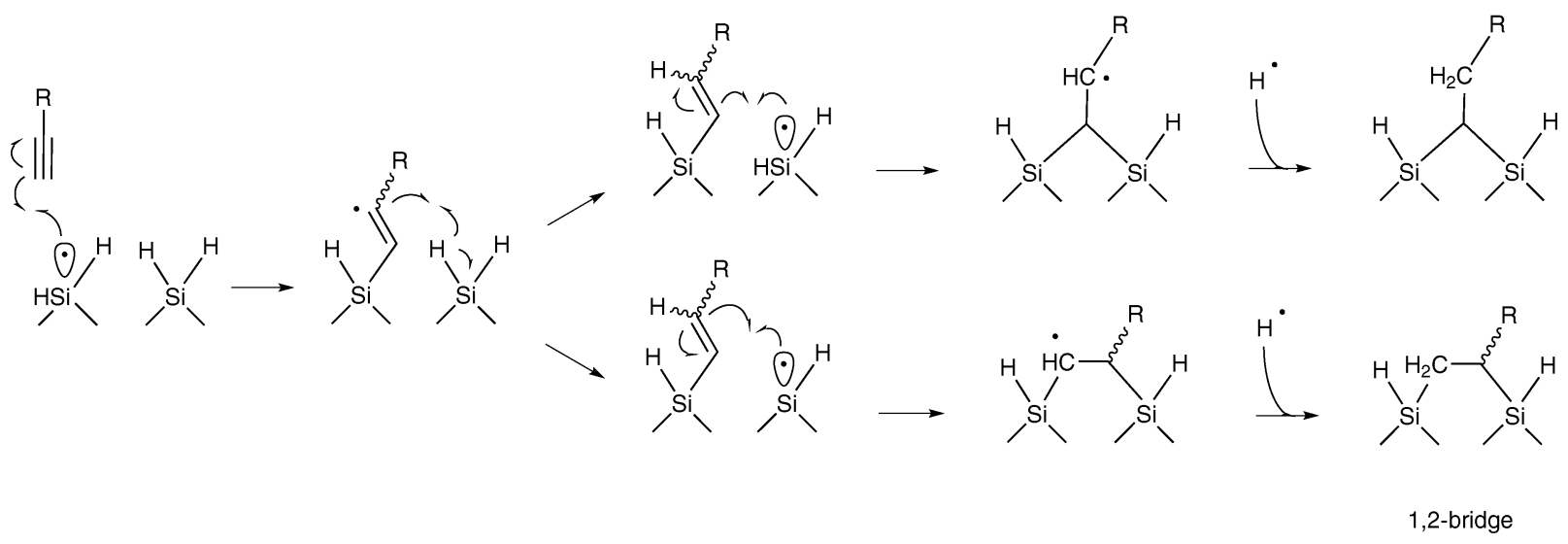

Fig. 9 Thermal hydrosilylation of 1-alkynes at the $\mathrm{Si}(100)-\mathrm{H}$ surface as suggested by Sieval and co-workers (ref. 125). FTIR spectral evidence supported the complete reduction of $\pi$ bonds, as for tethered molecules bound to two adjacent Si surface sites.

bonds (bis-silylation) through a radical mechanism (Fig. 9). Therefore, based on FTIR spectral data and quantum mechanical calculations, the formation of surface heterocycles (either 1,1- or 1,2-bridged products) involving bridged silicon surface atoms cannot be disregarded on $\mathrm{Si}(100)-\mathrm{H} .{ }^{125}$ Interestingly, analogous discrepancies for the immobilization of 1 -alkynes are found in the porous silicon literature. ${ }^{28,84,183}$ Whether the different conclusions of Sun et al. ${ }^{126,166}$ and Cerofolini and co-workers ${ }^{180}$ with regards to the hydrosilylation mechanism are due to either the different unsaturated hydrocarbons used (e.g. different lengths), or due to differences in reaction conditions, surface preparation protocols or characterization techniques, is not clear at present and will require further work.

It also needs to be noted that covalent silicon-carbon linked layers may degrade after prolonged (e.g. ca. $2 \mathrm{~h}$ ) exposure to UV radiation. XPS and FTIR spectral evidence support the UV-mediated cleavage of the $\mathrm{Si}-\mathrm{C}$ bond of both $\mathrm{Si}(111)$ and $\mathrm{Si}(100)$ of alkyl layers, under either $\operatorname{argon}^{184}$ or air. ${ }^{185}$ These findings could lead to a novel surface patterning approach, ${ }^{185}$ but most notably add serious implications in regards to the quality of monolayers prepared under UV irradiation.

2.2.5 Lewis acid-catalyzed hydrosilylation reactions. A well-established functionalization approach for the derivatization of hydride-terminated porous silicon (PSi) ${ }^{186,187}$ is the Lewis acid-mediated (e.g. $\mathrm{AlEtCl}_{2}$ ) attachment of olefins and acetylenes. This method has attracted little interest on crystalline surfaces ${ }^{83}$ presumably due to the low surface coverage initially reported. ${ }^{188}$ Further, in contrast to the data reported for $\mathrm{PSi}$, this catalytic reaction requires heating and significantly longer reaction times when performed on $\mathrm{Si}(111)-\mathrm{H}$ surfaces. ${ }^{83,186}$

2.2.6 Electrochemical approaches to $\mathrm{Si}-\mathrm{C}$-bound hydrocarbon monolayers. Expanding to crystalline silicon surfaces a technique previously used only to graft aryl layers on carbon substrates, ${ }^{189,190}$ Allongue and co-workers ${ }^{107,191}$ showed the electrochemical formation of phenyl layers on n-type $\operatorname{Si}(111)$ by reduction of commercially available aryl diazonium salts.
These experiments were, in part, prompted by the findings of Chazalviel and co-workers for PSi systems. They showed that under anodic polarization, methoxy-terminated surfaces $\left(\equiv \mathrm{Si}-\mathrm{OCH}_{3}\right.$ and $=\mathrm{Si}-\left(\mathrm{OCH}_{3}\right)_{2}$ can be prepared. ${ }^{192}$ The aryl diazonium approach benefits from the low cathodic overpotentials necessary to generate aryl radicals

$$
\begin{gathered}
\mathrm{X}-\mathrm{Ar}-\mathrm{N}_{2}{ }^{+}+\mathrm{e}^{-} \rightarrow \mathrm{X}-\mathrm{Ar} \mathbf{\bullet}^{\bullet}+\mathrm{N}_{2} \\
\left(\mathrm{X}=\mathrm{NO}_{2}, \mathrm{Br}, \mathrm{COOH}, \mathrm{CN}\right)
\end{gathered}
$$

The prepared $\mathrm{Si}-\mathrm{C}$ bound layers resist chemical etching in $40 \%$ hydrofluoric acid. ${ }^{193}$ When the reduction was performed in aqueous electrolytes containing diluted sulfuric acid combined with $2 \%$ hydrofluoric acid, the reaction gave no detectable high-binding energy shifts in the Si 2p XPS spectra (even at low take off angles, 5-10 $)$ indicating the absence of $\mathrm{SiO}_{x}$ species. ${ }^{107}$ Allongue and co-workers, on the basis of Rutherford backscattering, STM imaging, angle resolved XPS, capacitance measurements, and from the measured charged passed during the grafting process, ${ }^{194}$ concluded that no appreciable multilayer formation occurred ${ }^{107,117,191}$ under the cathodic conditions used. A reaction scheme for the electrochemical reduction of diazonium salts on hydride silicon was also proposed: ${ }^{191}$

$$
\begin{aligned}
\mathrm{X}-\mathrm{Ar}-\mathrm{N}^{+} \equiv \mathrm{N}+\mathrm{e}^{-} \rightarrow \mathrm{X}-\mathrm{Ar}^{\bullet}+\mathrm{N}_{2} \\
\equiv \mathrm{Si}-\mathrm{H}+\mathrm{X}-\mathrm{Ar}^{\bullet} \rightarrow \equiv \mathrm{Si}^{\bullet}+\mathrm{X}-\mathrm{Ar}-\mathrm{H} \\
\equiv \mathrm{Si}^{\bullet}+\mathrm{X}-\mathrm{Ar}^{\bullet} \rightarrow \equiv \mathrm{Si}-\mathrm{Ar}-\mathrm{X} \\
\equiv \mathrm{Si}-\mathrm{H}+\mathrm{H}_{2} \mathrm{O}+\mathrm{e}^{-} \rightarrow \equiv \mathrm{Si}^{\bullet}+\mathrm{H}_{2}+\mathrm{OH}^{-} \\
\equiv \mathrm{Si}+\mathrm{H}_{2} \mathrm{O}+\mathrm{e}^{-} \rightarrow \equiv \mathrm{Si}-\mathrm{H}+\mathrm{OH}^{-}
\end{aligned}
$$

where $\mathrm{X}$ is either a bromine atom or a nitro group, and $\equiv \mathrm{Si}-\mathrm{H}$ depicts the monohydro phase of the ammonium fluoride etched $\mathrm{Si}(111)$ surface. Importantly the proposed mechanism accounts for the observed hydrogen evolution (7) via a Heyrovsky-type reaction. ${ }^{90,94}$ The silyl radical generated can either react with aryl groups (6) or abstract hydrogen from a water molecule to regenerate the hydride terminated species (8). As supported by FTIR spectral data, ${ }^{107}$ reaction products 
include hydride terminated species with lack of sizable $\mathrm{SiO}_{x}$-related XPS emissions. ${ }^{107,191}$

An important difference between the approach of the Allongue group and almost all of the available literature on un-oxidized silicon-carbon bound layers is that they use straightforward aqueous conditions used in handling etched $\mathrm{Si}(111)$ wafers. As the $\mathrm{Si}-\mathrm{C}$ bond is completely inert towards $2 \%$ hydrofluoric acid, its presence in the electrolyte during the reduction of the diazonium salt allowed for any $\mathrm{SiO}_{x}$ species formed during the reaction to be dissolved without interfering with the organic layer formation. This approach to limit silicon oxidation in the final surface is in contrast to the entire body of work on non-oxidized passivated silicon surfaces, where the strategy has been to minimize oxidation of the substrate by thoroughly excluding oxygenated species from the reaction chamber.

An alternative electrochemical route to give silicon-carbon bound monolayers, adapted from anodic and cathodic galvanostatic procedures initially reported for PSi, ${ }^{195}$ is the cathodic electrografting of terminal alkynes onto highly-doped hydrideterminated $\mathrm{Si}(111)$ and $\mathrm{Si}(100)$ substrates. ${ }^{196}$ The method uses a conducting (Pt-coated) atomic force microscope (AFM) tip acting as the anode in a electrografting reaction to produce well-defined and chemically resistant nanoscale (ca. $40 \mathrm{~nm})$ features. The forward negative bias $(-1.0 \text { to }-2.2 \mathrm{~V})^{197}$ applied to the $\mathrm{SiH}$ surface limits oxidative events at the substrate when the electrografting of various 1-alkynes is done in air. There is no evidence of hydrogen shifts from the substrate to a $\pi$ bond since no consumption of $\nu(\mathrm{C} \equiv \mathrm{C})$ FTIR modes is found in porous silicon substrates after the galvanostatic attachment of various 1-alkynes. ${ }^{195}$ The mechanism involved in the formation of a silylated alkyne ( $\mathrm{Si}-\mathrm{C} \equiv \mathrm{CR})$ product via the cathodic reaction of a generic 1-alkyne $(\mathrm{R}-\mathrm{C} \equiv \mathrm{C}-\mathrm{H})$ was proposed to be as below

$$
\begin{aligned}
\equiv \mathrm{Si}-\mathrm{H}+\mathrm{e}^{-} \rightarrow \equiv \mathrm{Si}^{-}+\mathrm{H}^{\bullet}\left(\text { or } 1 / 2 \mathrm{H}_{2}\right) \\
\equiv \mathrm{Si}^{-}+\mathrm{R}-\mathrm{C} \equiv \mathrm{C}-\mathrm{H} \rightarrow \equiv \mathrm{Si}-\mathrm{H}+\mathrm{R}-\mathrm{C} \equiv \mathrm{C}^{-}
\end{aligned}
$$

$$
\begin{aligned}
& \equiv(\mathrm{H}) \mathrm{Si}-\mathrm{Si}(\mathrm{H}) \equiv+\mathrm{R}-\mathrm{C} \equiv \mathrm{C}^{-} \rightarrow \equiv \mathrm{Si}(\mathrm{H})-\mathrm{C} \equiv \mathrm{CR} \\
& +\equiv(\mathrm{H}) \mathrm{Si}^{-}
\end{aligned}
$$

where the initial formation of a silyl anion, after the reduction of a $\mathrm{Si}-\mathrm{H}$ site (9), is followed by an acid/base reaction to give a carbanion (10) and subsequent nucleophilic attack of a $\mathrm{Si}-\mathrm{Si}$ bond (11). ${ }^{195}$ Importantly, the reaction is highly selective toward acetylenes, with no monolayers forming from 1-alkenes, and the highly conjugated alkynyl system produced might show interesting electronic properties. ${ }^{196}$

\section{3. $\omega$-Functionalized monolayers on silicon surfaces}

To introduce a pivotal concept to the discussion of the following paragraphs, where an overview will be given of the available derivatization routes toward functional silicon layers, it should be noted that the silicon hydride phase has indeed a broad reactivity and, beside reactions with unsaturated hydrocarbons and halogens, the immobilization of nitriles, ${ }^{31}$ alcohols, ${ }^{44,81}$ aldehydes, ${ }^{168}$ and ketones ${ }^{198}$ have all been documented.

\subsection{Derivatization of methyl-terminated monolayers}

As discussed in the previous section, a rapidly expanding area in the literature is on the chemical and electrical passivation of hydride-terminated silicon surfaces with common $h k l$ orientations. This provides the surface chemist with an array of tools to access either carbon-silicon, ${ }^{31,87}$ nitrogen-silicon, ${ }^{156}$ or oxygen-silicon $^{81,139,168,199}$ bonded organic layers. ${ }^{27,29}$ A common feature of most of the early work in this area, and to some extent a limitation of most of the procedures reported in the literature, is a methyl termination at the distal end of the organic films. Chidsey and co-workers reported a brilliant chemical strategy to decorate octadecyl $\mathrm{Si}(111)$ monolayers with 4' -[3-trifluoromethyl-3 $H$-diazirin-3-yl]-benzoic acid $N$-hydroxysuccinimide ester (TBDA-OSu, a singlet carbene), that allowed for the subsequent immobilization of amine-tagged DNA molecules (Fig. 10). ${ }^{169}$ However, in general, covalent modification of a poorly reactive alkyl terminated surface suffers from low yields (ca. 10\%) and has seen very limited use. ${ }^{32}$ Similarly, in situ modification of a methyl-terminated layer with primary amines $\left(\mathrm{H}_{2} \mathrm{NR}^{\prime}\right)$, via a sulfonyl chloride intermediate $\left(\mathrm{Si}-\mathrm{RCH}_{2} \mathrm{SO}_{2} \mathrm{Cl}\right)$ to afford tethered sulfonamides $\left(\mathrm{Si}-\mathrm{RCH}_{2} \mathrm{SO}_{2} \mathrm{NHR}^{\prime}\right)$, was also among the first reports on the functionalization of covalent monolayers on non-oxidized silicon (111) surfaces. ${ }^{169,200}$ However, presumably as a result of the toxicity of chlorine and sulfur dioxide, this gas-phase procedure has not proven popular.

With regards to the further modification of chemically inert alkyl monolayers (i.e. methyl-terminated) two very recent reports by Zuilhof and co-workers have opened up novel chemical activation perspectives. In the first of the two papers the use of conducting atomic force microscopy (AFM) to oxidize hexadecyl monolayers, hereafter referred to as $\mathrm{C}_{16}$ film, on $\mathrm{Si}(111)$ substrates was reported. ${ }^{201}$ Oxidative conditions were tuned and, for a narrow range of bias and reaction times, terminal methyl groups (and possibly outer methylene units in the monolayer) can be oxidized with negligible oxidative damage of the underlying substrate. Although electro-oxidative patterning is a well-established tool in nanoscience and numerous examples for the activation of $n$-octadecyltrichlorosilane (OTS) layers on $\mathrm{SiO}_{x}$ are available, ${ }^{202,203}$ a significant difference has now emerged with regards to the bias threshold required to promote the monolayer oxidation. Compared to OTS systems, the bias required to initiate oxidation of methyl groups is significantly lowered in non-oxidized $\mathrm{Si}-\mathrm{C}$-bound SAMs. A plausible explanation for this effect is an increase in the effective electric field between the AFM tip and the substrate, experienced by the $\mathrm{C}_{16}$ layer, due to the absence of an insulating $\mathrm{SiO}_{x}$ layer. ${ }^{201}$ This finding is expected to allow for an improved chemical selectivity toward functionalities in the SAM of non-oxidized systems.

In the second of these two works, Zuilhof and co-workers showed that short plasma treatments could be used as a controlled and reproducible approach to the oxidation of $\mathrm{C}_{16}$ films on both $\mathrm{Si}(100)$ and $\mathrm{Si}(111)$ surfaces. ${ }^{204}$ Despite the chemical heterogeneity of the oxidized surface, described as containing a range of hydroxyl, carbonyl and carboxylic functionalities, spectroscopic data supported minimal disruption of the alkyl film. This is because experimental data suggest the oxidation process is limited to the top few $\AA$ of the 


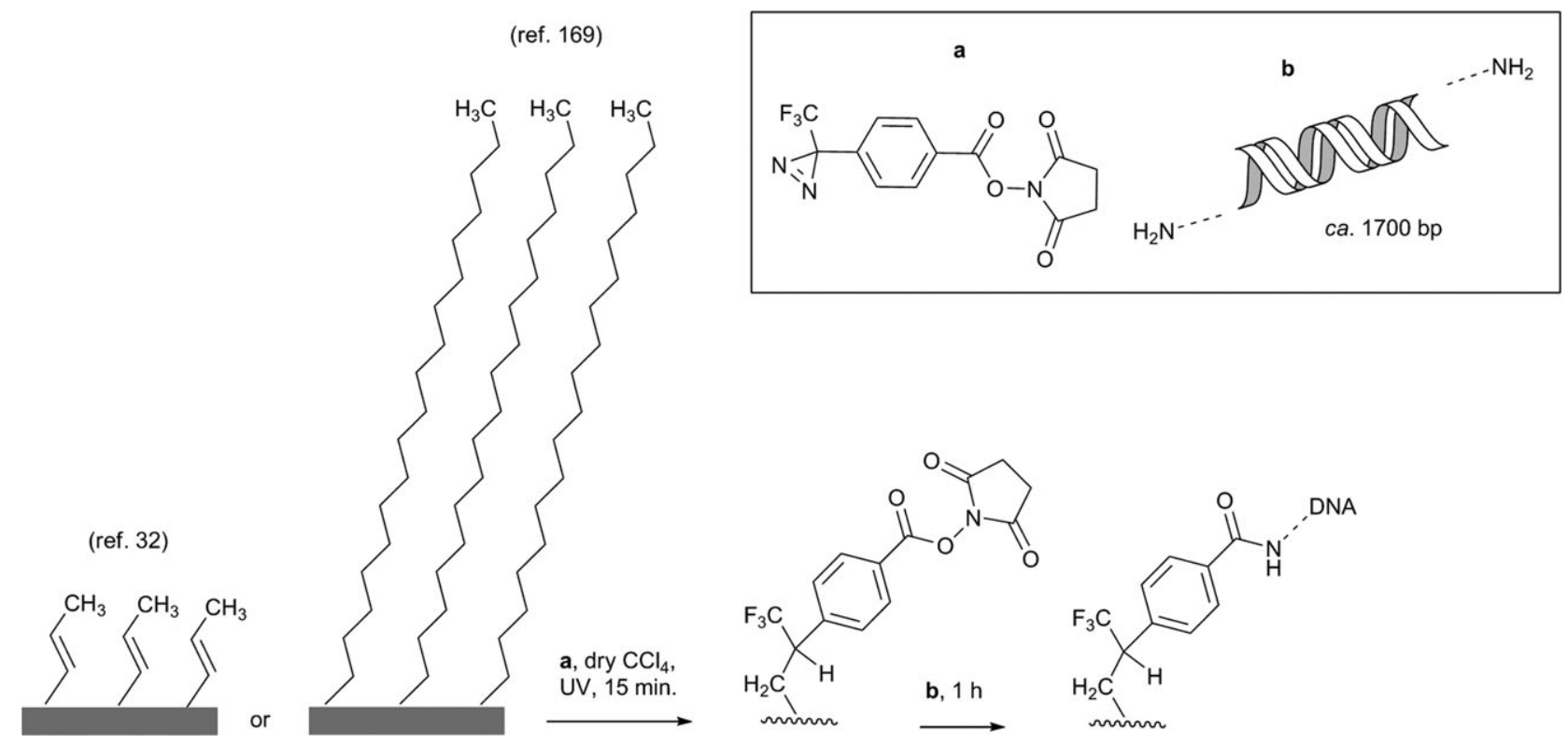

Fig. 10 Derivatization of methyl-terminated $\mathrm{Si}(111)$ layers with a photoactive aryldiaziridine cross-linker (a), TDBA-OSu (ref. 32 and 169). The activated octadecyl layer was further functionalized with dsDNA fragments amino-modified at both $5^{\prime}$ ends (b).

hydrocarbon layer. Notably, the plasma-induced oxidation of the $\mathrm{C}_{16}$ film was accompanied by minor to negligible substrate oxidation. Furthermore, (i) derivatization of the oxidized film by reaction of aldehyde functionalities with amine-derivatives ( $m$-trifluoromethylbenzylamine TFBA and cysteamine, a and $\mathrm{b}$ in Fig. 11, respectively), (ii) the subsequent grafting of $\mathrm{Au}$ nanoparticles onto the cysteamine-modified SAM, and (iii) an example of plasma treatment combined with PDMS masking to produce micrometer-sized oxidized patterns, have demonstrated the vast scope of this novel route to high-quality functional layers readily prepared from simple 1-alkenes.

\subsection{Formation and derivatization of amino-, hydroxyl- and thiol-terminated monolayers}

In order to fully benefit from the organic/semiconductor approach - in other words being able to expand the bulk properties of the substrate in a controlled fashion-more convenient protocols for the attachment of further functionality onto passivated silicon surfaces relies on the grafting of bifunctional molecules. The difficulties encountered with the insertion of a molecule of interest in carbon-hydrogen bonds prompted the investigation of chemical routes involving the grafting of $\omega$-functionalized 1-alkenes onto the $\mathrm{Si}-\mathrm{H}$ substrate. Restrictions are nevertheless dictated by functional group incompatibilities with surface hydrides. For example, competition between olefins and amine functionalities for the reactive surface termination ${ }^{156,205,206}$ makes it necessary to introduce protection/deprotection procedures to prevent side-reactions of the amine moiety with the surface.

As initially demonstrated by Smith and colleagues, ${ }^{49}$ and as shown in Fig. 12 and 13, attachment of thiol-modified DNA to the $\mathrm{Si}(100)$ surface could be achieved on tert-butoxycarbonyl-protected amine-terminated surfaces ( $t$-BOC protected 1-aminodec-1-ene) after SAM deprotection, and by using a suitable (water soluble) heterobifunctional cross-linker molecule (sulfosuccinimidyl 4-( $N$-maleimidomethyl) cyclohexane1-carboxylate, SSMCC). Further applications of aminodecane-modified silicon surfaces, ${ }^{53,207}$ alternative protection/ deprotection strategies ${ }^{86,208}$ and novel cross-linker molecules (i.e. $N$-succinimidyl 3-maleimidopropionate, $\mathrm{SMP}^{111}$ and diluted glutaraldehyde/sodium cyanoborohydride solutions ${ }^{207}$ ) have been also reported (Fig. 13). Similarly, formation of disordered monolayers for $\omega$-functionalized 1 -alkenes ${ }^{33}$ have been encountered in the preparation of oxygen- and thiolterminated $\mathrm{Si}(111)$ monolayers, and cross-reaction events were prevented only by using dimethoxytriphenylmethyl (Si-RODMT) ${ }^{209,210}$ tert-butyl dimethylsylyl (Si-ROTBDMS) ${ }^{120}$ and trifluoroacetyl $\left(\mathrm{Si}-\mathrm{RSC}(\mathrm{O}) \mathrm{CF}_{3}\right)^{66}$ protecting groups (Fig. 14) prior to attachment of DNA, ${ }^{209,210}$ amino acids (following activation with carbonyl diimidazole or disuccinimidyl carbonate), ${ }^{120}$ or prior to the assembly of semiconductor-alkylS-metal junctions and nanoelectrodes arrays. ${ }^{66,211}$

Note that standard solution phase deprotection procedures ${ }^{212}$ might be too harsh for organic-crystalline surface systems. As an example, conventional wet chemistry removal of the DMT group with aqueous ammonia resulted in a pitted $\mathrm{Si}(111)$ surface prompting the use of anhydrous methylamine. ${ }^{209}$ Further, removal of the TBDMS with diluted hydrochloric acid solutions caused minor oxidation of the silicon substrate ${ }^{120}$ and alkaline hydrolysis of trifluoroacetyl-protected amineterminated $\mathrm{Si}(100)$ surfaces caused significant corrosion of the substrate. ${ }^{49}$

\subsection{Formation and derivatization of carboxylic acid-based monolayers}

If compared to the approaches detailed in the previous paragraph, the preparation of monolayers with 1-alkenes bearing terminal ester groups appears to be less demanding; the reaction with the $\mathrm{H}$-terminated substrate is reported to occur preferentially at the $\mathrm{C}=\mathrm{C}$ end of the molecule 


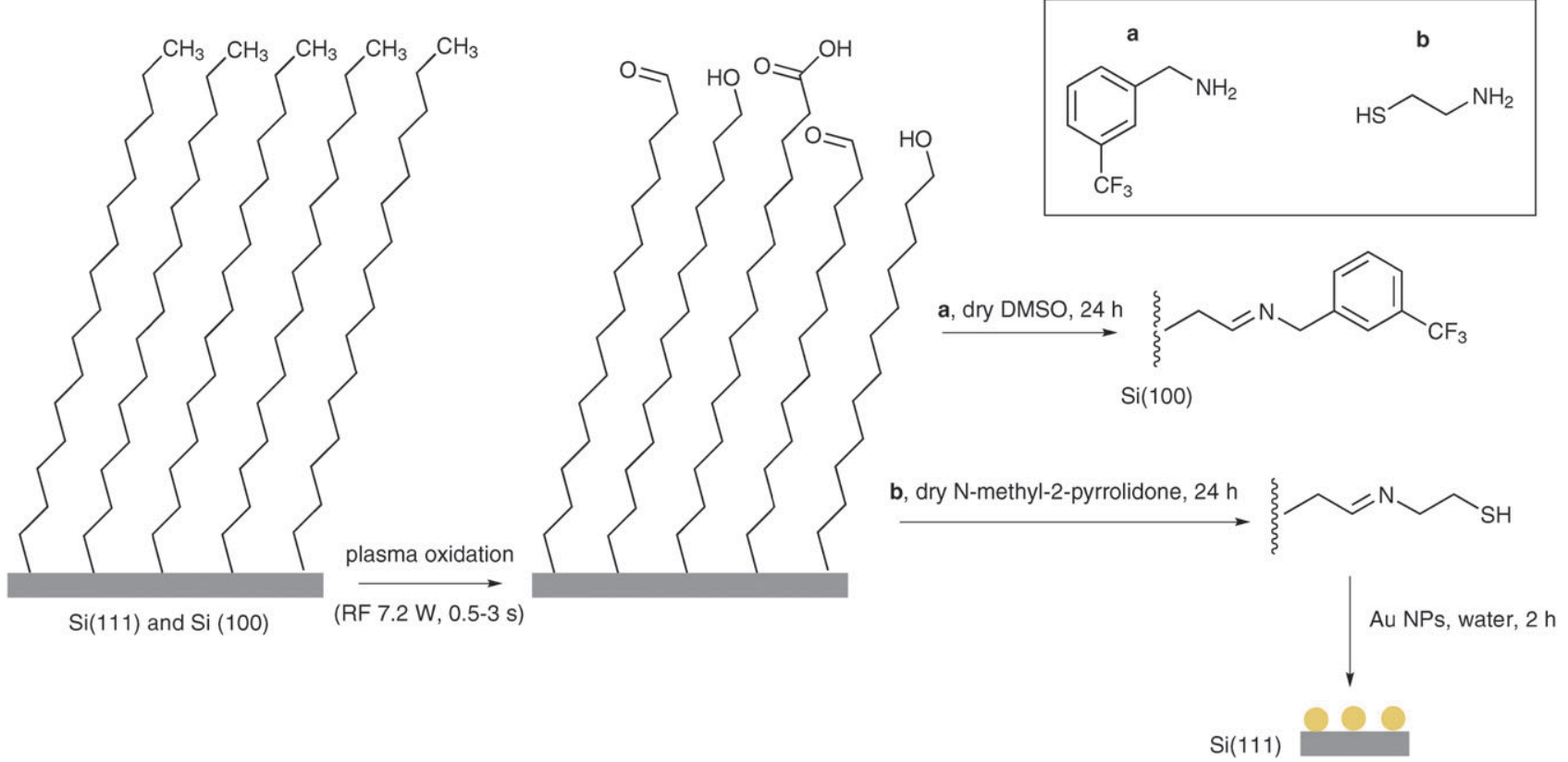

Fig. 11 Recent developments in the activation of chemically inert alkyl monolayers. Preparation of fluorine- and thiol-terminated surface-bound imines (ref. 204). Surface aldehydes formed upon the plasma-induced oxidation of alkyl chains were reacted with spectroscopic probes (a), TFBA and suitable thiol-terminated linker molecules (b), cysteamine for the subsequent attachment of Au nanoparticles.

ref. 49,53,111,207, 208 BOC-protected layer

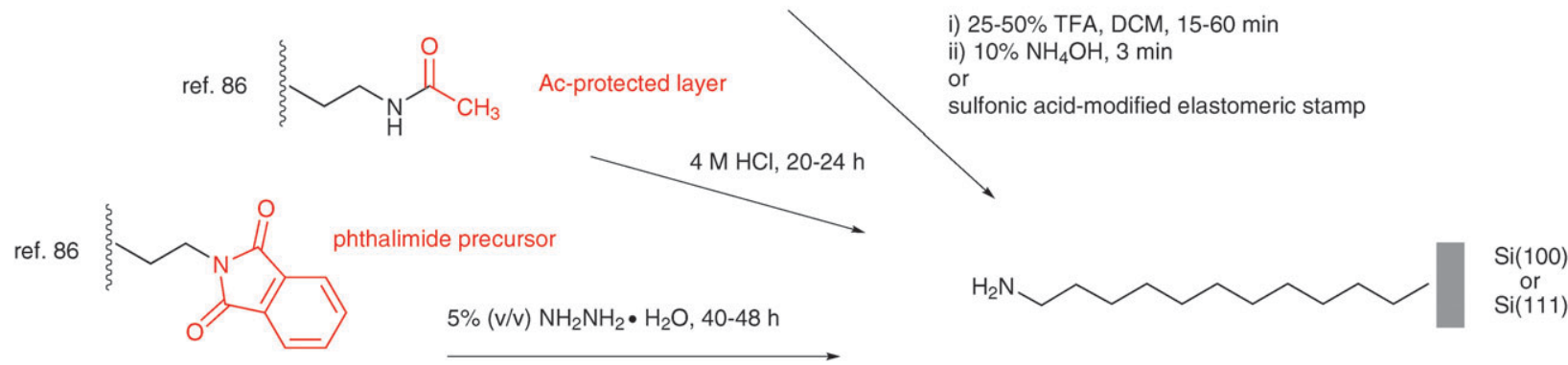

Fig. 12 Representative protection/deprotection schemes for the preparation of amino-terminated $\operatorname{Si}(100)$ and $\operatorname{Si}(111)$ layers. Note that the reaction of tethered phthalimide groups with hydrazine $\left(\mathrm{NH}_{2} \mathrm{NH}_{2}\right)$, to yield the amino-terminated layer, required long reaction times to reach completion ( $c a .2$ days). The BOC and acetamide (AcNH-) protecting groups were removed under strongly acidic conditions or by soft lithographic printing techniques (ref. 208).

(Fig. 15). ${ }^{33}$ Sieval et al. $^{33}$ conducted a systematic FTIR spectroscopy and XRR study on $\mathrm{Si}(100)$ monolayers prepared by thermal reaction of 1-alkenes bearing an ester moiety and reported high-quality films, with no appreciable SAM degradation, for methyl and propyl esters hydrolyzed in situ to the corresponding carboxylic acid surface (using concentrated hydrochloric acid/2-propanol). Milder reaction conditions for the chemical conversion of ethyl ester-terminated layers prepared on $\mathrm{Si}(111)$ were described by Boukherroub and Wayner, ${ }^{113}$ and are shown to be suitable for reaction with biological molecules. Largely based on FTIR spectral data, but also supported by XPS evidence, the authors reported (i) mild reduction conditions to the alcohol layer using $\mathrm{NaBH}_{4}$, (ii) reaction with alkyl Grignard reagent to alkylate tethered alkyl chains containing carbonyl groups and importantly, (iii) an example of biomolecule immobilization on the 'free' carboxylic acid surface using conventional solid phase amide coupling protocols (Fig. 15). ${ }^{113}$ Wayner and co-workers further expanded the repertoire of available wet-chemical modifications for ester-terminated surfaces by showing a two-step manipulation of a passivated $\mathrm{Si}(111)$ electrode surface. ${ }^{167}$ Conversion of the ester surface to a thiophene-terminated layer $\left(\mathrm{Si}-\mathrm{RCCOC} \mathrm{H}_{5}\right.$ to $\left.\mathrm{Si}-\mathrm{RC}(2 \text {-thienyl })_{2} \mathrm{OH}\right)$ was followed by the photoelectrochemical oxidation of the confined thiophene moieties in a thiophene solution. Generated polythiophene films showed superior morphological and electrical properties, and are therefore reasoned to be covalently attached to the underlying functionalized layer. ${ }^{167,213}$

Less conclusive, presumably as a result of diverse hydrosilylation conditions employed, are the results for layers 

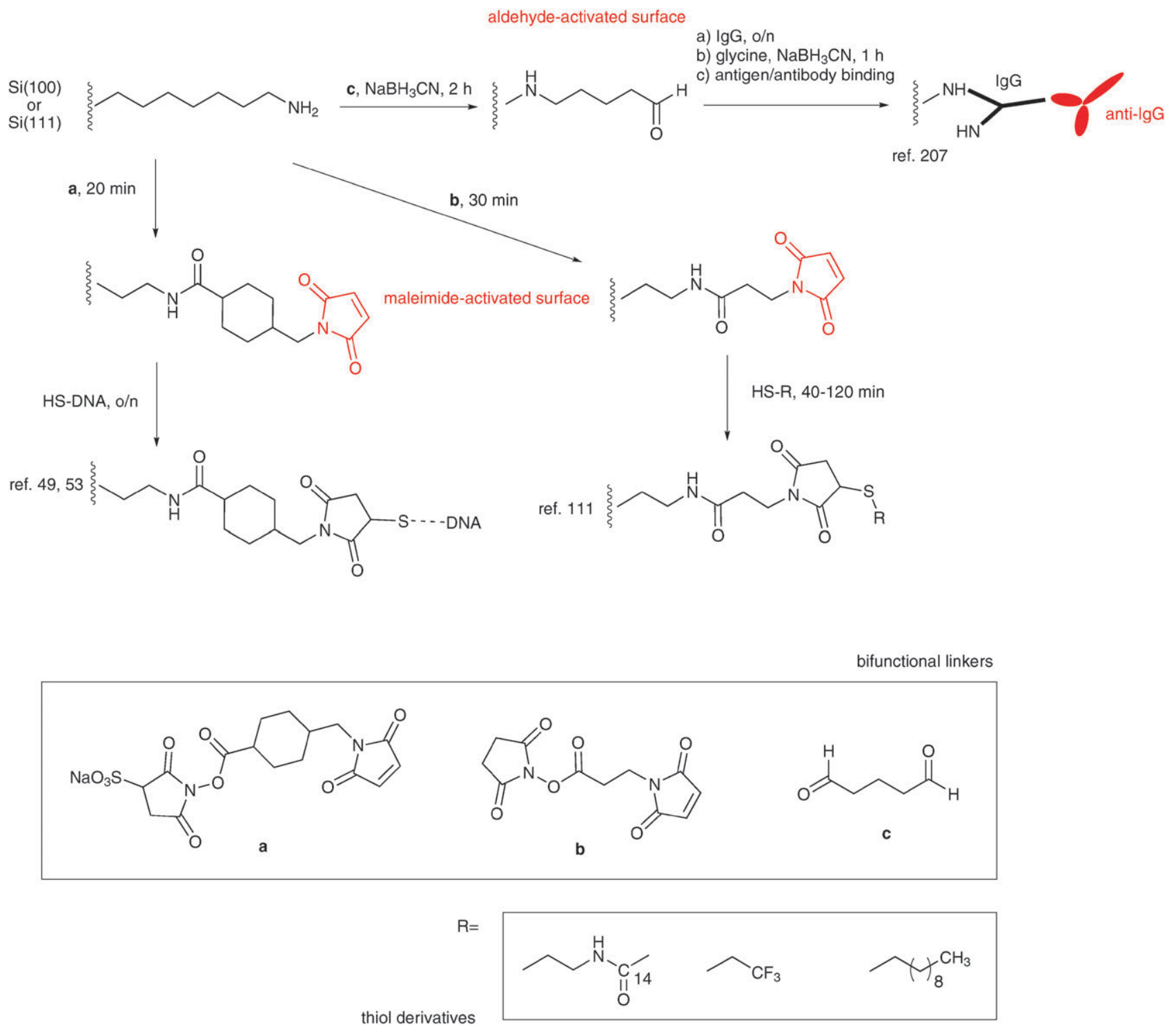

Fig. 13 Representative synthetic schemes for the modification of amino-terminated $\mathrm{Si}(100)$ and $\mathrm{Si}(111)$ layers. $\mathrm{Si}(100)$ arrays for DNA hybridization assays were prepared by reacting thiol-modified single-strand DNA oligomers with the thiol-reactive maleimide moiety in the SSMCC (a) linker. Immobilization of thiol-containing molecules ( $\mathrm{R}-\mathrm{SH}$, with $\mathrm{R}$ detailed in the inset) was also investigated on SMP (b) functionalized $\mathrm{Si}(111)$ surfaces (ref. 111). Glutaraldehyde (c, 3\%) in solutions of sodium cyanoborohydride was used to prepare biosensors for the detection of human IgG via electrochemical impedance spectroscopy.

prepared from 10-undecylenic acid. On the basis of FTIR data, where broadened antisymmetric and symmetry methylene stretching vibrations and shifts to higher frequencies were observed, Sieval and co-workers suggested the formation of disordered assemblies for the thermal reaction of the organic acid $\left(200{ }^{\circ} \mathrm{C}, 2 \mathrm{~h}\right){ }^{33}$ Opposite conclusions based on an XPS and FTIR analysis were drawn by Voicu et al. for films prepared on $\mathrm{Si}(111)-\mathrm{H}$ through light-promoted $(300 \mathrm{~nm}$, $3 \mathrm{~h}$ ) reactions with 10 -undecylenic acid. ${ }^{51}$ Voicu and co-workers prepared high quality acid-terminated films that were further reacted with DNA molecules, affording a convenient and simplified protocol for the immobilization of a bifunctional molecule (i.e. 10-undecylenic acid) with no deprotection steps being necessary. Minor, but detectable reactivity toward the acid function of undecylenic acid was reported in porous silicon (PSi). ${ }^{214}$ Nevertheless, under the same reaction conditions used to graft the acid-terminated olefin $\left(95^{\circ} \mathrm{C}, 16 \mathrm{~h}\right)$ only minor attenuations for the $\mathrm{Si}-\mathrm{H}_{x}$ stretchings (transmission mode FTIR spectroscopy) were found in control experiments with decanoic acid $\left(\mathrm{CH}_{3}\left(\mathrm{CH}_{2}\right)_{8} \mathrm{COOH}\right)$; this further supported a preferential reaction of silicon-hydrogen bonds at the $\mathrm{C}=\mathrm{C}$ terminus. ${ }^{214}$ The result was unexpected as freshly etched PSi surfaces display a Lewis acid character $(\mathrm{Si}-\mathrm{H})$, and hence reaction with Lewis bases might be expected to be favoured, and alcohols, ${ }^{81,139,140,215}$ ketones $^{198}$ and aldehydes ${ }^{123,168,216}$ have all been reported to react with the hydride-terminated silicon surface.

As presented in Fig. 16, Bowden et al. ${ }^{108}$ assembled undecylenic acid and octadecyl ${ }^{217}$ layers on $\mathrm{Si}(111)-\mathrm{H}$ at room temperature (24 h), without UV irradiation, in the presence of 

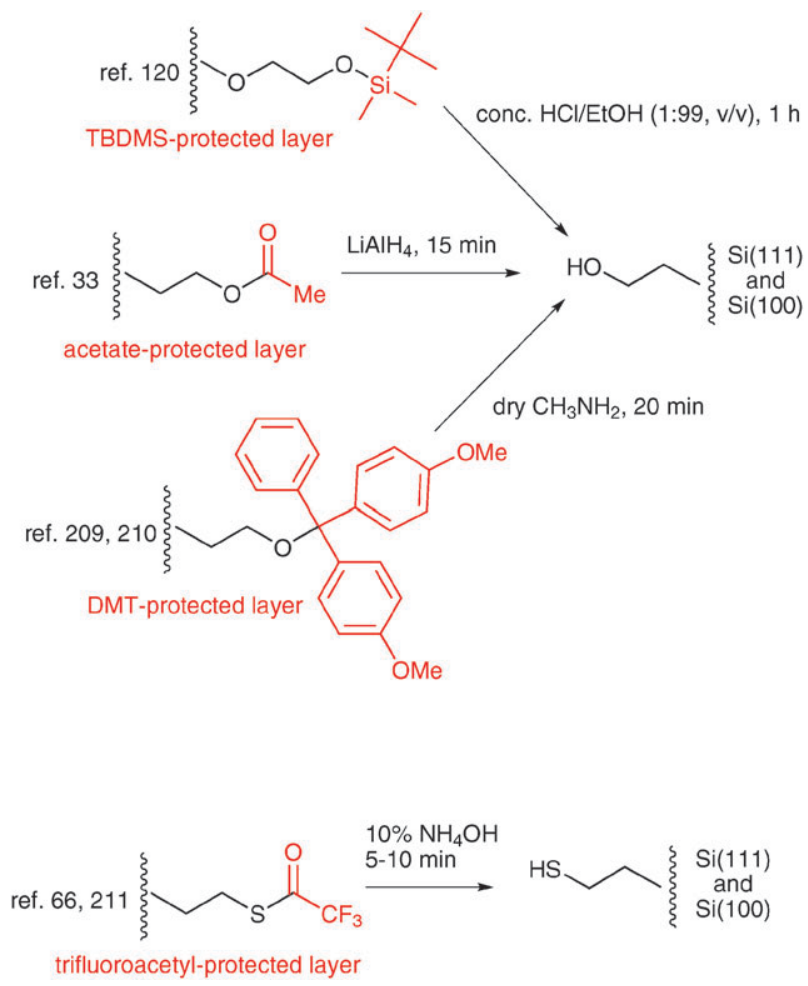

Fig. 14 Available protection/deprotection schemes for preparation of hydroxyl- and thiol-terminated $\mathrm{Si}(111)$ and $\mathrm{Si}(100)$ layers.

a derivative of TEMPO (4-(decanoate)-2,2,6,6-tetramethyl-1piperidinyloxy, TEMPO- $\left.\mathrm{C}_{10}\right) .{ }^{217}$ XPS and FTIR spectral data supported the formation of well-ordered and stable structures, preferentially bonded to the silicon substrate through the olefin end of the SAM-forming molecule. Further, the authors performed an elegant control experiment with a mixed 1-octadecene/fluorine-tagged acid molecule system<smiles>CC(C)C(=O)OC1CC(C)(C)N([O])C(C)(C)C1</smiles>

TEMPO derivative

$\mathrm{R}=\mathrm{C}_{16} \mathrm{H}_{33}$ or $\mathrm{C}_{8} \mathrm{H}_{16} \mathrm{CO}_{2} \mathrm{H}$
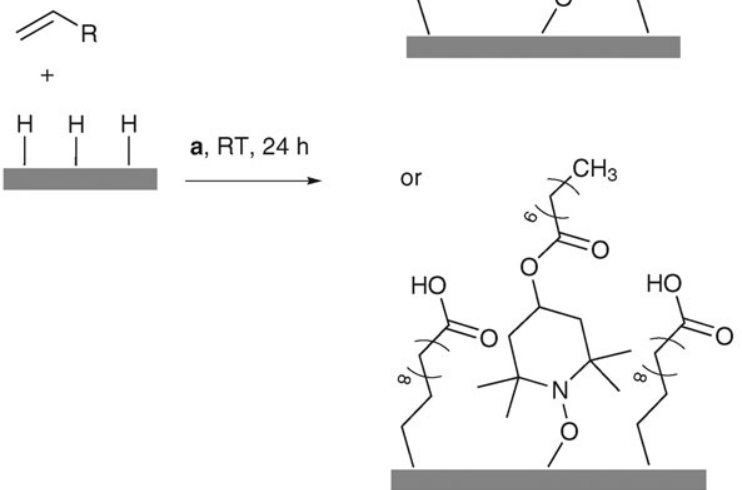

Fig. 16 Mild conditions for the assembly of methyl- and carboxylic acid-terminated layers on $\mathrm{Si}(111)$. In the presence of a TEMPO derivative (e.g. TEMPO- $\left.\mathrm{C}_{10}, \mathrm{a}\right)$, the hydrosilylation of 1-alkenes proceeded at room temperature. The presence of tethered TEMPO derivatives in the reaction product has been documented (ref. 108 and 217).

$\left(\mathrm{CH}_{3}\left(\mathrm{CH}_{2}\right)_{15} \mathrm{CH}=\mathrm{CH}_{2} / \mathrm{CF}_{3} \mathrm{CF}_{2} \mathrm{CF}_{2} \mathrm{C}(\mathrm{O}) \mathrm{O}\left(\mathrm{CH}_{2}\right)_{3} \mathrm{COOH}\right)$ to study whether the acid and olefin moieties would bind to the $\mathrm{Si}(111)-\mathrm{H}$ at competitive rates. The absence of a detectable fluorine-derived XPS emission demonstrated that olefins selectively bind to a $\mathrm{Si}(111)-\mathrm{H}$ surface even when 1-alkenes

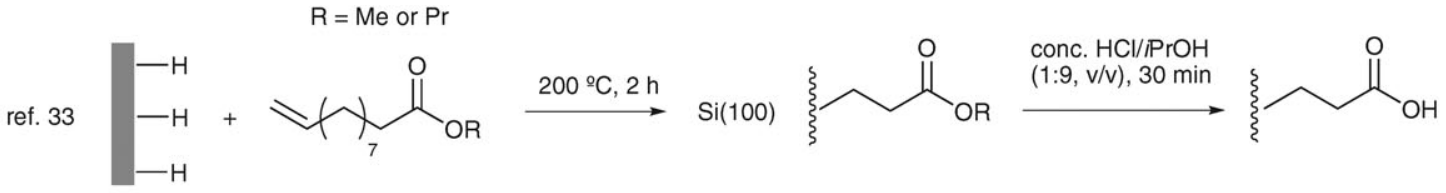

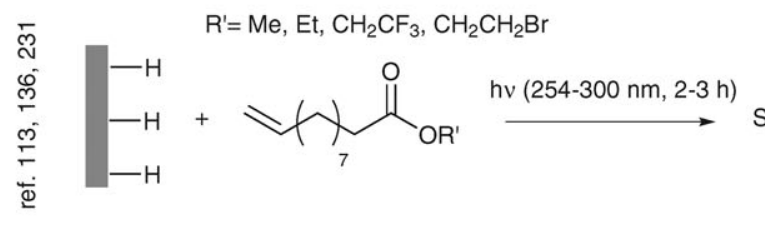

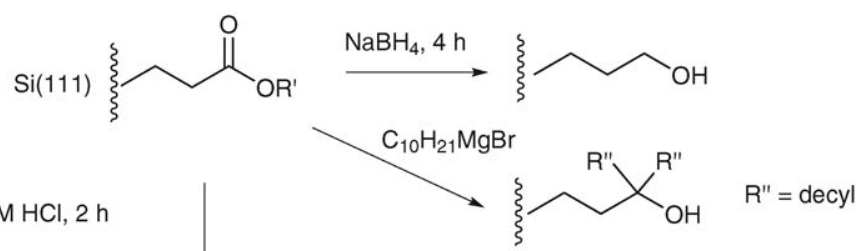
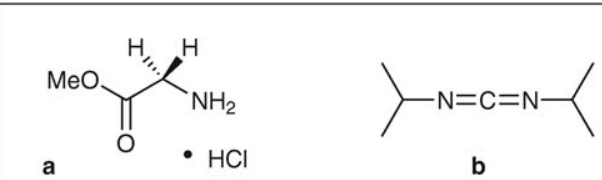
$0.25 \mathrm{M} \mathrm{t}-\mathrm{BuOK}, 3 \mathrm{~min}$

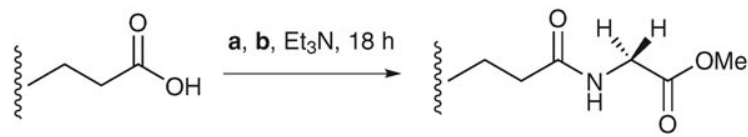

Fig. 15 Preparation and reactivity of 10-undecenoyl ester-derived monolayers on Si(100) and Si(111) substrates. An early example of biologicallyrelevant molecule immobilization is shown (ref. 113). Upon hydrolysis of the tethered ester molecule, the carboxylic acid terminated surface was coupled to glycine methyl ester (a) using a carbodiimide reagent, 1,3-diisopropylcarbodiimide, (b). 
are present in solution, and helped in elucidating the mode of binding of undecylenic acid. ${ }^{108}$

The knowledge of a negligible reactivity for carboxylic acid functionalities with surface hydrides has allowed for the preparation of more complex monolayers. Toward this end, Chazalviel and co-workers have demonstrated that well-defined mixed carboxyl-terminated alkyl monolayers $\left(\mathrm{Si}-\left(\mathrm{CH}_{2}\right)_{9} \mathrm{CH}_{3} / \mathrm{Si}-\left(\mathrm{CH}_{2}\right)_{10} \mathrm{COOH}\right)$ can be prepared on $\mathrm{Si}(111)$ via photochemical reactions $(312 \mathrm{~nm}) .{ }^{218}$ The authors, on the basis of IR spectroscopy and AFM data, argue in favour of no reaction between the acid functionalities and the silicon substrate, and stress on the need of a final rinse with hot acetic acid to remove adventitious contaminants. ${ }^{218}$ In the same report, they also propose a quantitative model, heavily reliant on a liquid-phase calibration procedure of the IR absorption intensity, to estimate the composition of the mixed monolayer, and reached the conclusion of SAMs richer in acid chains than the grafting solution. ${ }^{106,218}$

Cathodic electrografting of $\omega$-functionalized 1-alkynes has also been reported (Fig. 17). ${ }^{127}$ This showed an improved surface coverage for 10-undecynoic acid $\left(\mathrm{HC} \equiv \mathrm{C}\left(\mathrm{CH}_{2}\right)_{8} \mathrm{COOH}\right)$ and 6-heptynoic acid methyl ester $\left(\mathrm{HC} \equiv \mathrm{C}\left(\mathrm{CH}_{2}\right)_{4} \mathrm{COOCH}_{3}\right)$ layers in $\mathrm{Si}(111)$ and $\mathrm{Si}(100)$ systems when compared to thermal and photochemical $\left(\mathrm{HC} \equiv\left(\mathrm{CH}_{2}\right)_{4} \mathrm{COOCH}_{3}\right.$ only) processes. ${ }^{127}$ Both serving to introduce a convenient IR spectroscopic marker, and allowing for the subsequent attachment of amine-tagged molecules, an esterification protocol to activate an acid moiety ( $\mathrm{Si}-\mathrm{RCOOH})$ with $\mathrm{N}$-hydroxysuccinimide ( $\mathrm{Si}-\mathrm{RC}(\mathrm{O}) \mathrm{NHS}$ ), relying on the use of conventional carbodiimide reagents (generally $N$-ethyl$N^{\prime}$-(3-(dimethylamino)propyl)carbodiimide (EDC)), was initially discussed for silicon substrates in a report by Boukherroub et al. $^{214}$ This method now represents a widely used platform toward diverse functional silicon surfaces ${ }^{51,52,57,59,106,116,219-221}$ (Fig. 17, route A). A detailed quantitative IR spectroscopic study on the amidation reaction at monocrystalline $\mathrm{Si}(111)$ surfaces has been recently reported by Chazalviel and co-workers. ${ }^{106}$ The method presents some limitations with regards to sterically hindered molecules (e.g. single-strand DNA oligomers tethered to a primary amine linker) and provided that small capping agents, such as ethanolamine, are employed to deactivate unreacted sites, ${ }^{50,51}$ NHSactivated films are open to the immobilization of primary amines (-CO-NH-R), as well as substituted hydrazine $(-\mathrm{CO}-\mathrm{NH}-\mathrm{NH}-\mathrm{R}){ }^{221}$ This two-step procedure (activation followed by nucleophilic displacement) does not require harsh hydrolysis steps as in the case of tethered acid esters. ${ }^{33,222}$ It was implemented by Wojtyk et al. ${ }^{223}$ and by Yin et al. ${ }^{52}$ through the direct thermal and photochemical (UV-mediated) attachment of $N$-succinimidyl undecenoate ( $\omega$-NHS-functionalized 1-alkene) onto porous silicon and $\mathrm{Si}(100)-\mathrm{H}$ surfaces, respectively. Furthermore, irradiation with visible light $(447 \mathrm{~nm})$ at room temperature of n-type $\mathrm{Si}(111)-\mathrm{H}$ substrates has been recently reported to afford good quality NHS-terminated layers in a one-pot procedure. ${ }^{224}$ On the contrary, under thermal hydrosilylation conditions, there are spectroscopic indications of partial degradation of this NHS-functionalized $\mathrm{Si}(111)$ assembly if prepared through the direct procedure. ${ }^{224}$ However, this one-pot approach toward the assembly of succinimidiyl ester-terminated surfaces requires significant synthetic effort as the relevant $\omega$-functionalized 1-alkene molecule is not commercially available and has to be customsynthesized. ${ }^{58,59,225} \mathrm{We}$ reason this as the major cause behind the limited number of literature examples on this directive approach, while on the other hand the step-wise NHS/EDC activation scheme ( $\mathrm{Si}-\mathrm{RCOOH}$ to $\mathrm{Si}-\mathrm{RC}(\mathrm{O}) \mathrm{NHS}$ ) remain widespread in surface science. ${ }^{50,51,226,227}$

It is also worth noting that an optimization study to evaluate the optimal range of NHS and EDC concentrations and molar ratios has only very recently been published for porous silicon substrates by Sam et. al. ${ }^{228}$ The authors have systematically varied the concentrations of the two reagents and semiquantitatively evaluated via transmission FTIR spectroscopy the presence and relative abundance of by-products (e.g. $N$-acylurea) and unreacted $O$-acylurea and anhydride species among the desired reaction product (i.e. pSi-RC(O)NHS). Very high yields for the activation reaction were found for a restricted range of NHS and EDC concentrations and molar ratios $(5 \mathrm{mM}<[\mathrm{EDC}] \sim[\mathrm{NHS}])$. This was explained in terms of kinetic competition between different reaction pathways. A similar report detailing reaction pathways and kinetic information for the activation reaction at flat silicon surfaces has yet to be published and is much needed. At present, experimental conditions for the preparation of succinimidyl esters of 10-undecylenic acid SAMs grafted onto crystalline silicon appear to be far from standardized, with a broad range of published reagent concentrations and molar ratios, ${ }^{50,51}$ as well as differences in reaction temperatures and $\mathrm{pH}$ values for the solutions. ${ }^{106,116,228}$

Few alternative protocols to carbodiimide based strategies have been reported for the manipulation of carboxylic acidterminated silicon surfaces. A notable exception is the procedure for the functionalization and patterning of acid layers on $\mathrm{Si}(111)$ surfaces reported by Perring et al. ${ }^{108}$ This group used trifluoroacetic anhydride and triethylamine to yield a nucleophile-reactive anhydride-terminated layer (Fig. 17, route $\mathbf{B})$. The activated surface was then used in a multistep procedure, where immobilized allylamine moieties ( $\mathrm{Si}-\mathrm{RC}(\mathrm{O}) \mathrm{NHCH}_{2} \mathrm{CH}=\mathrm{CH}_{2}$ ) were further reacted, in the presence of Grubbs' first generation catalyst, with norbornene molecules in a ring-opening polymerization procedure. ${ }^{108}$

In the search for coupling alternatives to the amide chemistry-based approaches described above, procedures such as those involving $\mathrm{Si}(111)$ layers terminated with semicarbazide groups $\left(\mathrm{Si}-\mathrm{RNHC}(\mathrm{O}) \mathrm{NHNH}_{2}\right)$ to attach peptides bearing a glyoxylyl group $\left(\mathrm{Si}-\mathrm{RNHC}(\mathrm{O}) \mathrm{NHN}=\mathrm{CHC}(\mathrm{O}) \mathrm{R}^{\prime}\right){ }^{229}$ epoxide-functionalized $\mathrm{Si}(111)$ films to confine thiolated oligonucleothides, ${ }^{112}$ as well as aryl molecules covalently grafted onto $\mathrm{Si}(111)-\mathrm{H}$ and functionalized with fullerene molecules, ${ }^{230}$ have been the subject of recent research. However, these are still only selected examples from a rapidly expanding area.

Despite not being of major concern in most of the biosensing applications so far published, ${ }^{50-53,210,231}$ the outcome of a multi-step strategy, such as any of those discussed above, is potentially affected by one, or more, of the following shortcomings: (a) cross-reactivity of $\omega$-functionalized 1-alkene (or 1-alkyne) molecules with the hydride-terminated silicon 

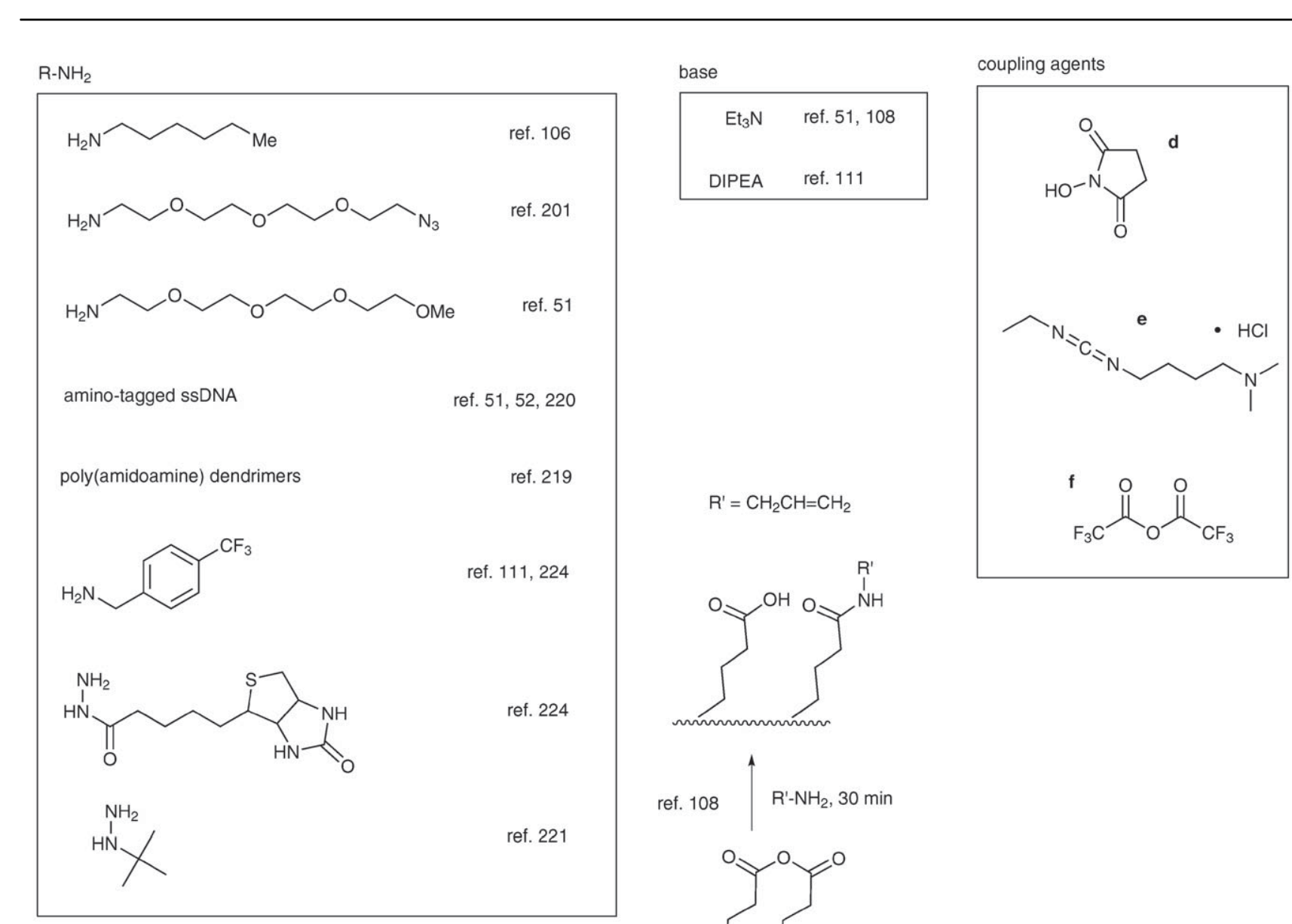

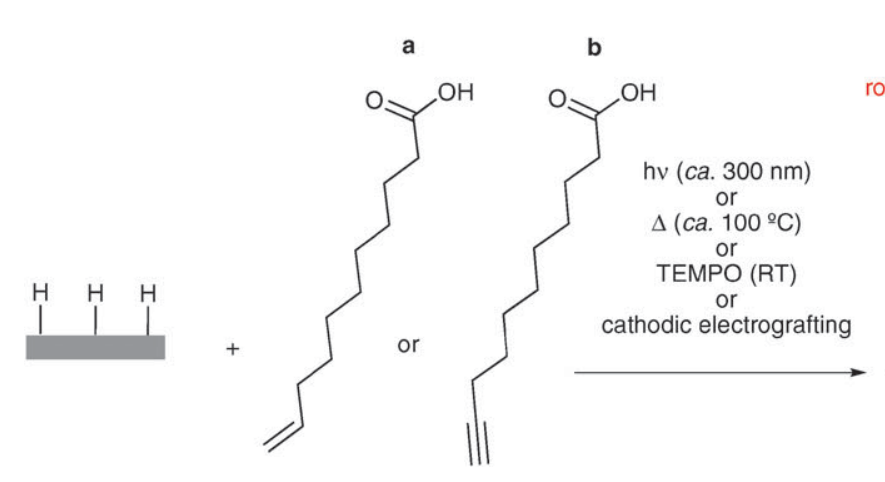

ref. $51,106,108,217$
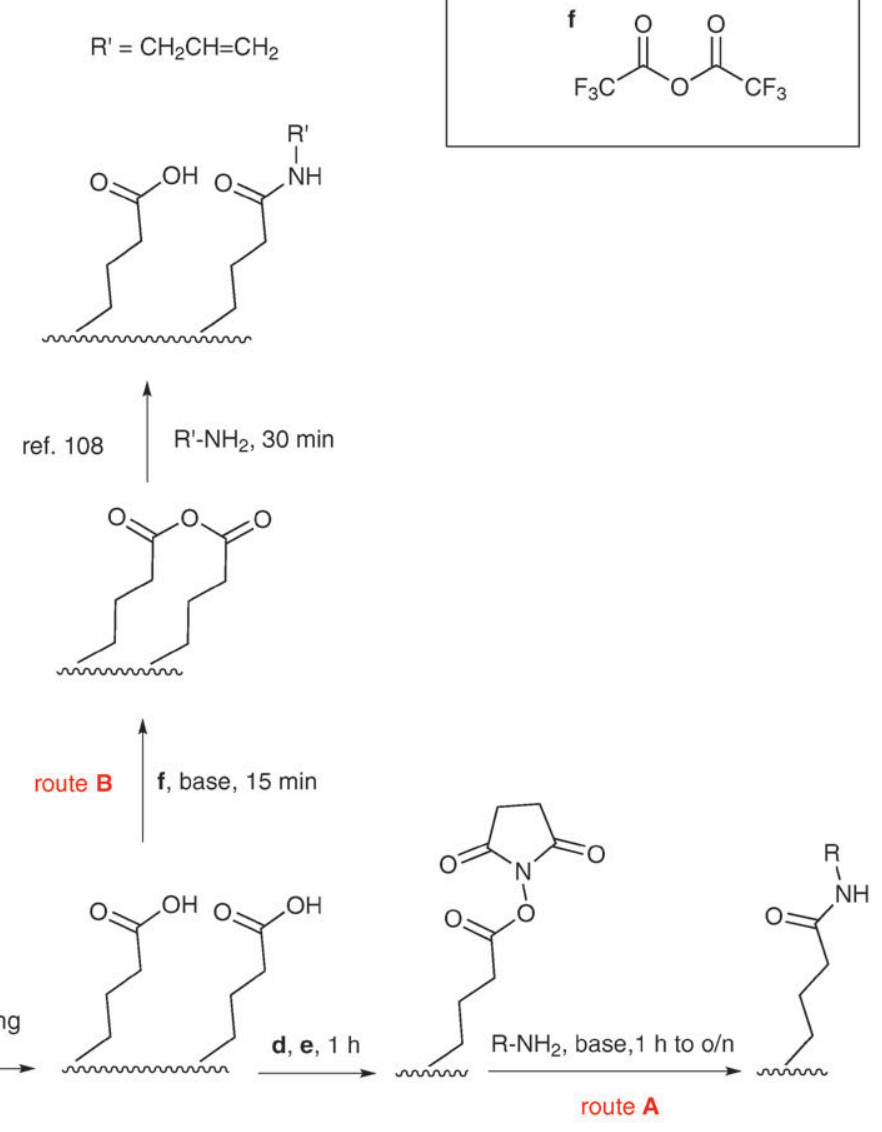

$$
\text { hv (UV or } 447 \mathrm{~nm})
$$

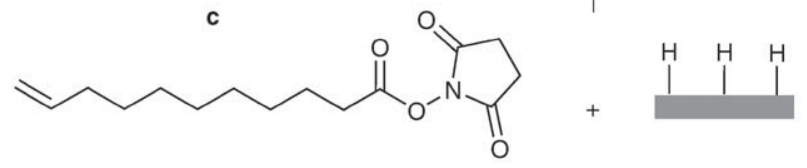

ref. $52,111,201,224$

Fig. 17 Preparation and reactivity of $N$-hydroxysuccinimide(NHS)-ester-terminated $\mathrm{Si}(100)$ and $\mathrm{Si}(111)$ monolayers. Several protocols for the attachment of 10-undecylenic acid (a) and 10-undecynoic acid (b) onto hydride-terminated silicon surface are now available. Two schemes (routes $\mathbf{A}$ and $\mathbf{B})$ for the reaction of the acid surface with primary amines $\left(\mathrm{R}-\mathrm{NH}_{2}\right.$ and $\left.\mathrm{R}^{\prime}-\mathrm{NH}_{2}\right)$ are shown. Route A. Chemical modification of the carboxylic acid function with $N$-hydroxysuccinimide (NHS, d) in the presence of the coupling agent $N$-ethyl- $N^{\prime}$-(3-(dimethylamino)propyl)carbodiimide hydrochloride $(\mathrm{EDC}, \mathrm{e})$ prior to the reaction with the amine nucleophile $\left(\mathrm{R}-\mathrm{NH}_{2}\right)$. An alternative, direct, approach to the succinimide surface proceeds via the hydrosilylation of $\omega$-NHS-functionalized 1-alkenes (c). Route B. Activation of the acid surface with trifluoroaceticanhydride (f) to yield an amine-reactive anhydride surface. 
surface leading to ambiguous reaction products (e.g. silylester formation $\left.{ }^{33,214}\right)$; (b) use of poorly controlled activation procedures (e.g. capping agents required ${ }^{51}$ ); (c) harsh deprotection reactions required, ${ }^{33,49}$ (d) non-quantitative coupling yields; $;^{51,127}$ (e) surface segregation ${ }^{232}$ of acid and alkyl chain in mixed decyl/10-carboxydecyl mixed layers; ${ }^{233}$ and (f) long term oxidation of the silicon substrate starting from defects sites in the monolayer. ${ }^{107,117}$ To address some or all of the above concerns is a precondition if both the structural ${ }^{78,89,119}$ and electronic ${ }^{95}$ properties of the unoxidized crystalline silicon surface are to be retained upon the formation of an organicpassivated interface, that does not possess significant defect sites, ${ }^{66,114,117,124,234,235}$ but rather increases the chemical stability of the interface. ${ }^{32,115,147,152}$

\subsection{Reactivity of olefin- and acetylene-terminated monolayers}

It is intuitive that issues on functional group incompatibilities with hydride terminations, as mentioned above, could be easily addressed by employing a symmetrical $\alpha, \omega$-bifunctional molecule in the hydrosilylation step. Further, selective and highly efficient coupling procedures, involving neither activation nor protection/deprotection steps, might be amenable to prepare high quality modified surfaces with reduced chemical ambiguity in the surface product.

A significant step forward in this direction was the report in 2006 by Dutta et al., ${ }^{236}$ describing the grafting of a diene species $\left(\mathrm{CH}_{2}=\mathrm{CH}\left(\mathrm{CH}_{2}\right)_{9} \mathrm{O}\left(\mathrm{CH}_{2}\right)_{9} \mathrm{CH}=\mathrm{CH}_{2}\right.$, a, Fig. 18) onto $\mathrm{Si}(111)-\mathrm{H}$ at room temperature, in the presence of trace amounts of TEMPO-C $10 .{ }^{108,217}$ The hydrosilylation product is an alkene-terminated layer, showing no signs of oxidation (XPS), and exposing a distal alkene moiety used in a subsequent cross-metathesis reaction. In diluted layers (1-octadecene $\mathbf{b}$ to a, 1/1 mole ratio), the tethered alkenes are exposed above surrounding methyl groups and thus accessible to the Grubbs' catalyst (c, Fig. 18). The subsequent reaction to confine substituted 1-alkene molecules (and release ethylene) was claimed to have reached $c a$. $50 \%$ conversion. However, the authors suggested possible side reactions between adjacent surface-bound olefins $^{236}$ (Fig. 18). The alkene-terminated structure was demonstrated to be compatible with soft lithography patterning, ${ }^{236}$ and analogously functionalized surfaces $\left(\mathrm{Si}-\mathrm{RCH}=\mathrm{CH}_{2}\right)$ have seen further applications on scribed silicon surfaces to localize copper deposition, ${ }^{237}$ on $\mathrm{Si}(111)$ surfaces for the electrochemical deposition of platinum nanoparticles, ${ }^{238}$ and on $\mathrm{Si}(100)$ surfaces for the assembly of multilayer films using thiol-ene chemistry. ${ }^{239}$

Two general aspects of the surface cross-metathesis approach are worth a discussion and might be addressed in an improved derivatization protocol. First, despite the authors ${ }^{236}$ indicating the need for a mild method to assemble functional layers on silicon, the reported metathesis transformation required long reaction times ( 2 days), heat to be supplied (dichloromethane at reflux) and was carried out under a nitrogen atmosphere. Second, and perhaps not relevant in the case of commercially available alkenes, but surely of concern for less readily available molecules (e.g. requiring design and synthetic efforts), is the consumption of solution phase 1-alkenes to yield homodimers as byproducts of the metathesis reaction. As discussed in a previous section of this review, one of the apparent limitations of the halogenation/ alkylation route, i.e. the presence of poorly reactive methyl terminations in the monolayer, was elegantly circumvented by Lewis and co-workers in a recent report on the preparation of acetylene and methylacetylene terminated $\mathrm{Si}(111)$ surfaces $\left(\mathrm{Si}-\mathrm{C} \equiv \mathrm{CH}\right.$ and $\left.\mathrm{Si}-\mathrm{C} \equiv \mathrm{C}-\mathrm{CH}_{3}\right) .{ }^{155}$ The surface protocol described still required the use of a nitrogen purged glove box and anhydrous conditions, but via reaction of $\mathrm{Si}(111)-\mathrm{Cl}$ surfaces with solutions of sodium acetylides the authors have convincing evidence (from XPS, IR spectroscopy and chargecarrier recombination measurements) to argue for a complete passivation of silicon hydride sites followed by reaction of surface acetylenes. The reaction of 1-bromo-4-trifluoromethylbenzene in the presence of $n$-butyllithium was used to confine $p$-trifluoromethylbenzene groups $\left(\mathrm{Si}-\mathrm{C} \equiv \mathrm{C}-\mathrm{C}_{6} \mathrm{H}_{5} \mathrm{CF}_{3}\right)$ and was estimated to have proceeded in a satisfactory, $c a$. $35 \%$, yield.

Prompted by the work of Lewis and co-workers, ${ }^{155}$ Heath and co-workers ${ }^{110}$ reported the first copper-catalyzed Huisgen 1,3-dipolar cycloaddition of azides and terminal alkynes $(\mathrm{CuAAC})^{240-242}$ applied to passivated silicon surfaces. CuAAC are the archetypal example of 'click' reactions, ${ }^{243}$ and have found numerous recent application in the field of surface chemistry. ${ }^{244,245} \mathrm{CuAAC}$ reactions benefit from high selectivity, modularity, the absence of both activation and protection/deprotection steps, and are tolerant to a wide range of solvents and functional groups. ${ }^{246,247}$ The authors ${ }^{110}$ assembled a system where a fully acetylenylated $\mathrm{Si}(111)$ surface $(\mathrm{Si}-\mathrm{C} \equiv \mathrm{CH})$ was coupled, albeit in $c a$. $7 \%$ yield, to a solution coumarin azide derivative. The observed poor outcome of the 'click' step was reasoned to be a direct consequence of the significant steric hindrance introduced upon conversion of densely packed surface alkynes to the corresponding immobilized triazole species. However, the study of Heath and co-workers was motivated towards a full surface passivation, with every surface silicon atom site grafted to an sp-hybridized carbon atom, ${ }^{102,124}$ as distinct from an average of every second silicon surface atom as achieved on a $\mathrm{Si}(111)$ surface using hydrosilylation (see Section 2.2.2). ${ }^{31,111}$ Hence no attempt was made to achieve better surface coverage in the 'click' step.

Gooding and co-workers have recently reported the use of an $\alpha, \omega$-diacetylene molecule to passivate the $\mathrm{Si}(100)-\mathrm{H}$ surface forming an acetylene-decorated interface that allows for the immobilization of solution phase azides in satisfactory yields $(>40 \%) .{ }^{128}$ The surface modification approach investigated is outlined in Fig. 19 and benefits from the use of an highly selective and efficient conjugation method, i.e. CuAAC reactions. 1,8-Nonadiyne a was chosen as a convenient candidate for the evaluation of the outcome of this synthetic strategy because it exhibits a number of key properties. Being commercially available, no synthetic effort was required. Further, its symmetrical nature allowed the intended alkyne-terminated monolayer to be prepared in a single-step hydrosilylation procedure (as opposed to two step halogenation/alkylation routes). Further derivatization of this organic structure using $\mathrm{CuAAC}$ reactions proceeded to afford hydrolytically resistant 1,4-disubstituted surface triazole species through a coupling 
$R=$

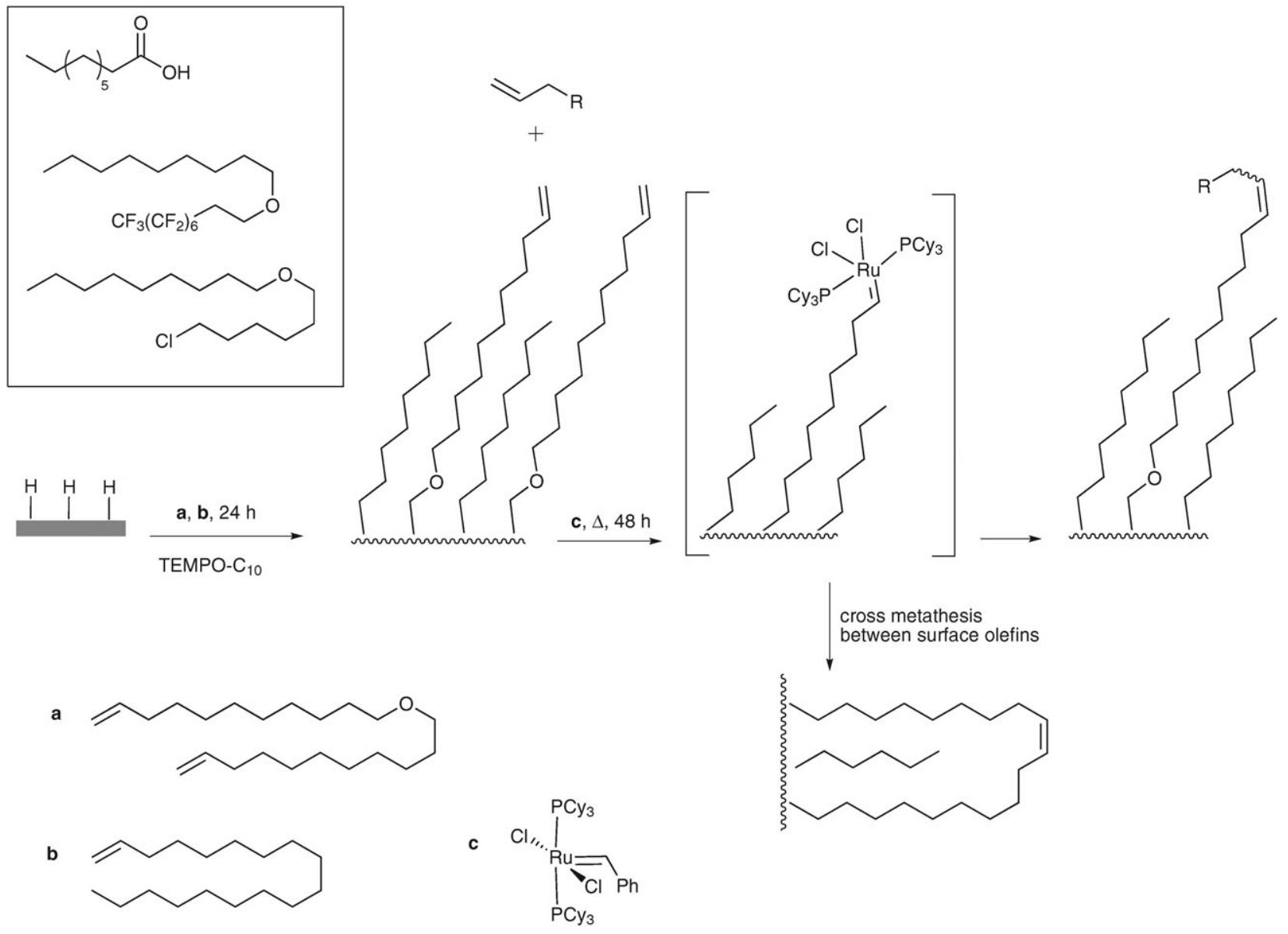

Fig. 18 Cross-metathesis reactions between an alkene-terminated $\mathrm{Si}(111)$ layer and 1-alkenes. Mixed layers were prepared from a $(\alpha, \omega$-diene) and $\mathrm{b}$ (1-alkene) in the presence of traces of TEMPO- $\mathrm{C}_{10}$. In the presence of first generation Grubbs' catalyst (c), the diene at the distal end was further reacted with $\omega$-functionalized 1 -alkenes to yield carboxylic acid-, fluoride- and chloride-terminated layers (ref. 236).

procedure that did not require protection/activation steps and was generally insensitive to steric factors. A range of alkyl and aryl azides, with different chemical functionalities, were used in this process without the need to vary the reaction conditions and without any apparent disruption of the base monolayer. Furthermore, improved 'click' coupling efficiencies were achieved for SAMs composed of a mixture of 1,8-nonadiyne a/1-heptyne (a mole fraction, $\chi_{\sin }$, in the hydrosilylation mixture ranging from 1.0 to 0.05 ). With progressive dilutions of the diyne a species, close to quantitative 'click' yields were approximated by electrochemical methods for a $\chi_{\sin }$ value of $0.05 .^{152}$

Modified $\mathrm{Si}(100)$ surfaces produced using this procedure have found applications in the preparation of redox assemblies for aqueous environments, ${ }^{152,248,249}$ antifouling surfaces, ${ }^{128,250}$ and have allowed for the first example of covalently immobilized porphyrins (Ni(II) $\beta$-azido-meso-tetraphenylporphyrin $\mathbf{h}$, Fig. 19) attached to the substrate via the $\beta$-pyrrolic position. ${ }^{251}$ In particular, the 'click' immobilization of azidomethylferrocene (i in Fig. 19) has been proved by Gooding and co-workers as viable and efficient method toward ferrocenyl-modified $\mathrm{Si}(100)$ electrodes that showed no evidence of silicon oxide species even after prolonged cycling between -100 and $800 \mathrm{mV}$ in aqueous electrolytes. ${ }^{152}$ The authors proposed that $\pi-\pi$ interactions between alkyne moieties at the distal end provide a surface that is resistant to silicon oxidation. Evidence for this conclusion comes from a deviation from ideality of the surface electrochemistry as the dialkyne is diluted with 1-heptyne such that the distal alkynes are diluted. This approach opens the door to the application of modified silicon electrodes in the field of bioelectronics, and 'clicked' $\mathrm{Si}(100)$ electrodes presenting isonicotinic acid derivatives have been reported for the direct electrochemistry of cytochrome $c .252$

\subsection{Reactions of halo-alkyl monolayers}

As detailed in Section 3.2.1, alternative grafting routes appear to be operating during the hydrosilylation of $\omega$-bromo-1-alkenes. ${ }^{136}$ The presence of alternative binding modes, as well as the direct abstraction of bromine atoms by surface silyl radicals, has not hampered the preparation of well-behaved $\mathrm{Si}(100)$ electrodes and Si-molecular monolayer junctions. ${ }^{137,253}$ Nucleophilic halide/azide exchange is a well established synthetic protocol in solid-state systems, ${ }^{254-257}$ and Prato and co-workers have recently demonstrated its applicability for the modification of non-oxidized silicon surfaces. ${ }^{253} \mathrm{~A}$ three-step procedure, consisting 
a
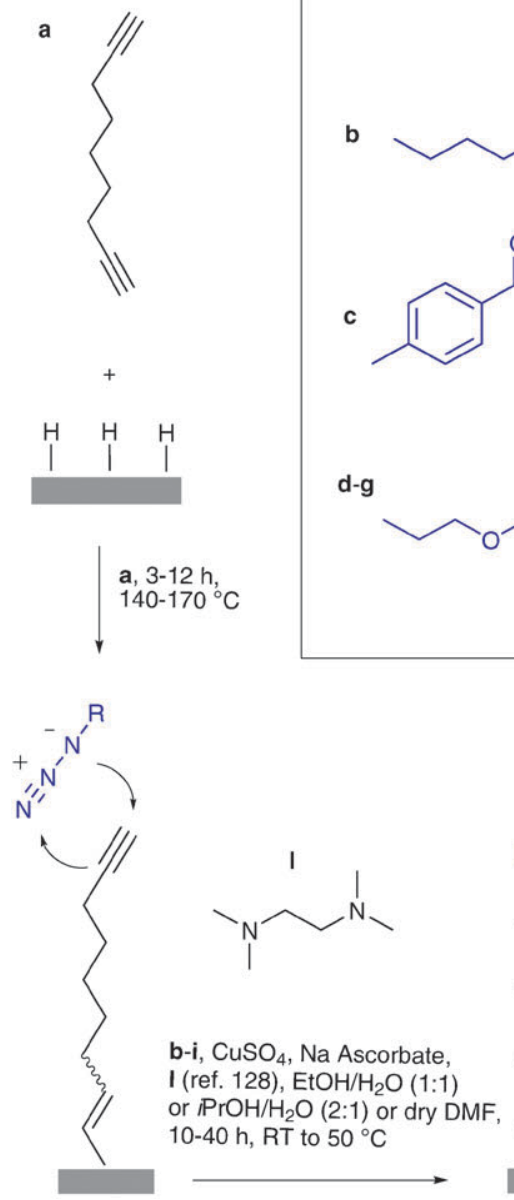

d-g

$\mathrm{R}=$

b

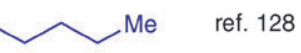

c<smiles>Cc1ccc(C(=O)CBr)cc1</smiles>

h
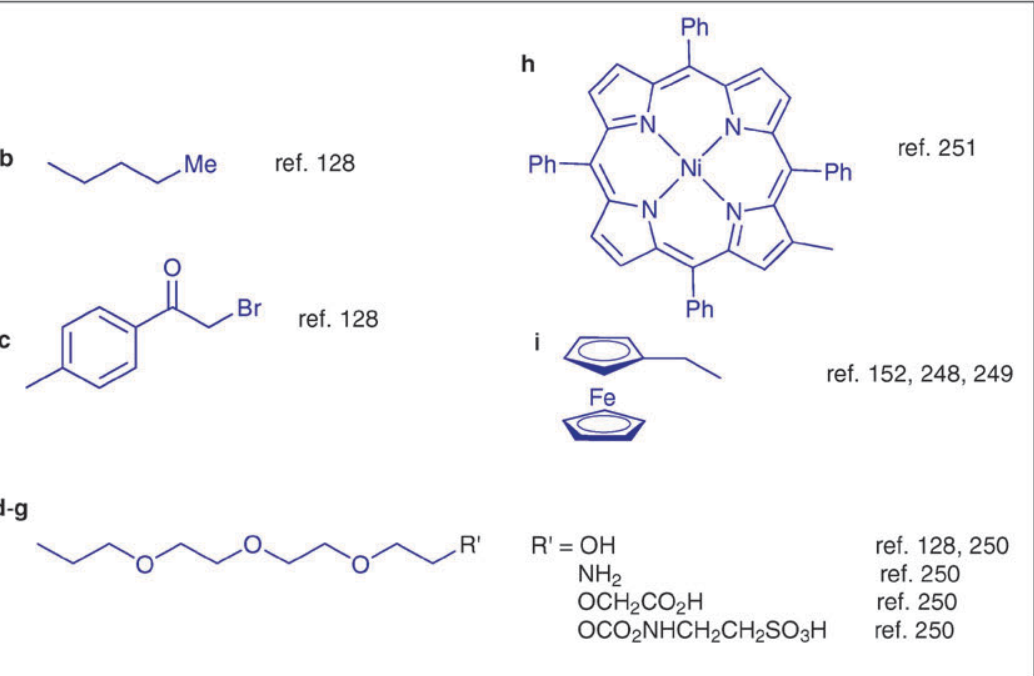

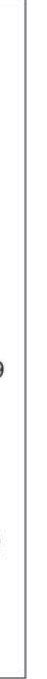
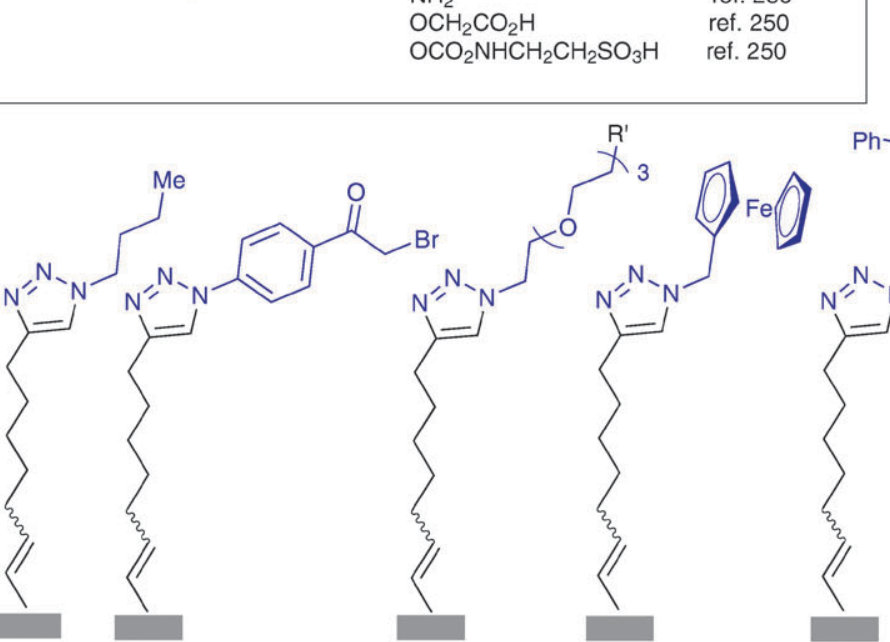

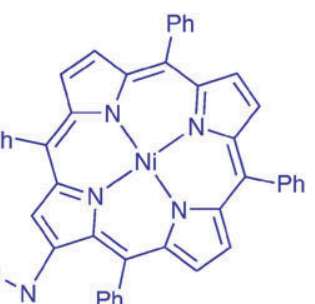

Fig. 19 Huisgen-type 'click' cycloaddition reactions on acetylene-terminated silicon (100) surfaces.

of the photochemical anchoring of 11-bromo-1-undecene onto $\mathrm{Si}(100)-\mathrm{H}$, followed by treatment with sodium azide and reaction of the azide-decorated surface with ethynylferrocene via 'click' chemistry, was used to prepare ferrocenyl electrodes. Despite this preparative protocol requiring the use of anhydrous solvents for each step, the ferrocene-bearing $\mathrm{Si}(100)$ electrodes, as prepared, showed significant levels of $\mathrm{SiO}_{x}$ species. Nevertheless, cyclic voltammetry in dry acetonitrile showed only a modest $30 \%$ decrease in the peak current intensity after $c a$. $1000 \mathrm{Fe}^{\mathrm{II}} / \mathrm{Fe}^{\mathrm{III}}$ oxidation/reduction cycles. More recently Cahen and co-workers have used the chemical manipulation of terminal bromine groups $(-\mathrm{Br})$ in 1-bromo-1-undecene Si(111) SAMs to correlate chemical changes with electrical changes in MIS junctions. ${ }^{137}$ The authors have shown how an improved packing density, resulting from the hydrolysis of $-\mathrm{Br}$ terminal groups to hydroxyl functionalities $(-\mathrm{OH}),{ }^{258}$ was accompanied by an increased effective Schottky barrier height and a decreased junction ideality factor. ${ }^{137}$

\section{Chemical and biochemical sensing: selected examples}

Biosensors research is a rapidly expanding field, with a broad spectrum of applications and transduction schemes available. For example, optical, morphological and electrochemical properties of porous silicon have been exploited to prepare a range of platforms for chemical or biological molecule sensing. ${ }^{55,259-261}$ More often, (bio)chemical siliconbased sensors have used MIS structures (metal-insulatorsemiconductor) and the ability of biomolecular binding events to modulate the conductance near the surface of a semiconductor. ${ }^{262,263}$ A general problem with standard (i.e. oxidized) silicon-based chemical sensors is low selectivity to different analytes of many oxidic transducer layers. ${ }^{264}$ However, this problem can be overcome by controlling the surface chemistry of the putative sensing interface through one of the wet-chemical methods described in the previous sections of this review. Numerous examples have appeared in the literature, ${ }^{53,59,62,207,209,259,265}$ and diverse transduction schemes are available. These schemes range from monitoring chromate ions concentrations by deflection of quaternary ammonium salt-terminated silicon AFM cantilevers ${ }^{266}$ to electrochemical impedance spectroscopy measurements of DNA- and antigen-modified $\mathrm{Si}(111)$ electrodes toward a labelfree sensor for detecting interactions with complementary DNA oligonucleotides, ${ }^{53}$ and antibodies. ${ }^{207}$ The following are therefore only selected examples from an expanding field. 


\subsection{Molecular oxygen detection}

Charge trapping at tert-butylhydrazine amide-modified undecylenic acid $\mathrm{Si}(111)$ layers $\left(-\mathrm{CO}-\mathrm{NH}-\mathrm{NH}-\mathrm{C}\left(\mathrm{CH}_{3}\right)_{3}\right)$ has been demonstrated by Lopinski and co-workers for the detection of molecular oxygen. ${ }^{221}$ The occurrence of electric fieldinduced second harmonic generation (EFISH), a technique largely used to study charge trapping at oxidized silicon surfaces, ${ }^{267}$ was used to monitor the charging of the hydrazide monolayers, and did not require electrical contacts with the sensor (i.e. the modified silicon sample) to be made.

Molecular oxygen adsorbed onto the SAM can act as an electron acceptor, with charged $\mathrm{O}^{2-}$ species being able to induce appreciable band bending in the underlying semiconductor. Enhancement of EFISH upon exposure of the hydrazide SAM to air was attributed to this electron trapping event. However, the interpretation of the experimental EFISH data was complicated by (i) plausible sample perturbation by photogenerated charge carriers (i.e. a laser light is needed to for optical second harmonic generation), (ii) 'ageing' in air of the modified silicon samples (IR spectral data), (iii) ionized hydrazide species actively acting as trap for holes, and (iv) charge trapping being influenced by moisture, even in the absence of oxygen.

\subsection{Biomolecules detection}

'Gating' effects at modified semiconductor surfaces open vast possibilities for attractive electrochemical transduction schemes of molecular events occuring at chemically modified semiconductor surfaces. ${ }^{268}$ As discussed extensively elsewhere, ${ }^{262,269}$ opposite to the situation in metals, electric fields can penetrate a large distance into a semiconductor and consequently shift energy levels near the surface region (i.e. band bending in the space charge layer, SCL). ${ }^{95}$ The binding of charged or polar species, as well as the presence of surface states (i.e. available energy levels in the band gap eventually occupied by electrons escaping the silicon lattice), can thus lead to changes in band bending and alter conductivity near the semiconductor surface (Fig. 20). Alternating-current (AC) electrochemical impedance spectroscopy (EIS) can be used to probe this field-effect by monitoring conductivity changes in the semiconductor space charge region. Both frequency- and potential-dependent EIS measurements have been used to demonstrate the direct (i.e. label-free) binding of DNA and antibodies at monolayer-modified $\mathrm{Si}(111)$ surfaces. ${ }^{53,207}$ The method does not require the use of either auxiliary redox agents (e.g. ferricyanide/ferrocyanide, ${ }^{270,271} 2$-anthraquinonemonosulfonic acid ${ }^{19,272,273}$ ) or large bias voltages. For example, by selecting an appropriate AC frequency ( $c a \cdot 10^{4}-10^{6} \mathrm{~Hz}$ ), and biasing the electrode into depletion, it is possible to enhance sensitivity toward field-effects induced in the semiconductor by the binding of charged species. Hamers and co-workers have demonstrated that stable, reproducible and distinct (i.e. well outside any statistical fluctuation) changes in the impedance response can be measured when either p- or n-type DNA-modified substrates are exposed to solutions containing complementary DNA strands. ${ }^{53}$ On the other hand, the electrochemical response to non-complementary DNA strands (four-base mismatch) was indistinguishable

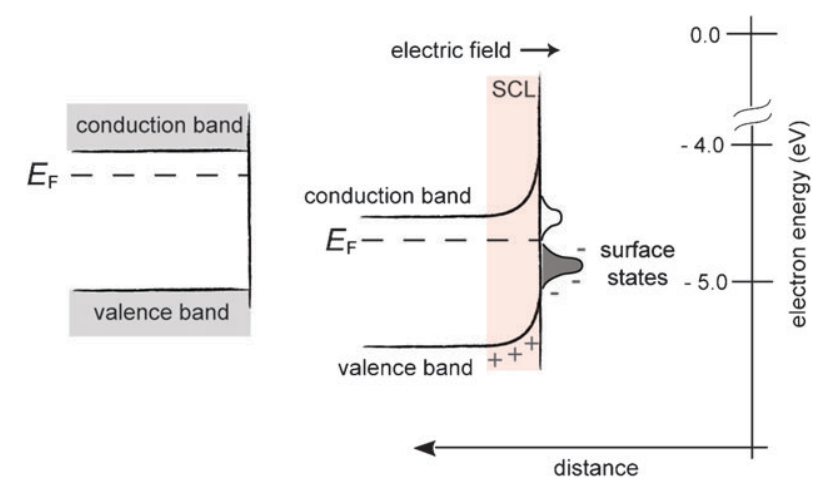

Fig. 20 Energy level diagram for n-type semiconductors. Electrons escape the semiconductor lattice until near-surface (i.e. SCL) electric fields oppose to a further electrons migration toward the surface. An electric field pointing toward the semiconductor surface is schematically depicted as an upward band-bending.

from that elicted by denaturation of the hybridized device. Interpretation of the experimental data, to fully understand the physical basis of the EIS response, requires refinement of the electrical equivalent circuit models depicted in Fig. 21. The overall impedance is largely controlled by the properties of the space charge region $\left(R_{\mathrm{scl}}\right.$ and $\left.C_{\mathrm{scl}}\right)$ and by the molecular layer resistance $\left(R_{\text {org }}\right)$. In brief, regardless of the doping level (from 0.005 to $10 \Omega \mathrm{cm}$ ) similar trends were found within the same doping type group, with upward band-bending observed upon hybridization. In the case of p-type substrates this field-effect resulted in a decreased resistance of the SCL $\left(R_{\mathrm{scl}}\right)$ upon DNA binding, as expected for a decrease in the depleted region due to the electric field arising from negative charges of the DNA phosphate back-bone (Fig. 22a). Conversely, in n-type electrodes the binding of a complementary strand gave a depletion region of increased resistance and decreased capacitance, and was thus consistent with an increased band-bending (Fig. 22b). It is worth mentioning that hybridization also resulted in changes of the molecular layer conductivity $\left(R_{\mathrm{org}}\right)$, with opposite trends observed in p- and n-type substrates. These changes are believed to be dictated by the nature of the electrolyte/SCL field interactions, but at present a conclusive explanation is still lacking and will be needed to fully elucidate the signal transduction process of similar biosensing EIS devices.

A significant implementation of this field-induced effect approach to the sensing of biomolecules was recently reported by the same group for the direct and label-free detection of antigen-antibody interactions. ${ }^{207}$ Hamers and co-workers demonstrated that EIS measurements at a single AC frequency can afford information on the binding of a specific antibody to its surface-confined antigen (Fig. 13). This last report represents a significant technological advance since, as stressed by Abbott, ${ }^{274}$ the fabrication of protein biochips appears to face more serious challenges than for the corresponding DNA systems. ${ }^{275} \mathrm{We}$ also note that major advantages of this label-free field-effect approach include (i) the lack of interference with the protein's activity and/or with its structure, as on the other hand is expected if dyes are used to tag the analyte in conventional fluorescence-based methods, and (ii) simplified protocols, with no need for post-incubation rinsing 


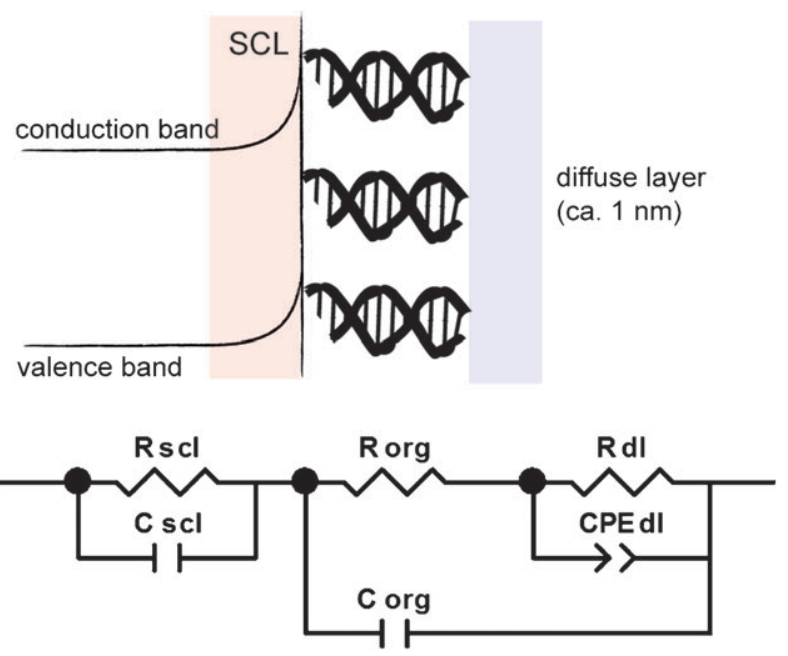

Fig. 21 Schematic representation of DNA-modified $\mathrm{Si}(111)$ surfaces and electrical equivalent circuit used to fit experimental EIS data and explain physical changes in the sensing device upon DNA hybridization (ref. 53).
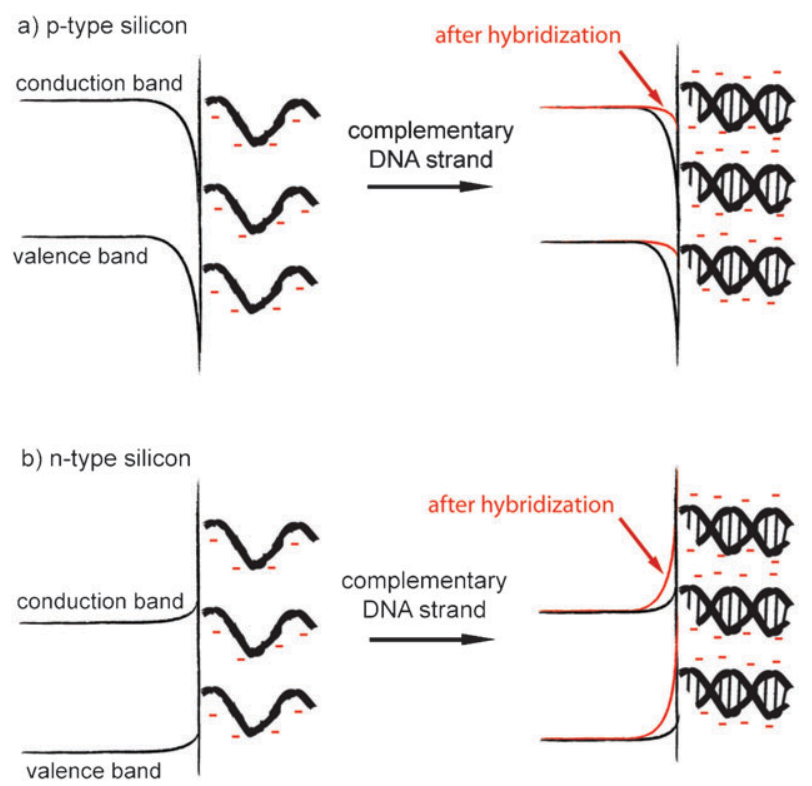

Fig. 22 Schematic depiction for the changes in the semiconductor near-surface fields upon DNA hybridization at (a) p- and (b) n-type silicon-based biosensors (ref. 53). Single-strand DNA sequences were immobilized according to the procedure of Strother et al. (ref. 49).

procedures of the sensing surface as required for fluorescence measurements.

It is very important to note that the electronic properties of such sensing surfaces will be very sensitive to defects in the device surface. Therefore only minor densities of electrically active traps, even below $10^{-5}$ monolayers equivalent, can lead to appreciable band-bending and have a detrimental effect on the sensing capabilities. The fabrication of robust monolayers resistant to aqueous environments will therefore be imperative to allow for further progress in the area of monolayer-modified field effect silicon sensing devices.

\section{Summary and perspectives}

$\mathrm{Si}(111)$ hydrogen-terminated silicon surfaces, as prepared through standard, widespread, chemical etching procedures are the prime example of electrically well-behaved semiconductor surfaces. If kept in fluoride-containing electrolytes, the silicon-hydride surfaces display minimal band bending and show the lowest to-date reported charge recombination velocities $\left(c a .0 .25 \mathrm{~cm} \mathrm{~s}^{-1}\right) .^{72}$ However, the $\mathrm{Si}-\mathrm{H}$ surface is chemically unstable and prone to oxidation, ${ }^{79}$ yielding a $\mathrm{Si}-\mathrm{SiO}_{2}$ interface ${ }^{276}$ which displays surface recombination velocities higher than $3 \mathrm{~cm} \mathrm{~s}^{-1} \cdot 277$

As discussed in Section 3, provided that care is taken, silicon-carbon linked organic monolayers offer a convenient approach to chemically and electrically well-passivated silicon surfaces. The organic-semiconductor structure promises to expand the performances and applications of conventional semiconductor devices, with novel biosensing interfaces ${ }^{259}$ and high-density memory storage $40,44,215$ among the envisioned devices. For example, surface-bound molecules either charged or polarized can influence the energy levels near the surface (i.e. changes in the band-bending) and alter the conductivity of the substrate. ${ }^{53,207}$ This molecular gate ${ }^{129}$ approach has stimulated vast research, ${ }^{43,63,64,129,278}$ but despite encouraging recent reports, ${ }^{279}$ at present the development of real-world molecular electronics, such as high density memories, ${ }^{40,41}$ remain a long-term target. Serious practical obstacles toward the fabrication of a real device still exist. These include complex wiring, ${ }^{45}$ the required stability with regards to a large number of read-write cycles, ${ }^{280}$ and the requirement to minimize the damage to the organic layer after a solid contact is made. ${ }^{67,165,281}$

While a practical molecular memory device would be required to withstand extreme operational conditions, ${ }^{280}$ on the contrary, real-world applications of modified silicon surfaces in the field of chemical ${ }^{266}$ and biological sensing appear to be less demanding. ${ }^{60}$ The design of tailored interfaces benefits from numerous chemical strategies now available for the reaction of the $\mathrm{Si}-\mathrm{H}$ surface with organic molecules. Nevertheless, a continuing challenge is in the development of robust chemistries to prevent side reactions, most notably oxidation, at the silicon surface. Although simple $\mathrm{Si}-\mathrm{C}$ linked alkyl layers, with minimal traces of silicon oxides, are relatively simple to obtain, and particularly for the $\mathrm{Si}(111)$ surface, preparation of functional layers, as required in the design of complex, chemically well-defined sensing interfaces, is still a field rich in challenges and opportunities.

\section{Acknowledgements}

The authors thank the Australian Research Council (project number DP0772356 and DP1094564) for support.

\section{Notes and references}

1 A. Ulman, Chem. Rev., 1996, 96, 1533-1554.

2 J. Sagiv, J. Am. Chem. Soc., 1980, 102, 92-98.

3 D. L. Allara and R. G. Nuzzo, Langmuir, 1985, 1, 45-52.

4 R. G. Nuzzo, F. A. Fusco and D. L. Allara, J. Am. Chem. Soc., 1987, 109, 2358-2368. 
5 N. Tillman, A. Ulman and T. L. Penner, Langmuir, 1989, 5, 101-111.

6 M. Calistri-Yeh, E. J. Kramer, R. Sharma, W. Zhao, M. H. Rafailovich, J. Sokolov and J. D. Brock, Langmuir, 1996, 12, 2747-2755.

7 J. Sagiv, Isr. J. Chem., 1980, 18, 339-345.

8 J. Sagiv, Isr. J. Chem., 1980, 18, 346-353.

9 M. D. Porter, T. B. Bright, D. L. Allara and C. E. D. Chidsey, J. Am. Chem. Soc., 1987, 109, 3559-3568.

10 C. D. Bain, E. B. Troughton, Y. T. Tao, J. Evall, G. M. Whitesides and R. G. Nuzzo, J. Am. Chem. Soc., 1989, 111, 321-335.

11 C. D. Bain, J. Evall and G. M. Whitesides, J. Am. Chem. Soc., 1989, 111, 7155-7164.

12 C. D. Bain and G. M. Whitesides, J. Am. Chem. Soc., 1989, 111, $7164-7175$

13 J. J. Gooding, F. Mearns, W. Yang and J. Liu, Electroanalysis, 2003, 15, 81-96.

14 C. E. D. Chidsey, C. R. Bertozzi, T. M. Putvinski and A. M. Mujsce, J. Am. Chem. Soc., 1990, 112, 4301-4306.

15 K. Weber and S. E. Creager, Anal. Chem., 1994, 66, 3164-3172.

16 K. Weber, L. Hockett and S. Creager, J. Phys. Chem. B, 1997, 101, 8286-8291.

17 T. C. Chilcott, E. L. S. Wong, H. G. L. Coster, A. C. F. Coster and M. James, Electrochim. Acta, 2009, 54, 3766-3774.

18 A. B. Horn, D. A. Russell, L. J. Shorthouse and T. R. E. Simpson, J. Chem. Soc., Faraday Trans., 1996, 23, 4759-4762.

19 E. L. S. Wong and J. J. Gooding, J. Am. Chem. Soc., 2007, 129, 8950-8951.

20 E. L. S. Wong, E. Chow and J. J. Gooding, Electrochem. Commun., 2007, 9, 845-849.

21 F. J. Mearns, E. L. S. Wong, K. Short, D. B. Hibbert and J. J. Gooding, Electroanalysis, 2006, 18, 1971-1981.

22 J. J. Gooding, Electroanalysis, 2008, 20, 573-582.

23 H. O. Finklea, S. Avery, M. Lynch and T. Furtsch, Langmuir, 1987, 3, 409-413.

24 W. R. Everett, T. L. Welch, L. Reed and I. Fritsch-Faules, Anal. Chem., 1995, 67, 292-298.

25 E. Chow, D. B. Hibbert and J. J. Gooding, Anal. Chim. Acta, $2005, \mathbf{5 4 3}, 167-176$.

26 D. Wayner and R. Wolkow, J. Chem. Soc., Perkin Trans. 2, 2002, 23-34.

27 J. M. Buriak, Chem. Commun., 1999, 1051-1060.

28 J. M. Buriak, Chem. Rev., 2002, 102, 1271-1308.

29 R. Boukherroub, Curr. Opin. Solid State Mater. Sci., 2005, 9, 66-72.

30 N. Shirahata, A. Hozumi and T. Yonezawa, Chem. Rec., 2005, 5, $145-159$.

31 M. R. Linford, P. Fenter, P. M. Eisenberger and C. E. D. Chidsey, J. Am. Chem. Soc., 1995, 117, 3145-3155.

32 S. R. Puniredd, O. Assad and H. Haick, J. Am. Chem. Soc., 2008, 130, 13727-13734.

33 A. B. Sieval, A. L. Demirel, J. W. M. Nissink, M. R. Linford, J. H. van der Maas, W. H. de Jeu, H. Zuilhof and E. J. R. Sudhölter, Langmuir, 1998, 14, 1759-1768.

34 M. M. Sung, G. J. Kluth, O. W. Yauw and R. Maboudian, Langmuir, 1997, 13, 6164-6168.

35 P. Ball, Nat. Mater., 2005, 4, 119-119.

36 F. J. Ruess, L. Oberbeck, M. Y. Simmons, K. E. J. Goh, A. R. Hamilton, T. Hallam, S. R. Schofield, N. J. Curson and R. G. Clark, Nano Lett., 2004, 4, 1969-1973.

37 M. Y. Simmons, F. J. Ruess, K. E. J. Goh, W. Pok, T. Hallam, M. J. Butcher, T. C. G. Reusch, G. Scappucci, A. R. Hamilton and L. Oberbeck, Int. J. Nanotechnol., 2008, 5, 352-369.

38 M. Y. Simmons, F. J. Ruess, K. E. J. Goh, T. Hallam, S. R. Schofield, L. Oberbeck, N. J. Curson, A. R. Hamilton, M. J. Butcher, R. G. Clark and T. C. G. Reusch, Mol. Simul., 2005, 31, 505-515.

39 A. Vilan, O. Yaffe, A. Biller, A. Salomon, A. Kahn and D. Cahen, Adv. Mater., 2009, 22, 140-159.

40 K. M. Roth, A. A. Yasseri, Z. Liu, R. B. Dabke, V. Malinovskii, K.-H. Schweikart, L. Yu, H. Tiznado, F. Zaera, J. S. Lindsey, W. G. Kuhr and D. F. Bocian, J. Am. Chem. Soc., 2003, 125, 505-517.
41 G. F. Cerofolini, G. Arena, C. M. Camalleri, C. Galati, S. Reina, L. Renna and D. Mascolo, Nanotechnology, 2005, 16, 1040-1047.

42 R. A. Wolkow, Annu. Rev. Phys. Chem., 1999, 50, 413-441.

43 G. Ashkenasy, D. Cahen, R. Cohen, A. Shanzer and A. Vilan, Acc. Chem. Res., 2002, 35, 121-128.

44 Q. Li, G. Mathur, S. Gowda, S. Surthi, Q. Zhao, L. Yu, J. S. Lindsey, D. F. Bocian and V. Misra, Adv. Mater., 2004, 16, 133-137.

45 G. F. Cerofolini and D. Mascolo, Semicond. Sci. Technol., 2006, 21, 1315-1325.

46 H.-Z. Yu, S. Morin, D. D. M. Wayner, P. Allongue and C. Henry de Villeneuve, J. Phys. Chem. B, 2000, 104, 11157-11161.

47 E. L. S. Wong, M. James, T. C. Chilcott and H. G. L. Coster, Surf. Sci., 2007, 601, 5740-5743.

48 H. Haick and D. Cahen, Prog. Surf. Sci., 2008, 83, 217-261.

49 T. Strother, R. J. Hamers and L. M. Smith, Nucleic Acids Res., 2000, 28, 3535-3541.

50 F. Wei, B. Sun, Y. Guo and X. S. Zhao, Biosens. Bioelectron., 2003, 18, 1157-1163.

51 R. Voicu, R. Boukherroub, V. Bartzoka, T. Ward, J. T. C. Wojtyk and D. D. M. Wayner, Langmuir, 2004, 20, 11713-11720.

52 H. B. Yin, T. Brown, R. Greef, J. S. Wilkinson and T. Melvin, Microelectron. Eng., 2004, 73-74, 830-836.

53 W. Cai, J. R. Peck, D. W. van der Weide and R. J. Hamers, Biosens. Bioelectron., 2004, 19, 1013-1019.

54 M. P. Stewart and J. M. Buriak, Comments Inorg. Chem., 2002, 23, 179-203.

55 M. P. Stewart and J. M. Buriak, Adv. Mater., 2000, 12, 859-869.

56 Application: WO, WO Pat., 99-US14289937409, 1999.

57 K. A. Kilian, T. Böcking, K. Gaus, M. Gal and J. J. Gooding, Biomaterials, 2007, 28, 3055-3062.

58 K. A. Kilian, T. Böcking, K. Gaus, M. Gal and J. J. Gooding, ACS Nano, 2007, 1, 355-361.

59 K. A. Kilian, T. Böcking, K. Gaus and J. J. Gooding, Angew. Chem., Int. Ed., 2008, 47, 2697-2699.

60 K. A. Kilian, T. Böcking, S. Ilyas, K. Gaus, J. Wendy, M. Gal and J. J. Gooding, Adv. Funct. Mater., 2007, 17, 2884-2890.

61 L. Britcher, T. J. Barnes, H. J. Griesser and C. A. Prestidge, Langmuir, 2008, 24, 7625-7627.

62 G. Palestino, V. Agarwal, R. Aulombard, E. a. Pérez and C. Gergely, Langmuir, 2008, 24, 13765-13771.

63 O. Yaffe, L. Scheres, S. R. Puniredd, N. Stein, A. Biller, R. H. Lavan, H. Shpaisman, H. Zuilhof, H. Haick, D. Cahen and A. Vilan, Nano Lett., 2009, 9, 2390-2394.

64 A. Salomon, T. Böcking, K. Chan Calvin, F. Amy, O. Girshevitz, D. Cahen and A. Kahn, Phys. Rev. Lett., 2005, 95, 266807.

65 A. Salomon, T. Böcking, J. J. Gooding and D. Cahen, Nano Lett., 2006, 6, 2873-2876.

66 T. Böcking, A. Salomon, D. Cahen and J. J. Gooding, Langmuir, 2007, 23, 3236-3241.

67 H. Haick and D. Cahen, Acc. Chem. Res., 2008, 41, 359-366.

68 T. L. Niederhauser, G. Jiang, Y.-Y. Lua, M. J. Dorff, A. T. Woolley, M. C. Asplund, D. A. Berges and M. R. Linford, Langmuir, 2001, 17, 5889-5900.

69 L. Yang, Y.-Y. Lua, M. V. Lee and M. R. Linford, Acc. Chem. Res., 2005, 38, 933-942.

70 R. J. Hamers, S. K. Coulter, M. D. Ellison, J. S. Hovis, D. F. Padowitz, M. P. Schwartz, C. M. Greenlief and J. N. Russell, Jr., Acc. Chem. Res., 2000, 33, 617-624.

71 G. P. Lopinski, D. D. M. Wayner and R. A. Wolkow, Nature, 2000, 406, 48-51.

72 E. Yablonovitch, D. L. Allara, C. C. Chang, T. Gmitter and T. B. Bright, Phys. Rev. Lett., 1986, 57, 249-252.

73 W. Cai, Z. Lin, T. Strother, L. M. Smith and R. J. Hamers, J. Phys. Chem. B, 2002, 106, 2656-2664.

74 A. Bansal, X. Li, I. Lauermann, N. S. Lewis, S. I. Yi and W. H. Weinberg, J. Am. Chem. Soc., 1996, 118, 7225-7226.

75 H. Ubara, T. Imura and A. Hiraki, Solid State Commun., 1984, 50, 673-675.

76 G. S. Higashi, R. S. Becker, Y. J. Chabal and A. J. Becker, Appl. Phys. Lett., 1991, 58, 1656-1658.

77 Y. J. Chabal, G. S. Higashi, K. Raghavachari and V. A. Burrows, J. Vac. Sci. Technol., A, 1989, 7, 2104-2109. 
78 G. S. Higashi, Y. J. Chabal, G. W. Trucks and K. Raghavachari, Appl. Phys. Lett., 1990, 56, 656-658.

79 M. Niwano, J.-I. Kageyama, K. Kurita, K. Kinashi, I. Takahashi and N. Miyamoto, J. Appl. Phys., 1994, 76, 2157-2163.

80 M. Morita, T. Ohmi, E. Hasegawa, M. Kawakami and M. Ohwada, J. Appl. Phys., 1990, 68, 1272-1281.

81 G. Cleland, B. R. Horrocks and A. Houlton, J. Chem. Soc., Faraday Trans., 1995, 91, 4001-4003.

82 A. Bansal and N. S. Lewis, J. Phys. Chem. B, 1998, 102, $1067-1070$

83 R. Boukherroub, S. Morin, F. Bensebaa and D. D. M. Wayner, Langmuir, 1999, 15, 3831-3835.

84 J. E. Bateman, R. D. Eagling, D. R. Worrall, B. R. Horrocks and A. Houlton, Angew. Chem., Int. Ed., 1998, 37, 2683-2685.

85 A. B. Sieval, V. Vleeming, H. Zuilhof and E. J. R. Sudhoelter, Langmuir, 1999, 15, 8288-8291.

86 A. B. Sieval, R. Linke, G. Heij, G. Meijer, H. Zuilhof and E. J. R. Sudhölter, Langmuir, 2001, 17, 7554-7559.

87 M. R. Linford and C. E. D. Chidsey, J. Am. Chem. Soc., 1993, 115, 12631-12632.

88 R. L. Cicero, C. E. D. Chidsey, G. P. Lopinski, D. D. M. Wayner and R. A. Wolkow, Langmuir, 2002, 18, 305-307.

89 P. Allongue, C. Henry de Villeneuve, S. Morin, R. Boukherroub and D. D. M. Wayner, Electrochim. Acta, 2000, 45, 4591-4598.

90 P. Allongue, V. Kieling and H. Gerischer, Electrochim. Acta, 1995, 40, 1353-1360.

91 P. Allongue, Phys. Rev. Lett., 1996, 77, 1986-1989.

92 V. A. Burrows, Y. J. Chabal, G. S. Higashi, K. Raghavachari and S. B. Christman, Appl. Phys. Lett., 1988, 53, 998-1000.

93 P. Allongue, V. Costa-Kieling and H. Gerischer, J. Electrochem. Soc., 1993, 140, 1009-1018.

94 P. Allongue, V. Costa-Kieling and H. Gerischer, J. Electrochem. Soc., 1993, 140, 1018-1026.

95 G. Zhang, Electrochemistry of Silicon and its Oxide, Kluwer/ Plenum, New York, 2001.

96 The nomenclature $(2 \times 1)$ designates the doubling in size of the unit cell when compared to the unreconstructed surface.

97 M. V. Lee, D. Guo, M. R. Linford and H. Zuilhof, Langmuir, 2004, 20, 9108-9113.

98 G. F. Cerofolini, C. Galati, S. Reina and L. Renna, Mater. Sci. Eng., C, 2003, 23, 253-257.

99 G. F. Cerofolini, C. Galati, S. Reina and L. Renna, Semicond. Sci. Technol., 2003, 18, 423-429.

100 G. F. Cerofolini, C. Galati, S. Reina and L. Renna, Appl. Phys. A: Solid Surf., 2004, 80, 161-166.

101 The surface is predominantly terminated with dihydride $\left(=\mathrm{SiH}_{2}\right)$. Nevertheless the formation of an homogeneous dihydride array on $\mathrm{Si}(100)$ is prevented due to strong $\mathrm{H}-\mathrm{H}$ repulsions.

102 E. J. Nemanick, P. T. Hurley, L. J. Webb, D. W. Knapp, D. J. Michalak, B. S. Brunschwig and N. S. Lewis, J. Phys. Chem. B, 2006, 110, 14770-14778.

103 P. Dumas and Y. J. Chabal, Chem. Phys. Lett., 1991, 181, $537-543$.

104 P. Dumas, Y. J. Chabal and P. Jakob, Surf. Sci., 1992, 269-270, $867-878$.

105 I. T. Clark, B. S. Aldinger, A. Gupta and M. A. Hines, J. Phys. Chem. C, 2010, 114, 423-428.

106 A. Moraillon, A. C. Gouget-Laemmel, F. Ozanam and J. N. Chazalviel, J. Phys. Chem. C, 2008, 112, 7158-7167.

107 P. Allongue, C. H. De Villeneuve, J. Pinson, F. Ozanam, J. N. Chazalviel and X. Wallart, Electrochim. Acta, 1998, 43, 2791-2798.

108 M. Perring, S. Dutta, S. Arafat, M. Mitchell, P. J. A. Kenis and N. B. Bowden, Langmuir, 2005, 21, 10537-10544.

109 A. Bansal, X. Li, S. I. Yi, W. H. Weinberg and N. S. Lewis, J. Phys. Chem. B, 2001, 105, 10266-10277.

110 R. D. Rohde, H. D. Agnew, W.-S. Yeo, R. C. Bailey and J. R. Heath, J. Am. Chem. Soc., 2006, 128, 9518-9525.

111 T. Böcking, M. James, H. G. L. Coster, T. C. Chilcott and K. D. Barrow, Langmuir, 2004, 20, 9227-9235.

112 T. Böcking, K. A. Kilian, K. Gaus and J. J. Gooding, Langmuir, 2006, 22, 3494-3496.

113 R. Boukherroub and D. D. M. Wayner, J. Am. Chem. Soc., 1999, 121, 11513-11515.
114 L. J. Webb and N. S. Lewis, J. Phys. Chem. B, 2003, 107, 5404-5412.

115 P. Gorostiza, C. H. De Villeneuve, Q. Y. Sun, F. Sanz, X. Wallart, R. Boukherroub and P. Allongue, J. Phys. Chem. $B, 2006,110,5576-5585$.

116 B. Fabre and F. Hauquier, J. Phys. Chem. B, 2006, 110, 6848-6855.

117 P. Allongue, C. Henry de Villeneuve and J. Pinson, Electrochim. Acta, 2000, 45, 3241-3248.

118 P. Allongue, C. H. de Villeneuve, G. Cherouvrier, R. Cortes and M. C. Bernard, J. Electroanal. Chem., 2003, 550-551, $161-174$.

119 B. J. Eves, Q.-Y. Sun, G. P. Lopinski and H. Zuilhof, J. Am. Chem. Soc., 2004, 126, 14318-14319.

120 T. Böcking, K. A. Kilian, T. Hanley, S. Ilyas, K. Gaus, M. Gal and J. J. Gooding, Langmuir, 2005, 21, 10522-10529.

121 H.-Z. Yu, R. Boukherroub, S. Morin and D. D. M. Wayner, Electrochem. Commun., 2000, 2, 562-566.

122 X. Wallart, C. H. de Villeneuve and P. Allongue, J. Am. Chem. Soc., 2005, 127, 7871-7878.

123 N. Tajimi, H. Sano, K. Murase, K.-H. Lee and H. Sugimura, Langmuir, 2007, 23, 3193-3198.

124 E. J. Nemanick, P. T. Hurley, B. S. Brunschwig and N. S. Lewis, J. Phys. Chem. B, 2006, 110, 14800-14808.

125 A. B. Sieval, R. Opitz, H. P. A. Maas, M. G. Schoeman, G. Meijer, F. J. Vergeldt, H. Zuilhof and E. J. R. Sudhölter, Langmuir, 2000, 16, 10359-10368.

126 Q.-Y. Sun, L. C. P. M. de Smet, B. van Lagen, A. Wright, H. Zuilhof and E. J. R. Sudhöelter, Angew. Chem., Int. Ed., 2004, 43, 1352-1355.

127 F. Cattaruzza, A. Cricenti, A. Flamini, M. Girasole, G. Longo, A. Mezzi and T. Prosperi, J. Mater. Chem., 2004, 14, 1461-1468.

128 S. Ciampi, T. Böcking, K. A. Kilian, M. James, J. B. Harper and J. J. Gooding, Langmuir, 2007, 23, 9320-9329.

129 E. J. Faber, L. C. P. M. de Smet, W. Olthuis, H. Zuilhof, E. J. R. Sudhoelter, P. Bergveld and A. van den Berg, ChemPhysChem, 2005, 6, 2153-2166.

130 The reaction was also reported to occur even in the complete absence of any deliberately added radical initiator, but under these conditions it yielded a poorer surface coverage.

131 Alternatively the alkyl radical will abstract an hydrogen from the allylic position of an unreacted olefin in solution.

132 C. Chatgilialoglu, Acc. Chem. Res., 1992, 25, 188-194.

133 R. L. Cicero, M. R. Linford and C. E. D. Chidsey, Langmuir, 2000, 16, 5688-5695.

134 FTIR evidence of a silylated olefin (surface vinyl group) was also provided (see footnote 33 in ref. 31).

135 S. Di Bella, G. G. Condorelli, A. Motta, A. Ustione and A. Cricenti, Langmuir, 2006, 22, 7952-7955.

136 H. Jin, C. R. Kinser, P. A. Bertin, D. E. Kramer, J. A. Libera, M. C. Hersam, S. T. Nguyen and M. J. Bedzyk, Langmuir, 2004, 20, 6252-6258.

137 Y. S. Cohen, A. Vilan, I. Ron and D. Cahen, J. Phys. Chem. C, 2009, 113, 6174-6181.

138 It also became apparent that a six-membered ring configuration of the transient secondary alkyl radical, as resulting from addition of the silyl radical to the $\alpha$-carbon, would largely facilitate hydrogen abstraction from an adjacent site, thus making polymerization reactions less likely to occur.

139 R. Boukherroub, S. Morin, P. Sharpe, D. D. M. Wayner and P. Allongue, Langmuir, 2000, 16, 7429-7434.

140 N. Y. Kim and P. E. Laibinis, J. Am. Chem. Soc., 1997, 119, 2297-2298.

141 J. Terry, M. R. Linford, C. Wigren, R. Cao, P. Pianetta and C. E. D. Chidsey, Appl. Phys. Lett., 1999, 71, 1056-1058.

142 M. V. Lee, J. R. I. Lee, D. E. Brehmer, M. R. Linford and T. M. Willey, Langmuir, 2010, 26, 1512-1515.

143 O. Seitz, A. Vilan, H. Cohen, J. Hwang, M. Haeming, A. Schoell, E. Umbach, A. Kahn and D. Cahen, Adv. Funct. Mater., 2008, 18, $2102-2113$

144 H. Yu, L. J. Webb, R. S. Ries, S. D. Solares, W. A. Goddard, J. R. Heath and N. S. Lewis, J. Phys. Chem. B, 2005, 109, 671-674.

145 W. J. Royea, A. Juang and N. S. Lewis, Appl. Phys. Lett., 2000, 77, 1988-1990. 
146 J. Terry, M. R. Linford, C. Wigren, R. Cao, P. Pianetta and C. E. D. Chidsey, Appl. Phys. Lett., 1997, 71, 1056-1058.

147 S. R. Puniredd, O. Assad and H. Haick, J. Am. Chem. Soc., 2008, 130, 9184-9185.

148 L. J. Webb, E. J. Nemanick, J. S. Biteen, D. W. Knapp, D. J. Michalak, M. C. Traub, A. S. Y. Chan, B. S. Brunschwig and N. S. Lewis, J. Phys. Chem. B, 2005, 109, 3930-3937.

149 T. Okubo, H. Tsuchiya, M. Sadakata, T. Yasuda and K. Tanaka, Appl. Surf. Sci., 2001, 171, 252-256.

150 L. J. Webb, D. J. Michalak, J. S. Biteen, B. S. Brunschwig, A. S. Y. Chan, D. W. Knapp, H. M. Meyer, E. J. Nemanick, M. C. Traub and N. S. Lewis, J. Phys. Chem. B, 2006, 110, 23450-23459.

151 Hydrogen-terminated surfaces in contact with aqueous acid solutions display unique electronic properties with extremely low $\left(<1 \mathrm{~cm} \mathrm{~s}^{-1}\right)$ charge carrier recombination velocity because of the negligible number of defect sites but clearly lack ambient robustness.

152 S. Ciampi, P. K. Eggers, G. Le Saux, M. James, J. B. Harper and J. J. Gooding, Langmuir, 2009, 25, 2530-2539.

153 B. J. Eves and G. P. Lopinski, Surf. Sci., 2005, 579, L89-L96.

154 S. Rivillon, F. Amy, Y. J. Chabal and M. M. Frank, Appl. Phys. Lett., 2004, 85, 2583-2585.

155 P. T. Hurley, E. J. Nemanick, B. S. Brunschwig and N. S. Lewis, J. Am. Chem. Soc., 2006, 128, 9990-9991.

156 W. F. Bergerson, J. A. Mulder, R. P. Hsung and X. Y. Zhu, J. Am. Chem. Soc., 1999, 121, 454-455.

157 X. Y. Zhu, V. Boiadjiev, J. A. Mulder, R. P. Hsung and R. C. Major, Langmuir, 2000, 16, 6766-6772.

158 P. Cao, K. Xu and J. R. Heath, J. Am. Chem. Soc, 2008, 130, 14910-14911.

159 A likely halide contaminant is 1-bromododecane which is used in the Grignard synthesis.

160 S. Fellah, R. Boukherroub, F. Ozanam and J.-N. Chazalviel, Langmuir, 2004, 20, 6359-6364.

161 An electrochemical reaction is defined as involving charge transfer between reactants and the silicon substrate.

162 A possible chemical route would involve the homolytic cleavage of the alkyl Grignard $\left(\mathrm{R}^{\bullet}+{ }^{\bullet} \mathrm{MgBr}\right)$ mediated by the alkyl halide.

163 The grafting of an alkyl halide (e.g. tetradecyl bromide, $\mathrm{RBr}$ ) is reported to occur at the $\mathrm{Si}(111)-\mathrm{H}$ surface affording both $\equiv \mathrm{Si}-\mathrm{R}$ and $\equiv \mathrm{Si}-\mathrm{Br}$ surfaces. The latter is rapidly oxidized to silica related compounds unless the halogen is displaced by the alkyl Grignard $\left(\mathrm{R}^{\prime} \mathrm{MgBr}\right)$. Therefore, even at high alkyl bromide concentrations the overall reaction would result in passivated surfaces ( $\equiv \mathrm{Si}-\mathrm{R}$ and $\left.\equiv \mathrm{Si}-\mathrm{R}^{\prime}\right)$ with minimal oxidation.

164 H. O. Finklea, Semiconductor Electrodes, Elsevier Science Publishing, Amsterdam, 1988.

165 C. Miramond and D. Vuillaume, J. Appl. Phys., 2004, 96, $1529-1536$.

166 Q.-Y. Sun, L. C. P. M. de Smet, B. Van Lagen, M. Giesbers, P. C. Thuene, J. Van Engelenburg, F. A. De Wolf, H. Zuilhof and E. J. R. Sudhölter, J. Am. Chem. Soc., 2005, 127, 2514-2523.

167 B. Fabre, G. P. Lopinski and D. D. M. Wayner, Chem. Commun., 2002, 2904-2905.

168 F. Effenberger, G. Gotz, B. Bidlingmaier and M. Wezstein, Angew. Chem., Int. Ed., 1998, 37, 2462-2464.

169 P. Wagner, S. Nock, J. A. Spudich, W. D. Volkmuth, S. Chu, R. L. Cicero, C. P. Wade, M. R. Linford and C. E. D. Chidsey, J. Struct. Biol., 1997, 119, 189-201.

170 M. P. Stewart and J. M. Buriak, J. Am. Chem. Soc., 2001, 123, 7821-7830

171 L. C. P. M. de Smet, G. A. Stork, G. H. F. Hurenkamp, Q.-Y. Sun, H. Topal, P. J. E. Vronen, A. B. Sieval, A. Wright, G. M. Visser, H. Zuilhof and E. J. R. Sudhöelter, J. Am. Chem. Soc., 2003, 125, 13916-13917.

172 In the case of white light hydrosilylation of terminal acetylenes, as reported by Sudhölter and co-workers (ref. 126 and 166), no information is given by the authors in regard to the proposed binding mode and/or reaction mechanism.

173 J. M. Kanabus-Kaminska, J. A. Hawari, D. Griller and C. Chatgilialoglu, J. Am. Chem. Soc., 1987, 109, 5267-5268.

174 L. J. J. Laarhoven, P. Mulder and D. D. M. Wayner, Acc. Chem. Res., 1999, 32, 342-349.
175 The free radical chain mechanism for the hydrosilylation of olefins and that for the reaction of the surface hydrides with dioxygen are believed to be analogous.

176 In the absence of impurities, thermal formation of silicon dangling bonds is expected to be an extremely slow process (with a $c a .2 .3 \mathrm{eV}$ activation energy) and, as discussed in the text for the photoactivated process, impurities are therefore likely to be involved in the initiation step.

177 Hydrogen fluoride-etched $\mathrm{Si}(100)$ samples treated prior to the hydrosilylation with molecular hydrogen at high temperatures $\left(\right.$ ca. $\left.1000{ }^{\circ} \mathrm{C}\right)$. The distribution of surface hydride $\operatorname{SiH}_{n}(n=1,2,3)$ was inferred via infrared absorption spectroscopy in attenuated total reflection mode, with $\mathrm{SiH}$ signals at $2077 \mathrm{~cm}^{-1}, \mathrm{SiH}_{2}$ at $2111 \mathrm{~cm}^{-1}$ and $\mathrm{SiH}_{3}$ at $2137 \mathrm{~cm}^{-1}$. A sharp $\mathrm{Si}-\mathrm{H}$ absorption line at $2099.5 \mathrm{~cm}^{-1}$ was indicative of a predominant $\mathrm{SiH}_{2}$ population.

178 G. F. Cerofolini, C. Galati, S. Reina, L. Renna, O. Viscuso, G. G. Condorelli and I. L. Fragala, Mater. Sci. Eng., C, 2003, 23, 989-994.

179 G. F. Cerofolini, C. Galati, S. Reina, L. Renna, F. Giannazzo and V. Raineri, SIA Surf. Interface Anal., 2004, 36, 71-76.

180 G. F. Cerofolini, C. Galati, S. Reina and L. Renna, SIA Surf. Interface Anal., 2006, 38, 126-138.

181 G. F. Cerofolini, C. Galati, S. Reina and L. Renna, Trends Semicond. Res., 2005, 1-32.

182 The reaction vessel was immersed in a heated bath of dark wax, but was not otherwise shielded from ambient light.

183 S. Ciampi, T. Böcking, K. A. Kilian, J. B. Harper and J. J. Gooding, Langmuir, 2008, 24, 5888-5892.

184 K. Uosaki, M. E. Quayum, S. Nihonyanagi and T. Kondo, Langmuir, 2004, 20, 1207-1212.

185 N. Shirahata, T. Yonezawa, W.-S. Seo and K. Koumoto, Langmuir, 2004, 20, 1517-1520.

186 J. M. Buriak and M. J. Allen, J. Am. Chem. Soc., 1998, 120, $1339-1340$.

187 J. M. Buriak, M. P. Stewart, T. W. Geders, M. J. Allen, H. C. Choi, J. Smith, D. Raftery and L. T. Canham, J. Am. Chem. Soc., 1999, 121, 11491-11502.

188 The procedure was judged as $c a .20 \%$ less efficient on the basis of a reduced asymmetric methylene stretch in the FTIR spectrum at $2923 \mathrm{~cm}^{-1}$

189 M. Delamar, R. Hitmi, J. Pinson and J. M. Saveant, J. Am. Chem. Soc., 1992, 114, 5883-5884.

190 P. Allongue, M. Delamar, B. Desbat, O. Fagebaume, R. Hitmi, J. Pinson and J.-M. Saveant, J. Am. Chem. Soc., 1997, 119, 201-207.

191 C. Henry de Villeneuve, J. Pinson, M. C. Bernard and P. Allongue, J. Phys. Chem. B, 1997, 101, 2415-2420.

192 M. Warntjes, C. Vieillard, F. Ozanam and J. N. Chazalviel, J. Electrochem. Soc., 1995, 142, 4138-4142.

193 Superior stability was demonstrated for the $\mathrm{Si}-\mathrm{Ar}-\mathrm{Br}$ layer when both $40 \%$ hydrogen fluoride $(2 \mathrm{~min})$ and $10 \mathrm{M}$ ammonium fluoride $(\mathrm{pH} 4.5,1 \mathrm{~min})$ solutions were used in stability tests. Only in the case of the $\mathrm{Si}-\mathrm{Ar}-\mathrm{NO}_{2}$ structure was $c a .200 \mathrm{mV}$ anodic shift of the hydrogen evolution reaction (HER) measured and interpreted as a partial removal of the passivating layer.

194 As the authors noted, assuming a two-electron process for the grafting of a single aryl molecule would suggest a $250 \mu \mathrm{C} \mathrm{cm}$ charge is evolved if the reaction is stopped at full monolayer $\left(7.84 \times 10^{14}\right.$ molecules $\left.\mathrm{cm}^{-2}\right)$. While this figure is close to the experimental finding for bromine-terminated layers a larger than possible $\left(c a .375 \mu \mathrm{C} \mathrm{cm}^{-2}\right.$ ) charge is passed during the grafting of 4-nitrobenzenediazonium salts. This was explained as due to the occurrence of HER and possibly other side reactions.

195 E. G. Robins, M. P. Stewart and J. M. Buriak, Chem. Commun., 1999, 2479-2480.

196 P. T. Hurley, A. E. Ribbe and J. M. Buriak, J. Am. Chem. Soc., 2003, 125, 11334-11339.

197 Forward bias result in accumulation of mobile carriers (electrons) at the silicon-AFM tip junction. The adjective forward refers to the external bias compensating the internal potential of the junction. The electrons flow from the semiconductor to the tip until equilibrium is obtained (ionized donor centers will oppose any further movement of carriers).

198 S. R. Schofield, S. A. Saraireh, P. V. Smith, M. W. Radny and B. V. King, J. Am. Chem. Soc., 2007, 129, 11402-11407. 
199 C. A. Hacker, K. A. Anderson, L. J. Richter and C. A. Richter, Langmuir, 2004, 21, 882-889.

200 R. L. Cicero, P. Wagner, M. Lingford, C. J. Hawker, R. M. Waymouth and C. E. D. Chidsey, Polym. Prepr. (Am. Chem. Soc., Div. Polym. Chem.), 1997, 38, 904-905.

201 M. Yang, D. Wouters, M. Giesbers, U. S. Schubert and H. Zuilhof, ACS Nano, 2009, 3, 2887-2900.

202 R. Maoz, S. R. Cohen and J. Sagiv, Adv. Mater., 1999, 11, 55-61.

203 D. Wouters, R. Willems, S. Hoeppener, C. F. J. Flipse and U. S. Schubert, Adv. Funct. Mater., 2005, 15, 938-944.

204 M. Rosso, M. Giesbers, K. Schroën and H. Zuilhof, Langmuir, 2010, 26, 866-872.

205 T. Bitzer, T. Alkunshalie and N. V. Richardson, Surf. Sci., 1996, 368, 202-207.

206 X. Y. Zhu, J. A. Mulder and W. F. Bergerson, Langmuir, 1999, 15, 8147-8154

207 W. Yang, J. E. Butler, J. N. Russell, Jr. and R. J. Hamers, Analyst, 2007, 132, 296-306.

208 A. A. Shestopalov, R. L. Clark and E. J. Toone, Langmuir, 2009, 26, 1449-1451.

209 A. R. Pike, L. H. Lie, R. A. Eagling, L. C. Ryder, S. N. Patole, B. A. Connolly, B. R. Horrocks and A. Houlton, Angew. Chem., Int. Ed., 2002, 41, 615-617.

210 S. N. Patole, A. R. Pike, B. A. Connolly, B. R. Horrocks and A. Houlton, Langmuir, 2003, 19, 5457-5463.

211 G. Le Saux, S. Ciampi, K. Gaus and J. J. Gooding, ACS Appl. Mater. Interfaces, 2009, 1, 2477-2483.

212 T. W. Greene and P. G. M. Wuts, Protective Groups in Organic Synthesis, John Wiley \& Sons, New York, 1999.

213 B. Fabre, G. P. Lopinski and D. D. M. Wayner, J. Phys. Chem. B, 2003, 107, 14326-14335.

214 R. Boukherroub, J. T. C. Wojtyk, D. D. M. Wayner and D. J. Lockwood, J. Electrochem. Soc., 2002, 149, H59-H63.

215 Q. Li, G. Mathur, M. Homsi, S. Surthi, V. Misra, V. Malinovskii, K.-H. Schweikart, L. Yu, J. S. Lindsey, Z. Liu, R. B. Dabke, A. Yasseri, D. F. Bocian and W. G. Kuhr, Appl. Phys. Lett., 2002, 81, 1494-1496.

216 R. Boukherroub, S. Morin, D. D. M. Wayner, F. Bensebaa, G. I. Sproule, J. M. Baribeau and D. J. Lockwood, Chem. Mater., 2001, 13, 2002-2011.

217 S. N. Arafat, S. Dutta, M. Perring, M. Mitchell, P. J. A. Kenis and N. B. Bowden, Chem. Commun., 2005, 3198-3200.

218 A. Faucheux, A. C. Gouget-Laemmel, C. Henry de Villeneuve, R. Boukherroub, F. Ozanam, P. Allongue and J.-N. Chazalviel, Langmuir, 2006, 22, 153-162.

219 T. Böcking, E. L. S. Wong, M. James, J. A. Watson, C. L. Brown, T. C. Chilcott, K. D. Barrow and H. G. L. Coster, Thin Solid Films, 2006, 515, 1857-1863.

220 F. Cattaruzza, A. Cricenti, A. Flamini, M. Girasole, G. Longo, T. Prosperi, G. Andreano, L. Cellai and E. Chirivino, Nucleic Acids Res., 2006, 34, e32/31-e32/13.

221 S. A. Mitchell, T. R. Ward, D. D. M. Wayner and G. P. Lopinski, J. Phys. Chem. B, 2002, 106, 9873-9882.

222 Y.-J. Liu, N. M. Navasero and H.-Z. Yu, Langmuir, 2004, 20, 4039-4050.

223 J. T. C. Wojtyk, K. A. Morin, R. Boukherroub and D. D. M. Wayner, Langmuir, 2002, 18, 6081-6087.

224 M. Yang, R. L. M. Teeuwen, M. Giesbers, J. Baggerman, A. Arafat, F. A. de Wolf, J. C. M. van Hest and H. Zuilhof, Langmuir, 2008, 24, 7931-7938.

225 J. Macossay, S. A. Shamsi and I. M. Warner, Tetrahedron Lett., 1999, 40, 577-580.

226 J. Lahiri, L. Isaacs, J. Tien and G. M. Whitesides, Anal. Chem., 1999, 71, 777-790.

227 N. Patel, M. C. Davies, M. Hartshorne, R. J. Heaton, C. J. Roberts, S. J. B. Tendler and P. M. Williams, Langmuir, 1997, 13, 6485-6490.

228 S. Sam, L. Touahir, J. Salvador Andresa, P. Allongue, J. N. Chazalviel, A. C. Gouget-Laemmel, C. Henry de Villeneuve, A. Moraillon, F. Ozanam, N. Gabouze and S. Djebbar, Langmuir, 2010, 26, 809-814.

229 Y. Coffinier, C. Olivier, A. Perzyna, B. Grandidier, X. Wallart, J. O. Durand, O. Melnyk and D. Stievenard, Langmuir, 2005, 21, 1489-1496.
230 B. Chen, M. Lu, A. K. Flatt, F. Maya and J. M. Tour, Chem. Mater., 2008, 20, 61-64.

231 T. Strother, W. Cai, X. Zhao, R. J. Hamers and L. M. Smith, J. Am. Chem. Soc., 2000, 122, 1205-1209.

232 D. Aureau, F. Ozanam, P. Allongue and J. N. Chazalviel, Langmuir, 2008, 24, 9440-9448.

233 Through in situ-intensity-calibrated FTIR spectroscopic experiments Chazalviel and co-workers found no dependence on dilution of the local environment for tethered undecylenic acid moieties deliberately spaced among alkyl chains (1-decene). The authors propose an explanation based on phase separation at a molecular scale during the photochemical hydrosilylation reaction.

234 A. B. Sieval, R. Linke, H. Zuilhof and E. J. R. Sudhölter, $A d v$. Mater., 2000, 12, 1457-1460.

235 C. A. Richter, C. A. Hacker, L. J. Richter and E. M. Vogel, Solid-State Electron., 2004, 48, 1747-1752.

236 S. Dutta, M. Perring, S. Barrett, M. Mitchell, P. J. A. Kenis and N. B. Bowden, Langmuir, 2006, 22, 2146-2155.

237 L. Yang, Y.-Y. Lua, M. Tan, O. A. Scherman, R. H. Grubbs, J. N. Harb, R. C. Davis and M. R. Linford, Chem. Mater., 2007, 19, 1671-1678.

238 M. Ohashi, S. Takabayashi, K. Mashima and Y. Nakato, Chem. Lett., 2006, 956-957.

239 Y.-h. Li, D. Wang and J. M. Buriak, Langmuir, 2010, 26, $1232-1238$.

240 R. Huisgen, Pure Appl. Chem., 1989, 61, 613-628.

241 V. V. Rostovtsev, L. G. Green, V. V. Fokin and K. B. Sharpless, Angew. Chem., Int. Ed., 2002, 41, 2596-2599.

242 C. V. Tornøe, C. Christensen and M. Meldal, J. Org. Chem., 2002, 67, 3057-3064.

243 H. C. Kolb, M. G. Finn and K. B. Sharpless, Angew. Chem., Int. Ed., 2001, 40, 2004-2021.

244 N. K. Devaraj and J. P. Collman, QSAR Comb. Sci., 2007, 26, $1253-1260$.

245 L. Nebhani and C. Barner-Kowollik, Adv. Mater., 2009, 21, 3442-3468.

246 H. C. Kolb and K. B. Sharpless, Drug Discovery Today, 2003, 8, 1128-1137.

247 V. D. Bock, H. Hiemstra and J. H. van Maarseveen, Eur. J. Org. Chem., 2006, 51-68.

248 S. Ciampi, G. Le Saux, J. B. Harper and J. J. Gooding, Electroanalysis, 2008, 20, 1513-1519.

249 A. Ng, S. Ciampi, M. James, J. B. Harper and J. J. Gooding, Langmuir, 2009, 25, 13934-13941.

250 A. Ng, S. Ciampi, J. B. Harper and J. J. Gooding, Surf. Sci., 2010, submitted.

251 H. Liu, F. Duclairoir, B. Fleury, L. Dubois, Y. Chenavier and J.-C. Marchon, Dalton Trans., 2009, 3793-3799.

252 S. Ciampi and J. J. Gooding, Chem.-Eur. J., 2010, DOI: 10.1002/ chem. 200903316.

253 A. G. Marrani, E. A. Dalchiele, R. Zanoni, F. Decker, F. Cattaruzza, D. Bonifazi and M. Prato, Electrochim. Acta, 2008, 53, 3903-3909.

254 K. M. Kacprzak, N. M. Maier and W. Lindner, Tetrahedron Lett., 2006, 47, 8721-8726.

255 W. F. Paxton, J. M. Spruell and J. F. Stoddart, J. Am. Chem. Soc., 2009, 131, 6692-6694.

256 D. I. Rozkiewicz, D. Janczewski, W. Verboom, B. J. Ravoo and D. N. Reinhoudt, Angew. Chem., Int. Ed., 2006, 45, 5292-5296.

257 D. A. Fleming, C. J. Thode and M. E. Williams, Chem. Mater., 2006, 18, 2327-2334.

258 Cahen and co-workers suggest that by changing $-\mathrm{Br}$ groups to $-\mathrm{OH}$ groups the interactions at the distal end of the SAM are modified from repulsive (steric and electronic factors), as for the - Br layer, to attractive, due to hydrogen bonding between $-\mathrm{OH}$ moieties.

259 K. A. Kilian, T. Böcking and J. J. Gooding, Chem. Commun., 2009, 630-640.

260 M. J. Sailor and J. R. Link, Chem. Commun., 2005, 1375-1383.

261 M. Archer, M. Christophersen and P. M. Fauchet, Biomed. Microdevices, 2004, 6, 203-211.

262 M. Grattarola and G. Massobrio, Bioelectronics Handbook, McGraw-Hill, New York, 1998.

263 P. Bergveld, Sens. Actuators, A, 1996, 56, 65-73. 
264 M. J. Schöning and H. Lüth, Phys. Status Solidi A, 2001, 185, 65-77.

265 K. A. Kilian, T. Böcking, K. Gaus, J. King-Lacroix, M. Gal and J. J. Gooding, Chem. Commun., 2007, 1936-1938.

266 V. I. Boiadjiev, G. M. Brown, L. A. Pinnaduwage, G. Goretzki, P. V. Bonnesen and T. Thundat, Langmuir, 2005, 21, $1139-1142$.

267 V. Fomenko, J.-F. Lami and E. Borguet, Phys. Rev. B: Condens. Matter, 2001, 63, 121316.

268 R. J. Hamers, Аnnu. Rev. Anal. Chem., 2008, 1, 707-736.

269 G. Parker, Introductory Semiconductor Physics, Institute of Physics Publishing, London, 1994.

270 A. Bardea, F. Patolsky, A. Dagan and I. Willner, Chem Commun., 1999, 21-22.

271 T. C. Chilcott, E. L. S. Wong, T. Bocking and H. G. L. Coster, Physiol. Meas., 2008, 29, S307-S319.

272 E. L. S. Wong and J. J. Gooding, Anal. Chem., 2006, 78, $2138-2144$
273 E. L. S. Wong and J. J. Gooding, Anal. Chem., 2003, 75 3845-3852.

274 A. Abbott, Nature, 2002, 415, 112-114

275 W. Liao, F. Wei, M. X. Qian and X. S. Zhao, Sens. Actuators, B, 2004, 101, 361-367.

276 F. J. Himpsel, F. R. McFeely, A. Taleb-Ibrahimi, J. A. Yarmoff and G. Hollinger, Phys. Rev. B: Condens. Matter, 1988, 38, 6084-6096.

277 W. D. Eades and R. M. Swanson, J. Appl. Phys., 1985, 58, 4267-4276.

278 A. Salomon, D. Cahen, S. Lindsay, J. Tomfohr, V. B. Engelkes and C. D. Frisbie, Adv. Mater., 2003, 15, 1881-1890.

279 N. Gergel-Hackett, C. D. Zangmeister, C. A. Hacker, L. J. Richter and C. A. Richter, J. Am. Chem. Soc., 2008, 130, 4259-4261.

280 Z. Liu, A. A. Yasseri, J. S. Lindsey and D. F. Bocian, Science, 2003, 302, 1543-1545.

281 S. Kar, C. Miramond and D. Vuillaume, Appl. Phys. Lett., 2001, 78, 1288-1290 